\title{
DESENVOLVIMENTO DE UM MESTRE PROFIBUS COM A FINALIDADE DE ANÁLISE DE DESEMPENHO
}

\author{
Valéria Paula Venturini
}

Dissertação apresentada à Escola de Engenharia de São Carlos da Universidade de São Paulo, como parte dos requisitos para obtenção do título de Mestre em Engenharia Mecânica.

ORIENTADOR: Prof. Mário Pinotti Júnior

São Carlos

2007 



\section{AGRADECIMENTOS}

Primeiramente, agradeço a Deus pela oportunidade.

À minha mãe Maria Isabel que me ensinou a lutar e a dedicar-me a um ideal. Gostaria de agradecer em especial o meu esposo Marcelo pelo amor, carinho, compreensão e incentivo nos momentos mais difíceis. Também dedico esse trabalho a todos os meus amigos e familiares.

Ao amigo e Prof. Dr. Dennis Brandão pela orientação, confiança, amizade e por acreditar no trabalho.

Ao Prof. Dr. Mário Pinotti, que através de sua experiência, me auxiliou na elaboração deste trabalho e também pela oportunidade.

À minha amiga Daniele Cicillini pela amizade e companheirismo em todas as etapas desta caminhada.

Ao amigo Marcio Cunha pelos conselhos e amizade.

À Smar Equipamentos Industriais pelo incentivo à pós-graduação. 



\section{SUMÁRIO}

LISTA DE FIGURAS I

LISTA DE TABELAS V V

LISTA DE SIGLAS VII

RESUMO IX IX

ABSTRACT XI X X X

1 INTRODUÇÃO

$\begin{array}{lll}1.1 & \text { OBJETIVOS } & 19\end{array}$

1.2 ORGANIZAÇÃO DO TRABALHO 21

2 PROFIBUS

2.1 INTRODUÇÃO 23

2.2 PERFIS DE APLICAÇÃO 25

2.2.1 PROFIBUS-DP (Decentralized Periphery) 25

2.2.2 PROFIBUS-FMS (Fieldbus Message Specification) 26

2.2.3 PROFIBUS-PA (Process Automation) 26

$\begin{array}{lll}2.2 .4 & \text { PROFISafe } & 28\end{array}$

$\begin{array}{lll}2.2 .5 & \text { PROFInet } & 29\end{array}$

2.3 ESTRUTURA DO SISTEMA 29

$\begin{array}{lll}\text { 2.3.1 LAS } & 31\end{array}$

2.3.2 GAP 31

2.4 GERENCIAMENTO DE ACESSO AO BARRAMENTO 32

2.4.1 CAMADA FÍSICA 33

2.4.2 CAMADA DE APLICAÇÃO 33

2.4.3 CAMADA DE ENLACE 34

2.4.4 MÁQUINA DE ESTADOS DO FDL 40

2.4.5 MÁQUINA DE ESTADOS DA ESTAÇÃO ESCRAVA 45

2.5 TEMPOS DE OPERAÇÃO 47

2.6 ESTRUTURA DAS MENSAGENS 49

3 REVISÃO BIBLIOGRÁFICA

3.1 COMUNICAÇÃO EM REDES PROFIBUS 52 
3.2 MOTIVAÇÃO 64

4 DESENVOLVIMENTO

4.1 MOD_POLLLIST 68

4.2 MOD_BUSPARAMETER

4.3 MOD_ESTADOFDL 73

4.4 MOD_LIVELIST

4.5 MOD_COMCICLICA 77

4.6 MOD_MONIT

4.7 MOD_DIAGNOSIS 79

4.8 MOD_COMACICLICA 82

4.9 MOD_BUILDMESS 86

4.10 MOD_MESSRECEIVED 93

4.11 MOD_BUSANALYSE

4.12 MOD_GENERAL 99

5 RESULTADOS 103

5.1 ANÁLISE DA INFLUÊNCIA DO PARÂMETRO TTR NO TEMPO DE POLLING DA MENSAGEM 104

5.2 ANÁLISE DO TEMPO DE REINTEGRAÇÃO DA ESTAÇÃO-MESTRE NO BARRAMENTO APÓS PERDA DE MENSAGEM DE TOKEN 121

6 CONCLUSÃO 135

6.1 TRABALHOS FUTUROS 136

LITERATURA REFERENCIADA 137

LITERATURA CONSULTADA 143 


\section{LISTA DE FIGURAS}

Figura 1 - Protocolos padronizados no IEC 61158

Figura 2 - Sistema de Controle Direto (SCD) 15

Figura 3 - Sistema de Controle Fieldbus (SCF) 15

Figura 4 - Mecanismos de acesso ao meio físico $\quad 17$

Figura 5 - Representação da estrutura do protocolo PROFIBUS em camadas 24

Figura 6 - Perfis de aplicação $\quad 25$

Figura 7 - Rede PROFIBUS DP/PA

Figura 8 - Sistema Multi-mestre 30

Figura 9 - Representação da GAP Lista 32

Figura 10 - Representação da camada de Aplicação 34

Figura 11 - Tráfego de mensagens $\quad 35$

Figura 12 - Serviços de comunicação da camada de enlace $\quad 35$

Figura 13 - Loop de Controle $\quad 36$

Figura 14 - Poll-List $\quad 36$

Figura 15 - Algoritmo de passagem do token 38

Figura 16 - Máquina de Estados do FDL $\quad 40$

Figura 17 - Representação da máquina de estados da estação escrava 46

Figura 18 - Representação da estrutura das mensagens $\quad 50$

Figura 19 - Descrição dos bytes da mensagem $\quad 50$

Figura 20 - Exemplo do ciclo do token com TTR alto 54

Figura 21 - Exemplo do ciclo do token com TTR baixo $\quad 55$

Figura 22 - Reorganização da Poll-List para atender o polling-interval 58

Figura 23 - Representação do pior cenário de ciclo do token 59

Figura 24 - Estrutura dos módulos de funções do MPA 68

Figura 25 - Tela de configuração da Poll-List 69

Figura 26 - Tela de entrada de endereço do equipamento 69

Figura 27 - Representação de parte de um arquivo GSD 70

Figura 28 - Mapeamento das variáveis utilizadas pela Poll-List no MPA 71

Figura 29 - Tela de configuração do Bus Parameter 72 
Figura 30 - Funções do módulo Mod_EstadoFDL $\quad 74$

Figura 31 - Máquina de estados do FDL no MPA $\quad 75$

Figura 32 - Tela de representação da Lista de Estações presentes na rede 76

Figura 33 - Interpretação da resposta da mensagem de Pedido de status $\quad 77$

Figura 34 - Controle de transmissão de mensagens cíclicas 78

Figura 35 - Tela de Monitoração das variáveis definidas na Poll-List 79

Figura 36 - Tela de escolha do equipamento para monitoração de diagnóstico 80

Figura 37 - Tela de diagnóstico $\quad 80$

Figura 38 - Representação dos bytes de diagnostico da resposta do dispositivo 81

Figura 39 - Controle de transmissão de mensagens acíclicas 83

Figura 40 - Tela de configuração do dispositivo para transmissão acíclica 84

Figura 41 - Leitura acíclica do bloco Analog Input 85

Figura 42 - Leitura acíclica do bloco Analog Output $\quad 85$

Figura 43 - Leitura acíclica do bloco Totalizer 86

Figura 44 - Serviço SAP $\quad 87$

Figura 45 - Mensagem de Pedido de Status (RFS) 87

Figura 46 - Mensagem de token 88

Figura 47 - Mensagem de Requeste de Diagnóstico 88

Figura 48 - Mensagem de Parametrização 88

Figura 49 - Bytes da mensagem de Parametrização 89

Figura 50 - Representação do byte de dados da mensagem de Parametrização 89

Figura 51 - Representação do bit Lock/Unlock na mensagem de Parametrização 89

Figura 52 - Mensagem de Configuração 90

Figura 53 - Mensagem de troca de dados cíclico $\quad 91$

Figura 54 - Mensagem de conexão acíclica $\quad 91$

Figura 55 - Bytes da mensagem de Conexão Acíclica $\quad 91$

Figura 56 - Mensagem de Abort $\quad 92$

Figura 57 - Bytes da mensagem de Abort $\quad 92$

Figura 58 - Mensagem de confirmação 92

Figura 59 - Bytes da mensagem de Confirmação 93

Figura 60 - Mensagem de leitura de parâmetro 93

Figura 61 - Bytes da mensagem de leitura acíclica 93

Figura 62 - Tratamento do primeiro byte da mensagem 94

Figura 63 - Funcionamento da interface BC1 95

Figura 64 - Decodificação da mensagem recebida 96

Figura 65 - Verificação mensagem recebida 96

Figura 66 - Ambiente usado para analisar a rede $\quad 97$ 
Figura 67 - Verificação da mensagem para a adição da ListView 98

Figura 68 - Prioridades de mensagens (alta) 99

Figura 69 - Prioridades de mensagens (baixa) 100

Figura 70 - Tipos de dados $\quad 101$

$\begin{array}{ll}\text { Figura } 71 \text { - Estrutura da rede PROFIBUS } & 104\end{array}$

Figura 72 - Representação do tempo de Polling da mensagem $\quad 104$

Figura 73 - Cálculo de tempo do Polling da mensagem 105

Figura 74 - Polling da mensagem - dois ciclos do token 107

Figura 75 - Configuração D1M2 Figura 76 - Configuração D1M2D3 109

Figura 77 - Configuração D2M2 $\quad$ Figura 78 - Configuração D2M2D3 109

Figura 79 - Configuração D2M3 Figura 80 - Configuração D2M3D3 110

Figura 81 - Configuração D3M3 Figura 82 - Configuração D3M3D3 110

Figura 83 - Configuração D3M4 Figura 84 - Configuração D3M4D3 111

Figura 85 - Configuração D4M4 Figura 86 - Configuração D4M4D3 111

Figura 87 - Configuração D4M5 $\quad$ Figura 88 - Configuração D4M5D3 112

Figura 89 - Configuração D5M5 $\quad$ Figura 90 - Configuração D5M5D3 112

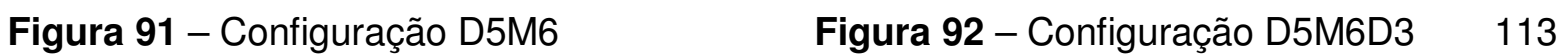

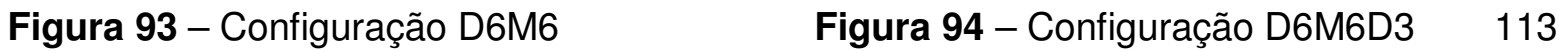

Figura 95 - Gráficos da Média do tempo de Polling da mensagem do TT303 115

Figura 96 - Gráfico de comparação entre amostra e TPM 120

Figura 97 - Perda de Token - Dois mestres no barramento 122

Figura 98 - GAPL do DF73 no endereço 2

Figura 99 - Perda de mensagem de token com três mestres na rede 123

Figura 100 - GAPL do DF73 no endereço $3 \quad 124$

Figura 101 - Configuração D1M2 Figura 102 - Configuração D1M2D3 126

Figura 103 - Configuração D2M2 Figura 104 - Configuração D2M2D3 126

Figura 105 - Configuração D3M2 $\quad$ Figura 106 - Configuração D3M2D3 127

Figura 107 - Configuração D4M2 $\quad$ Figura 108 - Configuração D4M2D3 127

Figura 109 - Configuração D5M2 Figura 110 - Configuração D5M2D3 128

Figura 111 - Configuração D6M2D3 Figura 112 - Configuração D6M2D3 128

Figura 113 - Gráficos da Média do tempo reintegração do MPA 129

Figura 114 - Gráfico de comparação entre amostra e TR 133 



\section{LISTA DE TABELAS}

Tabela 1 - Média do tempo de Polling da Mensagem do TT303 com dois mestres no barramento

Tabela 2 - Média do tempo de Polling da Mensagem do TT303 com três mestres no barramento

Tabela 3 - Representação dos valores utilizados na expressão TPM

Tabela 4 -Média do tempo de reintegração do MPA com dois mestres na rede

Tabela 5 - Média do tempo de reintegração do MPA com três mestres na rede 



\section{LISTA DE SIGLAS}

Al

$\mathrm{AO}$

COM

CSMA

CSRD

DP

DPM1

DPM2

DSAP

FDL

FIFO

FMS

GA

GSD

I/O

IEC

IEEE

ISO

LAS

MAC

NAMUR

NS
Analog Input

Analog Output

Component Object Model

Carrier Sense Multiple Access with Collision Detection

Cyclic Send and Request Data with Reply

Decentralized Periphery

DP Mestre Classe 1

DP Mestre Classe 2

Destination Service Access Point

Fieldbus Data Link

First-in-First-out

Fieldbus Message Specification

Generic Algoritm

General Station Description

Input / Output

Internacional Electrotechnical Commission

Institute of Electrical and Electrinics Engineers

International Standards Organizations

List Active Station

Médium Access Control

Usuário da indústria de controle de processo

Next Station 
OSI

PA

PC

PLC

PROFIBUS

PS

RFS

SAP

SCD

SCF

SDA

SDN

SRD

SSAP

TDMA

TGUD

TMC

TPM

TRR

TRT

TS

TSL

TT

TTH

TTO

TTR

ZVEI
Open System Interconnection

Process Automation

Computador Pessoal

Programable Logic Controller

PROcess Field BUS

Previous Station

Request FDL Status

Service Access Points

Sistema de controle direto

Sistema de controle Fieldbus

Send Data with Acknowledge

Send Data with No Acknowledge

Send and Request Data with Reply

Source Service Access Point

Time Division Multiple Access

Time GAP Update

Tempo Ciclo Mensagem

Tempo Polling Mensagem

Target Real Rotation

Tempo Reintegração Token

This Station

Target Slot Time

Timed token

Target Time Holding

Timeout

Target Time Rotation

German Electrical and Electronic Manufacturers Association 


\section{RESUMO}

VENTURINI, V. P. (2007). Desenvolvimento de um mestre PROFIBUS com a finalidade de análise de desempenho. Dissertação (Mestrado) - Escola de Engenharia de São Carlos, Universidade de São Paulo, São Carlos, 2007.

Quando se dispõe de um sistema de controle distribuído em tempo real, o atendimento aos requisitos temporais constitui-se num fator crucial para a aplicação. Assim, para garantir que tais requisitos sejam atendidos, é fundamental que 0 tráfego de mensagens no barramento seja gerenciado e controlado apropriadamente, evitando-se atrasos na comunicação para não prejudicar a performance do sistema e do produto final.

Este trabalho apresenta um mestre PROFIBUS desenvolvido em PC, cujas finalidades foram analisar por meio de dados experimentais, a influência do parâmetro TTR no tempo de atualização das variáveis de processo no sistema e o tempo de reintegração da estaçãomestre no anel lógico após perda de mensagem de token. .

Palavras-chave: automação industrial, controle distribuído em tempo real, PROFIBUS, performance, rede. 



\begin{abstract}
VENTURINI, V. P. (2007). Development of a PROFIBUS master for performance analyzing purpose. M.Sc. Dissertation - Escola de Engenharia de São Carlos, Universidade de São Paulo, São Carlos, 2007.
\end{abstract}

Using a real-time distributed control system, it is crucial to fulfill the time requirements for an application. Therefore, to guarantee that these requirements are fulfilled, it is essential to manage and control the message traffic in the bus properly, avoiding delays in the communication that could compromise the final product and the system performance.

This study presents a PROFIBUS master based on PC. The main purpose of the PROFIBUS master is to analyze, using empirical data, the influence of the TTR parameter in the updating time of the process variables and the time interval to reintegrate a Master device to the logical ring after a token message is lost.

Keywords: industrial automation, real-time distributed control, PROFIBUS, performance, network. 



\section{INTRODUÇÃO}

Nas últimas décadas, a área de automação industrial vem assumindo uma posição de vital importância e destaque, devido ao surgimento de grande número de equipamentos automáticos e de sistemas. Vários fatores têm contribuído fortemente para isso, tais como: a padronização dos protocolos industriais, desempenho, precisão dos equipamentos de campo e o acesso remoto.

Na década de 80 , as redes industriais eram dominadas por soluções proprietárias, havia grande número de protocolos de comunicação, cada qual com suas características particulares. Isso fez com que os usuários sentissem a ausência de um padrão de compatibilidade entre equipamentos de diferentes fabricantes, porque com a ampliação dos processos contínuos, surgiu a necessidade de se utilizarem diferentes tipos de equipamentos na planta, como por exemplo: transmissores (pressão, temperatura, densidade), atuadores, acionadores e conversores. Normalmente, o conjunto de equipamentos necessários ao processo era fornecido por diferentes fabricantes (FELSER e SAUTER, 2002).

Passando à década de 90, nota-se que a questão da padronização para as redes industriais começou a ser solucionada com a adoção das primeiras normas regulamentadas por institutos de normalização (BRANDÃO, 2000), essa foi uma das principais conquistas da indústria, pois proporcionou o aumento de velocidade na transmissão de dados, confiabilidade, flexibilidade e, principalmente, interoperabilidade entre os diversos equipamentos de uma planta industrial.

No ano 2000, visando definir padrões para as normas já existentes no mercado, a Comissão Internacional de Eletrotécnica (IEC) anunciou a norma IEC 61158 
(INTERNATIONAL ELECTROTECHNICAL COMISSION, 2000), que contempla os principais protocolos industriais. Devido à flexibilidade e aceitação desses protocolos, em diferentes aplicações no mundo todo, a norma continua em desenvolvimento e atualmente já engloba 10 tipos de protocolos de comunicação (POPP, 2003), conforme apresenta a Figura 1.

\begin{tabular}{cc}
\hline TIPO & PROTOCOLO \\
\hline TIPO 1 & FOUNDATION Fieldbus (FF) \\
TIPO 2 & Control Net \\
TIPO 3 & PROFIBUS \\
TIPO 4 & P-Net \\
TIPO 5 & FF High Speed Ethernet \\
TIPO 6 & SwiftNet \\
TIPO 7 & World FIP \\
TIPO 8 & INTERBUS \\
TIPO 9 & FOUNDATION Fieldbus (FF), FMS \\
TIPO 10 & PROFInet \\
\hline
\end{tabular}

Figura 1 - Protocolos padronizados no IEC 61158

Além da padronização, outro fator importante que acelerou o desenvolvimento industrial, nas ultimas décadas, foi a substituição dos tradicionais sistemas SCDs (Sistema de Controle Direto) pelos sistemas SCFs (Sistema de Controle Fieldbus). Nos primeiros, as tarefas de controle eram concentradas em apenas uma estação central, e a comunicação com os equipamentos (transmissores, atuadores) da planta era realizada através de uma conexão do tipo ponto a ponto, que requeria ao menos um par de fios para cada equipamento. (DOMINGUES, 2003)

Gradativamente, com o passar dos anos, os processos industriais foram se tornando cada vez mais complexos, os equipamentos mais inteligentes e a quantidade de equipamentos no processo cada vez maior. Diante deste cenário, os sistemas $S C D$ s deixaram de ser satisfatórios para a aplicação, devido ao aumento significativo de cabos e, 
principalmente, à perda de desempenho no sistema causada pelo processamento de grande quantidade de dados (LEE et al. , 2003b).

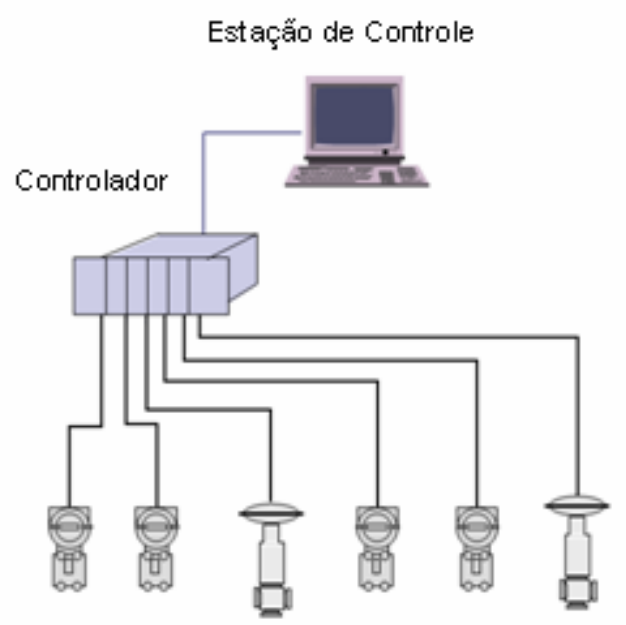

Figura 2 - Sistema de Controle Direto (SCD)

Nos atuais Sistemas de Controle Fieldbus (SCF), as tarefas de controle são distribuídas entre os diversos elementos de controle e processamento de uma rede de comunicação digital. Este sistema é composto pelos seguintes componentes: controladores, sensores, atuadores, estações de engenharia e supervisão, que interligados pela rede de comunicação, trabalham de forma simultânea e independente para controlar o processo (DOMINGUES, 2003).

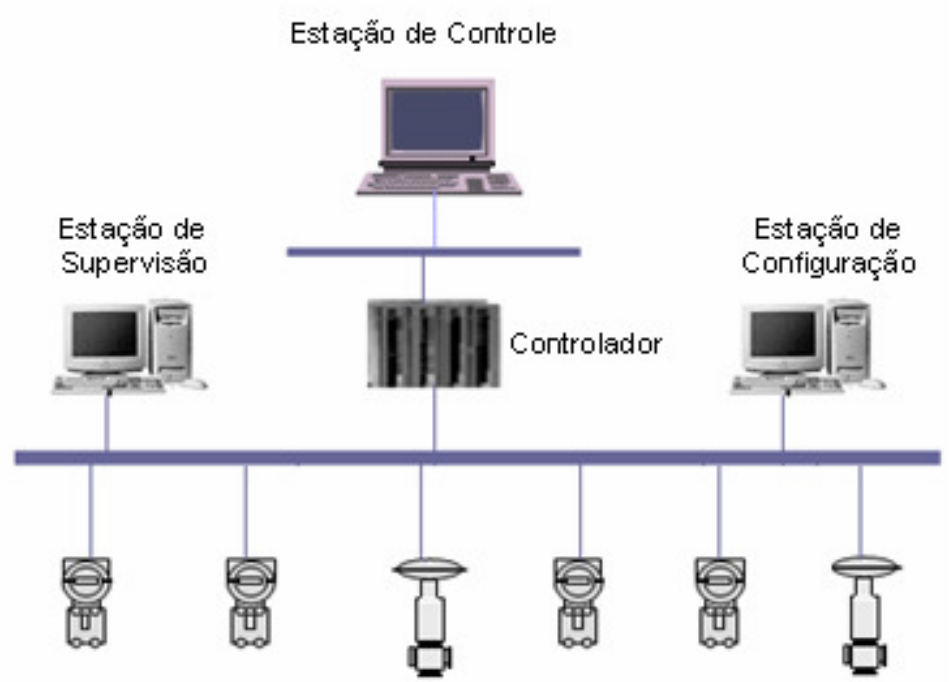

Figura 3 - Sistema de Controle Fieldbus (SCF) 
Segundo Brandão (2005), os sistemas fieldbus trouxeram para a indústria muitas vantagens em relação aos sistemas $S C D$, dentre as quais destacam-se:

- Segurança.

- Grande imunidade a ruídos externos.

- Maiores taxas de transmissão.

- Varias topologias físicas de rede, em modo multiponto.

- Facilidade na instalação, configuração e manutenção do sistema.

- Redução de custo em cabos e hardware.

- Fácil acesso as informações de campo

- Acesso Remoto

- Flexibilidade e versatilidade

Apesar de todo avanço tecnológico, a adesão aos fieldbuses trouxe alguns problemas que até então não existiam nos controladores centralizados. Dentre as desvantagens dos fieldbuses em relação aos SCDs, Brandão (2005) cita a falta de consistência de dados e de senso de tempo entre os diversos dispositivos de uma rede, vulnerabilidade a falhas no barramento e o fato de todo fieldbus ser um gargalo de comunicação, isto porque um único canal de comunicação é compartilhado por todos os equipamentos e deve ser utilizado para a transmissão de variáveis críticas de processo, como as informações de baixa prioridade e de monitoramento.

O compartilhamento do canal de comunicação, inevitavelmente aumenta o tempo de resposta da mensagem (utilizada para troca de dados entre o controlador e os equipamentos de campo) se comparado ao tradicional conexão ponto a ponto. (CAVALIERI et al., 2002).

Em muitos sistemas industriais, como de manufatura e controle de processo, o tempo de resposta da mensagem é considerado um fator crucial para a aplicação, pois os 
equipamentos que agem diretamente no processo alteraram seus valores rapidamente, por isso necessitam que suas variáveis sejam atualizadas periodicamente em tempo inferior a um determinado limite (KIM et al., 1999).

Neste tipo de aplicação, chamado de aplicação de tempo real, as mensagens precisam ser enviadas e recebidas num intervalo de tempo limitado (TOVAR e VASQUES, 1998). Assim, para garantir que os requisitos temporais deste tipo de aplicação sejam atendidos, é fundamental que o tráfego de mensagens seja gerenciado e controlado apropriadamente, evitando-se atrasos na comunicação para não prejudicar a performance do sistema e do produto final. Para se obter um bom desempenho em aplicações de tempo real, deve-se fazer, na fase de projeto, a escolha correta do protocolo de comunicação. Além dos aspectos físicos, é fundamental que se conheça o mecanismo usado para acessar o canal de comunicação (meio físico), isto porque cada protocolo possui características e tempos de resposta diferentes e se ajustam de modo mais adequado em áreas de aplicação específicas (TRISTÃO, 2004).

A Figura 4 apresenta alguns dos mecanismos de acesso ao meio físico, utilizados por diferentes protocolos de comunicação.

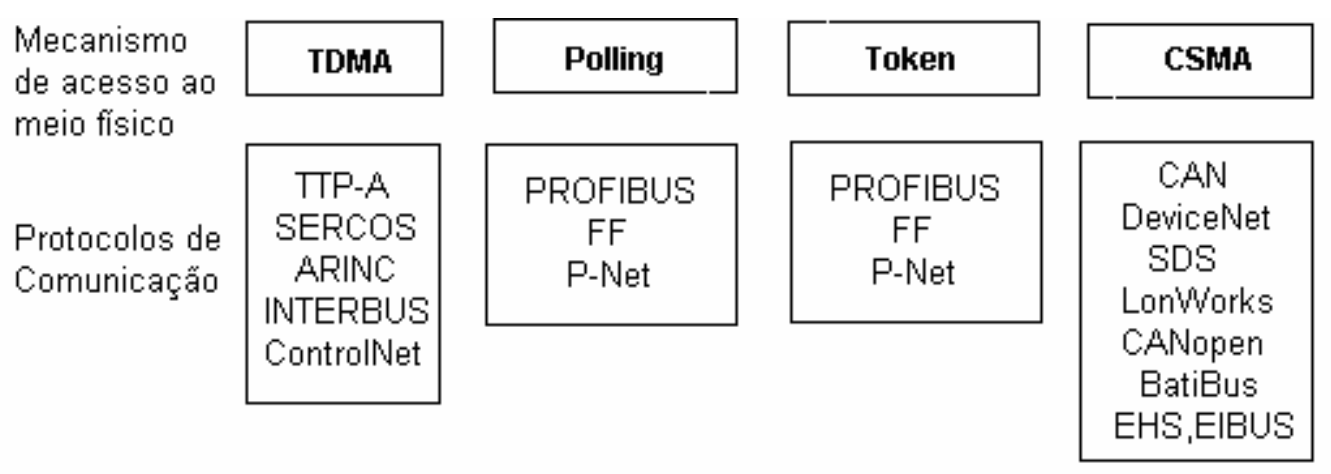

Figura 4 - Mecanismos de acesso ao meio físico 
Os mecanismos de acesso ao meio físico são descritos por Thomesse (2005), como:

- TDMA - O acesso ao meio físico é controlado por um algoritmo, que divide o tempo de acesso em slots e, posteriormente atribui os slots para os equipamentos de acordo com uma estratégia pré-definida. O instante em que cada equipamento pode transmitir mensagem no barramento é indicado pelo sincronismo do clock.

- Polling - O equipamento pode acessar o meio físico, apenas quando receber uma mensagem de request de uma estação do tipo mestre, somente assim a estação poderá responde-la ou reconhece-la, conforme o requerido.

- Token - O acesso ao meio físico é realizado a partir de um método descentralizado, de acordo com o princípio de passagem de token, para proporcionar direito de transmissão a todos os equipamentos mestres. Em cada instante, apenas um equipamento deve possuir o token para transmissão da mensagem, quanto aos demais equipamentos, estes apenas monitoram o barramento.

- CSMA - O acesso ao meio físico baseia-se em prioridades, ou seja, qualquer estação pode acessar o canal de comunicação quando este estiver ocioso, e um procedimento é usado para resolver problemas de colisão no barramento. Em caso de colisão, a mensagem de maior prioridade prosseguirá sem perceber esta ocorrência. Quanto às mensagens com prioridade inferior, serão abortadas e somente quando o canal de comunicação estiver ocioso elas serão transmitidas.

A otimização de comunicação em redes fieldbus é de extrema importância para indústria, principalmente em aplicações com requisitos temporais restritos, onde o tempo de atualização das variáveis de processo interfere na segurança, no custo de produção e também na qualidade do produto. 
Diante do exposto, a autora deste trabalho busca construir uma ferramenta de análise de desempenho de redes PROFIBUS que possibilite analisar, em tempo real, os mecanismos de acesso ao meio físico e o controle na transmissão de dados. Dentro os diversos protocolos de comunicação existentes no mercado, o PROFIBUS foi o escolhido devido à sua flexibilidade, determinismo, acesso fácil à documentação e, especialmente por sua ampla utilização nas áreas de fabricação de manufatura e controle de processo.

\subsection{OBJETIVOS}

Este trabalho tem como objetivos:

1) Projetar e implementar uma ferramenta que opere como mestre de uma rede PROFIBUS, denominada MPA (Mestre PROFIBUS Analisador).

Para se analisar uma rede PROFIBUS, deve-se conhecer as características e funcionalidades que envolvem o dispositivo mestre, responsável pelo controle do tráfego de mensagem no barramento e também pelo controle do processo. $\mathrm{O}$ dispositivo mestre deve obedecer a uma série de requisitos temporais e operacionais definidos pelo protocolo e pela aplicação.

Dentre os dispositivos mestres de rede PROFIBUS disponíveis no mercado, podem-se citar: DF73 (SMAR EQUIPAMENTOS INDUSTRIAIS, 2006), CP62 (FESTO, 2006), Simatic S7-300 (SIEMENS, 2006), MFI-MPB (FERTRON, 2006), F3LB01-ON (YOKOGAWA, 2006), P04053 (ALTUS, 2006), AC800M (ABB, 2006).

Tendo em vista uma melhor compreensão dos serviços suportados pelo dispositivo mestre, o MPA além das funcionalidades essências para operar como mestre da rede PROFIBUS, tem como objetivo oferecer serviços que geralmente são disponibilizados por ferramentas comerciais, utilizadas na configuração do dispositivo mestre e durante operação da rede, como: elaboração da Poll-List, Live-List, diagnóstico dos equipamentos, 
monitoração das variáveis de processo e leitura acíclica dos parâmetros de blocos funcionais. Dentre as ferramentas comerciais que disponibilizam estes tipos de serviços, estão: STUDIO302 (STUDIO302, 2007) e SIMATIC (SIMATIC MANAGER, 2007).

Outra finalidade do MPA é aumentar a quantidade de mestres ativo no barramento durante os experimentos, possibilitando assim, melhor aproximação de uma rede industrial de médio porte.

2) Projetar e Implementar no MPA um ambiente gráfico, que apresente em tempo real todas as mensagens transmitidas no barramento.

A finalidade deste ambiente é possibilitar a realização de análises de desempenho da comunicação em redes PROFIBUS.

Existem algumas ferramentas de análise de redes PROFIBUS no mercado, porém sua obtenção envolve um custo financeiro alto, pois além do software, há necessidade da compra de uma interface (hardware) de comunicação.

Dentre as ferramentas de análise de redes PROFIBUS disponíveis no mercado, estão: Profitrace (PROFIBUS CENTER NETHERLANDS, 2006), Amprolyzer (SIEMENS, 2006a), FNL-PA (TMG,2006) , PROFIBUS Analyzer (SOFTING,2006)

3) Analisar através do ambiente de análise do MPA, a influência do parâmetro TTR no tempo de Polling das mensagens e representar por meio de uma expressão matemática os resultados obtidos.

O tempo de Polling da mensagem determina a periodicidade de atualização das variáveis de processo, definindo assim a taxa de controle do sistema, por isso, é fundamental que o parâmetro TTR referente ao tempo de rotação do token esteja configurado apropriadamente, para que não haja atrasos na transmissão das mensagens, atendendo assim aos requisitos da aplicação. 
4) Analisar através do ambiente de análise do MPA uma das falhas de comunicação que pode causar degradação em redes PROFIBUS, que é a perda do token e representar por meio de uma expressão matemática os resultados obtidos.

No contexto dos sistemas distribuídos de controle de processo, falhas de comunicação são relevantes pela instabilidade que podem causar no sistema. O dispositivo mestre quando perde o token, é excluído do anel lógico, e o tempo da sua reintegração pode ser significativo e prejudicial para aplicação, caso o sistema não esteja configurado de modo adequado.

Este tipo de falha de comunicação ocorre com mais freqüência em redes WIRELESS (WILLIG, 2003), sendo assim, a realização desta análise em uma rede PROFIBUS com fio e sem interferência de sinais seria inviável, devido a pouca ocorrência da falha. Deste modo, para realização desta análise, o MPA deve ser adaptado para que em períodos de tempo aleatório rejeite a mensagem de token recebida por outro mestre. Está tarefa justifica a necessidade do MPA operar como mestre da rede PROFIBUS.

\subsection{ORGANIZAÇÃO DO TRABALHO}

Esta dissertação está organizada da seguinte maneira:

No Capítulo 1, encontra-se a Introdução; O Capítulo 2 descreve as características técnicas do protocolo PROFIBUS; o 3 apresenta a Revisão Bibliográfica das pesquisas relacionadas ao trabalho proposto e o 4 descreve o desenvolvimento do MPA. No capítulo 5, encontram-se descritos os ensaios realizados nos experimentos, bem como os resultados obtidos. Por fim, o capitulo 6 apresenta as conclusões e propõem trabalhos futuros. 



\section{PROFIBUS}

Este Capítulo apresenta as principais características e funcionalidades do protocolo PROFIBUS, que são importantes para o entendimento deste trabalho. Informações adicionais sobre o protocolo encontram-se melhor detalhadas em (PINELLI, 2006), (POPP, 2003), (PROFIBUS - Descrição Técnica, 2000), bem como nas próprias normas PROFIBUS.

\subsection{INTRODUÇÃO}

PROFIBUS é um protocolo aberto de rede de comunicação industrial, introduzido em 1989, foi desenvolvido por um comitê do governo alemão, com o apoio dos membros do ZVEI (Associação Central para a Indústria Elétrica). Utilizado em um amplo campo de aplicações, principalmente nas áreas da fabricação de manufatura, de automação de processos e predial. Permite comunicação digital, bidirecional, como também interligar dispositivos de diferentes fabricantes; além disso, garante transmissões em tempo real e é satisfatório em aplicações com tempos críticos e tarefas complexas de comunicação.

No período 1991/1993, o PROFIBUS foi padronizado pela DIN 19245, Parte 1-3, e em março de 1996 foi incorporado ao padrão Europeu EN 50170.

Finalmente, junto com outros protocolos industriais, o PROFIBUS é parte da norma IEC 61158, desde 1999. Em 2002, atividades de atualização na IEC 61158 trouxeram novas características para o PROFIBUS, entre elas o PROFInet. 
O protocolo PROFIBUS, hoje, encontra-se disponível em três versões bem definidas:

o DP-V0, DP-V1 e DP-V2.

[....] DP-V0 fornece a funcionalidade básica do DP, incluindo trocas cíclicas de dados, bem como diagnósticos de estação, diagnósticos de módulo e diagnóstico de canal específico. DP-V1 contém melhorias em relação à automação de processos, em particular comunicação acíclica de dados para parametrização,operação, visualização e manuseamento de alarmes de dispositivo de campo inteligente, paralelos à comunicação cíclica de dados do usuário. Isto permite acesso em tempo real para as estações utilizando ferramentas de engenharia. Em adição, DP-V1 define alarmes. Exemplos para diferentes tipos de alarmes são alarmes de estado, alarmes de atualização e alarmes específicos do fabricante. DP-V2 contêm melhorias adicionais e é o mecanismo principal em relação à demanda da tecnologia de acionamento (drive). Devido às funcionalidades adicionais como modo isócrono de escravo, comunicação de escravo para escravo (DXB, troca de dados broadcast)etc, o DP-V2 pode também ser implementado como uma rede de acionamentos (drives) para controle de seqüência de movimentos rápidos em controle de eixos. (PINELLI ,2006)

O modelo internacional ISO/OSI (International Standards Organizations / Open

System Interconection), usado como referência no desenvolvimento do protocolo

PROFIBUS, é constituído por sete camadas de rede com limites bem definidos e independentes. Cada camada possui um conjunto específico de serviços, utilizado durante a comunicação. Este modelo visa estruturar o projeto e reduzir a complexidade do sistema como um todo.

Devido aos requerimentos da indústria, utilizam-se somente a camada física (1), a camada de enlace (2) e a de aplicação (7), quanto às demais, são descartadas.

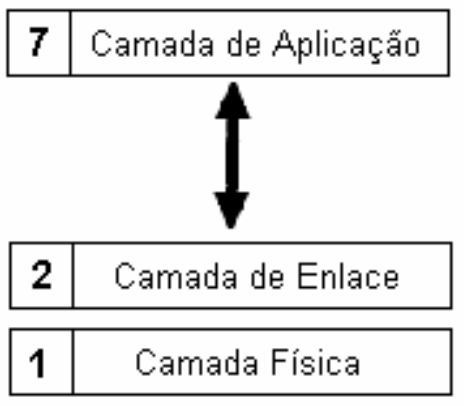

Figura 5 - Representação da estrutura do protocolo PROFIBUS em camadas 


\subsection{PERFIS DE APLICAÇÃO}

Por permitir acesso a um amplo campo de aplicação, a norma PROFIBUS define perfis, nos quais descreve a relação do protocolo com o meio de transmissão utilizado, bem como as características de desempenho e comportamento dos dispositivos e do sistema durante a comunicação.

Os perfis de aplicação especificam todos os aspectos da camada física e da camada de aplicação dos dispositivos e do sistema. Os serviços de comunicação disponíveis pela camada de enlace (FDL) são os mesmos para todos os perfis.

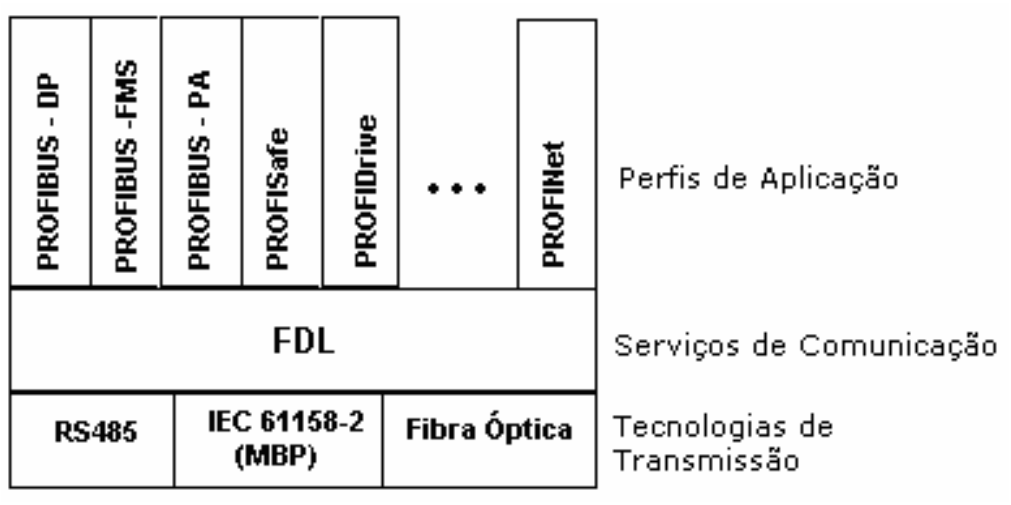

Figura 6 - Perfis de aplicação

A finalidade dos perfis de aplicação é prover interoperabilidade entre diferentes tipos de dispositivos e sistemas, para explorar completamente os recursos de uma rede industrial.

A seguir uma breve descrição dos principais perfis de aplicação; detalhamento maior é feito no PROFIBUS-PA, em razão deste trabalho envolver diretamente o mesmo.

\subsubsection{PROFIBUS-DP (Decentralized Periphery)}

É o perfil mais utilizado para rápida troca de dados entre controladores programáveis (PLCs, PCs) e dispositivos de campo (I/O, drives, transdutores). Atualmente, representa 90\% das aplicações, com bom desempenho em aplicações de tempo real. 


\subsubsection{PROFIBUS-FMS (Fieldbus Message Specification)}

Este foi o primeiro perfil de aplicação do protocolo, projetado para comunicação de tarefas complexas, cujas funções sofisticadas de comunicação são usadas principalmente, na comunicação entre sistemas de automação e comunicação entre $P L C s$, porém com o advento do PROfinet, o FMS é pouco utilizado.

\subsubsection{PROFIBUS-PA (Process Automation)}

O PROFIBUS PA foi desenvolvido em cooperação com os usuários da indústria de controle e processo, com o fim de atender às exigências da área de automação de processo. A principal exigência deste perfil é que os dispositivos estejam aptos a trabalhar em áreas intrinsecamente seguras.

Os serviços de comunicação do PROFIBUS PA são os mesmos do PROFIBUS DP; o que difere entre estes perfis são algumas características presentes na camada de aplicação e na camada física. O PROFIBUS DP utiliza o barramento RS485, que comunica numa velocidade máxima de 12Mbit/s, enquanto o PROFIBUS PA utiliza o barramento IEC 611582 (também conhecido como H1) que comunica a uma velocidade de $31.25 \mathrm{kbits} / \mathrm{s}$. Um acoplador DP/PA pode ser usado para traduzir as características físicas da rede entre PROFIBUS DP e PROFIBUS PA.

Os dispositivos de campo PROFIBUS PA podem ser conectados, à rede PROFIBUS DP também através de um link DP/PA, que atua como escravo da rede PROFIBUS DP e como um mestre da rede PROFIBUS PA. O link DP/PA, usado em grandes redes, tem o objetivo de aumentar a quantidade de dispositivos no barramento. A Figura 7 ilustra uma rede PROFIBUS DP/ PA. 


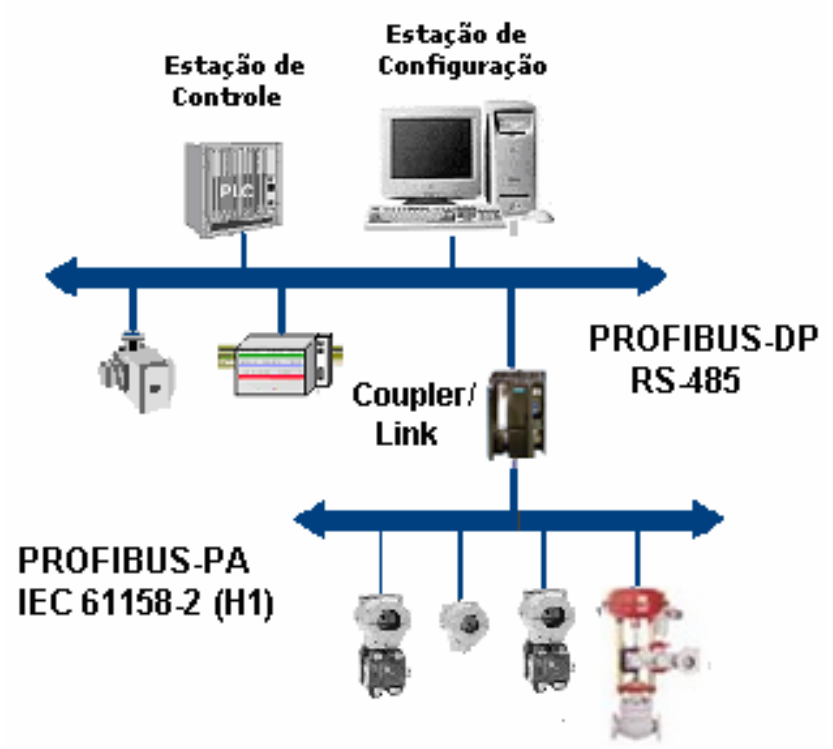

Figura 7 - Rede PROFIBUS DP/PA

Os dispositivos PROFIBUS PA são estruturados internamente em unidades de funções lógicas, chamados de módulos ou blocos, os quais contêm um número constante de bytes agrupados em posições físicas na forma de parâmetros. Através dos parâmetros, pode-se ter acesso às características e funcionalidades dos dispositivos. O endereçamento desses blocos baseia-se em identificadores chamados de slot e os parâmetros através de index relativo dentro do bloco; desse modo, para se acessar os parâmetros é necessário informar tanto o slot como o index.

\section{- BLOCO FísICO}

O bloco físico contém características gerais do dispositivo, como: nome do dispositivo, fabricante, número serial e versão, etc. Totalmente independente dos demais blocos, é utilizado para monitorar o estado de operação do hardware. 
- BLOCO TRANSDUTOR

[...] São responsáveis pelo processamento dos sinais de sensores ou atuadores no campo e disponibilizam um valor de saída que é transmitido através de interface particular a cada dispositivo, ou seja, ele reflete os princípios de medição. TORRES, Leandro H.B.(2005).

\section{- BLOCO DE FUNÇÃO}

O bloco de função armazena os dados de processamento final do valor medido, que deve ser transmitido para o sistema, ou então processado antes de se atuar no processo. Os blocos Al e AO são exemplos de bloco de função.

\section{- BLOCO DE ENTRADA ANALÓGICA (Al)}

O bloco Al, por meio de comunicação com o bloco transdutor acessa valores relacionados as medidas físicas; após processamento destes valores, disponibiliza - os para o sistema através dos parâmetros de saída junto com o status.

\section{- BLOCO DE SAídA ANALÓGiCA (AO)}

O bloco $\mathrm{AO}$, após processamento do valor recebido pelo sistema, informa ao bloco transdutor o valor que deve atuar no processo.

\subsubsection{PROFISafe}

O perfil PROFISafe é a ênfase principal para aplicações seguras (uso universal para quase todas as indústrias).

Este perfil define como os dispositivos devem-se comportar no caso de falha. Para cada função do dispositivo, elabora-se uma lista dos possíveis erros que podem ocorrer durante a comunicação, juntamente com as medidas preventivas para cada erro. 
Marques (2004) cita alguns erros possíveis de ocorrer durante a comunicação na rede: repetição, perda, inserção, seqüência incorreta, atraso, corrupção de dados e endereçamento errado.

\subsubsection{PROFInet}

Este perfil é destinado aos controladores, estações de configuração e supervisão. Com base no protocolo ETHERNET, comunica-se com os dispositivos de campo (atuadores, transmissores) através dos protocolos IP e TCP/UDP, com taxas de comunicação de 100Mbits/s (POPP e WEBER, 2004).

\subsection{ESTRUTURA DO SISTEMA}

Qualquer interligação, na qual se utilize um protocolo de comunicação, deve conter ao menos um dispositivo mestre e um dispositivo escravo. O primeiro deles denominado de estação ativa, pode enviar ou requerer dados para outras estações quando tem permissão de acesso ao meio físico; quanto ao dispositivo escravo ou estação passiva, apenas responde ou reconhece as mensagens recebidas.

No protocolo PROFIBUS, as estações-mestres são classificadas em dois tipos, descritos a seguir:

- DP MESTRE CLASSE 1 (DPM1): Funciona como um controlador central (PLCs, PCs) que troca dados cíclicos com os dispositivos escravos, com intuito de controlar o processo, e paralelamente executa tarefas acíclicas, como por exemplo: parametrização dos escravos. 
- DP MESTRE CLASSE 2 (DPM2): Destina-se ao uso de ferramentas de parametrização, manutenção e diagnóstico, ou seja, troca dados acíclicos com o dispositivo escravo, cuja operação não exige que a estação fique permanentemente conectada ao barramento.

Dependendo do tipo de aplicação, o sistema pode ser constituído por um único mestre e vários escravos, denominado de sistema mono-mestre, ou por mais de uma estaçãomestre e vários escravos, denominado de sistema multi-mestre.

Normalmente, os sistemas multi-mestres são constituídos por ferramentas de operação, engenharia, parametrização e supervisão e cada qual opera em uma estaçãomestre. Porém, neste tipo de sistema, apenas o mestre nomeado durante a configuração têm permissão para escrever na variável de saída do processo, enquanto as demais estações podem apenas monitorar o processo.

Estruturalmente, as estações-mestres são interconectadas formando um anel lógico; neste caso utiliza-se um método baseado no principio de passagem de token para proporcionar direito de acesso ao meio físico a todas as estações-mestres no anel.

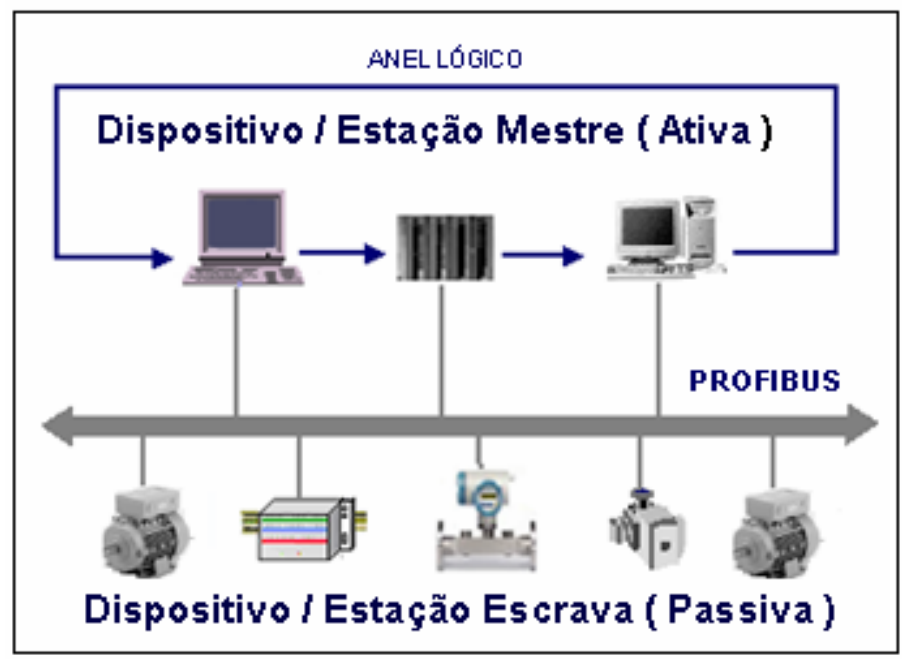

Figura 8 - Sistema Multi-mestre 
Em cada instante, somente a estação-mestre que, possui o token, esta autorizada a transmitir mensagens no barramento; deste modo, a estação se comunica com as estaçõesescravas através do método mestre-escravo e com outras estações-mestres pelo método mestre-mestre, quanto às demais estações, devem apenas monitorar o barramento sem direito à transmissão.

Periodicamente, o token circula entre as estações-mestres do anel lógico, em ordem crescente de endereço, no entanto, para fechar o anel, a estação com endereço mais alto passa o token para a que tem o mais baixo.

\subsubsection{LAS}

O controle do token é gerenciado pela estação-mestre do anel que conhece o endereço da sua estação antecessora (PS), o seu próprio endereço (TS) e também o da estação sucessora (NS). Tais informações, obtidas durante monitoração e manutenção da rede são armazenadas em uma lista chamada LAS (Lista de todas as estações-mestres presentes no anel lógico).

Durante a geração da $L A S$, apenas as estações que responderem às mensagens de pedidos de Status (RFS) como "pronto para entrar no anel lógico" ou aquelas estaçõesmestres que já estão ativas no barramento, farão parte da $L A S$.

\subsubsection{GAP}

Os endereços que pertencem ao intervalo entre TS e NS são conhecidos como GAP e são listados na GAPL (GAP Lista) 


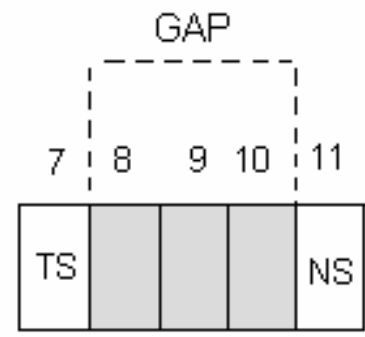

\begin{tabular}{|c|}
\hline GAPL \\
\hline 8 \\
\hline 9 \\
\hline 10 \\
\hline
\end{tabular}

Figura 9 - Representação da GAP Lista

Com a finalidade de detectar a inclusão e exclusão de estações no barramento, a GAPL é atualizada periodicamente pelas estações-mestres, nos períodos de manutenção da rede e após a expiração do parâmetro TGUD.

$\mathrm{Na}$ atualização da lista, a estação-mestre transmite uma mensagem de Pedido de Status (RFS) para o primeiro endereço do GAPL; se esta responder como "não pronta" ou como "estação-escrava", o endereço continua no GAPL ou é inserido, caso ainda não exista na lista, e o próximo endereço é checado. No caso da estação endereçada responder com o status "pronto para entrar no anel lógico", o seu endereço é atualizado na LAS como "estação-mestre ativa", e em seguida é removida da GAPL.

A cada posse do token, apenas um endereço do GAPL pode ser examinado pelas estações-mestres. As estações registradas na GAPL que não responderem a Pedidos de Status (RFS) serão consideradas estações não-operacionais.

\subsection{GERENCIAMENTO DE ACESSO AO BARRAMENTO}

Neste tópico estão descritos alguns aspectos específicos do protocolo PROFIBUS, relacionados a cada camada de rede do modelo ISO/OSI, representado na Figura 5. 


\subsubsection{CAMADA FÍSICA}

A camada 1 do modelo de referência ISO/OSI determina os aspectos físicos da rede, como por exemplo, distância máxima entre os dispositivos, número máximo de dispositivos no barramento, tipos de cabos utilizados, conectores, interfaces e todos os aspectos mecânicos e elétricos. O PROFIBUS define três tipos físicos de comunicação, que são:

- RS-485: Uso universal.

- IEC 61158-2 (H1): Aplicações na área de controle de processo.

- Fibra Ótica: Aplicações em sistemas com grande imunidade a interferências e longas distâncias.

\subsubsection{CAMADA DE APLICAÇÃO}

A camada 7 do modelo de referência ISO/OSI gerencia as informações recebidas e enviadas para os dispositivos, respeitando as características e funções do perfil utilizado. As informações geradas pela camada de aplicação são decodificadas e, por meio da camada de enlace são transmitidas no barramento no formato de mensagens. Da mesma forma as mensagens recebidas pela camada de enlace são decodificadas e transportadas para a camada de aplicação, que, se necessário, apresenta a informação ao usuário ou a processa para atuar novamente no processo. 


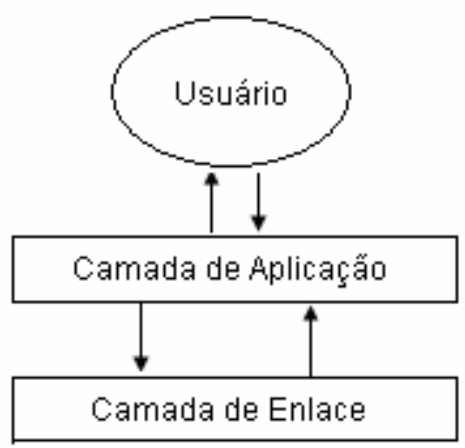

Figura 10 - Representação da camada de Aplicação

De uma forma geral, a camada de aplicação juntamente com o usuário é que definem os aspectos temporais e operacionais do sistema.

\subsubsection{CAMADA DE ENLACE}

A camada 2 do modelo de referência ISO/OSI ou FDL (Fieldbus Data Link) responde pelos serviços de comunicação do protocolo; entre suas funcionalidades estão: elaboração de mensagens, segurança de dados, detecção de erros e controle de acesso ao meio físico.

O FDL utiliza o protocolo MAC (Médium Access Control) para controlar o acesso ao meio físico. Este protocolo descreve um procedimento que determina o momento em que a estação pode transmitir mensagens no barramento, de maneira a evitar conflito com outras estações.

Para garantir os requisitos temporais referentes à troca de dados entre a aplicação e os dispositivos, o MAC divide o acesso ao meio físico em duas formas distintas e complementares, através da comunicação cíclica e acíclica.

A comunicação cíclica destina-se à troca rápida de dados entre a aplicação e os dispositivos, enquanto a comunicação acíclica é reservada à transmissão de mensagens de manutenção e parametrização dos dispositivos.

A cada ciclo do token, o MAC computa o período de tempo em que a estação pode transmitir mensagens no barramento. As mensagens acíclicas são transmitidas somente se 
houver tempo suficiente nos intervalos vagos entre as transmissões cíclicas. No tópico 2.4.3.3 (algoritmo de passagem de token) está descrito detalhadamente o gerenciamento do tráfego de mensagens no barramento.

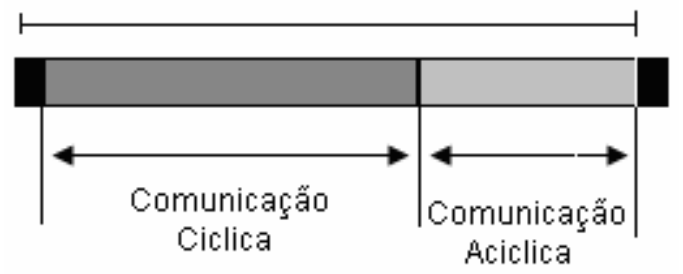

Figura 11 - Tráfego de mensagens

Ambos tipos de mensagens (cíclica e acíclica) são gerados por meio de serviços fornecidos pela camada de enlace, conforme requerimento da camada de aplicação (Figura 12):

\begin{tabular}{ll}
\hline SERVIÇO & DESCRIÇAOO \\
\hline SDN & Envia dados sem reconhecimento \\
SDA & Envia dados com reconhecimento \\
SRD & Envia e requisita dados com resposta \\
CSRD & Envia e requisita dados ciclicamente com resposta \\
\hline
\end{tabular}

Figura 12 - Serviços de comunicação da camada de enlace

O SDN é um serviço sem reconhecimento usado como broadcast/multicast, sendo estes últimos serviços globais transmitidos para todas ou para um grupo de estações escravas, através de uma única mensagem.

Contrariamente, todos os outros serviços baseiam-se em duplo relacionamento entre mestre e escravo. 


\subsubsection{COMUNICAÇÃO CÍCLICA}

A transferência de dados entre estações DPM1 e as estações-escravas geralmente é realizadas por meio de transmissão de mensagens cíclicas, periodicamente, de maneira rápida e determinista.

Usa-se a comunicação cíclica para dar feedback em loops de controle, sendo estes constituídos de controladores, sensores e atuadores. Os controladores são dispositivos $D P M 1$, enquanto os sensores e atuadores são dispositivos escravos; deste modo, o DPM1 lê informações do sensor e, se necessário, escreve a informação no atuador, com o fim de controlar o processo (LI e STOECKLI, 1996). Na literatura, a terminologia NCS é usada para indicar esse tipo de controle (SANTOS, et al., 2003).

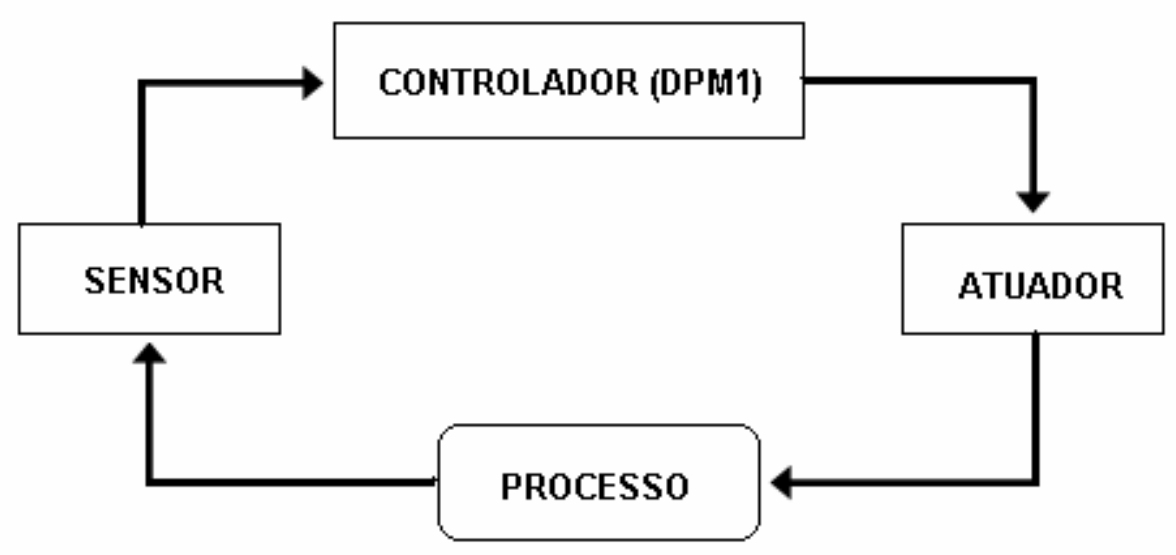

Figura 13 - Loop de Controle

Durante a fase de configuração do sistema, o usuário especifica quais os dispositivos e variáveis devem ser incluídos ou excluídos da transmissão cíclica de dados, uma vez que tais informações são inseridas na Poll-List, que se contitui em uma lista de mensagens executadas em seqüência e de modo cíclico pela estação DPM1.

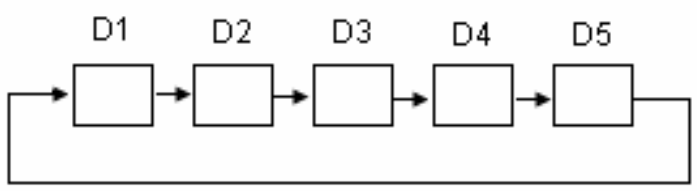

Figura 14 - Poll-List 
As variáveis usadas nas mensagens da Poll-List são mapeadas no dispositivo e disponibilizadas para o sistema através de um código de acesso encontrado no GSD (arquivo texto que contém informações específicas sobre o dispositivo).

[...] O arquivo gsd é como se fosse um datasheet eletrônico do equipamento que trás detalhes de revisão de hardware e software, bus timing do equipamento e informações sobre troca de dados cíclicos. (CASSIOLATO, 2005).

Apenas uma mensagem de cada dispositivo, com endereço, número de identificação e código de acesso, é armazenada na lista.

A cada ciclo do token, verifica-se a Poll-List, a fim de transmitir suas mensagens, com exceção dos casos em que a estação recebe o token atrasado e não há tempo suficiente para transmissão de todas as mensagens de uma só vez, deste modo, no próximo ciclo do token a Poll-List é iniciada a partir da última mensagem transmitida. A camada de enlace deve garantir que cada mensagem da Poll-List seja transmitida uma única vez a cada ciclo do token.

De uma forma geral, consegue-se uma boa performance no sistema, quando se executa a Poll-List completamente, em todos os ciclos do token.

Na literatura a terminologia usada para indicar comunicação cíclica é o MSO.

\subsubsection{COMUNICAÇÃO ACÍCLICA}

A transmissão das mensagens acíclicas, na maioria das vezes, é feita por ferramentas de parametrização, manutenção, diagnóstico e monitoração, para realização dos seguintes serviços: alarme, diagnóstico, leitura e escrita de parâmetros em dispositivos de campo (sensores, atuadores). Essa transmissão ocorre paralelamente as mensagens cíclicas, com prioridade menor, e somente nos intervalos em que a estação-mestre possuir tempo disponível, durante o ciclo do token. Neste sentido, é desejável que, na configuração do sistema, se destine um período de tempo para sua transmissão. 
A transmissão acíclica de dados, normalmente é realizada por estações $D P M 2 s$, mas as DPM1s também podem executar este tipo de tarefa.

A terminologia usada para indicar comunicação acíclica no DPM1 é $M S 1$, enquanto que para o DPM2 é MS2.

\subsubsection{ALGORITMO DE PASSAGEM DE TOKEN}

A comunicação feita por meio de sistemas complexos de automação deve assegurar que cada estação detenha tempo suficiente para executar suas tarefas de comunicação dentro de um intervalo preciso de tempo. Para isso, o token deve ser recebido pelo menos uma vez por cada estação-mestre, dentro de um intervalo denominado Tempo de Rotação do Token (TTR).

Com a finalidade de se obter um bom desempenho em sistemas PROFIBUS, o MAC utiliza um algoritmo para gerenciar a transmissão de mensagens no barramento, como é representado na Figura 15:

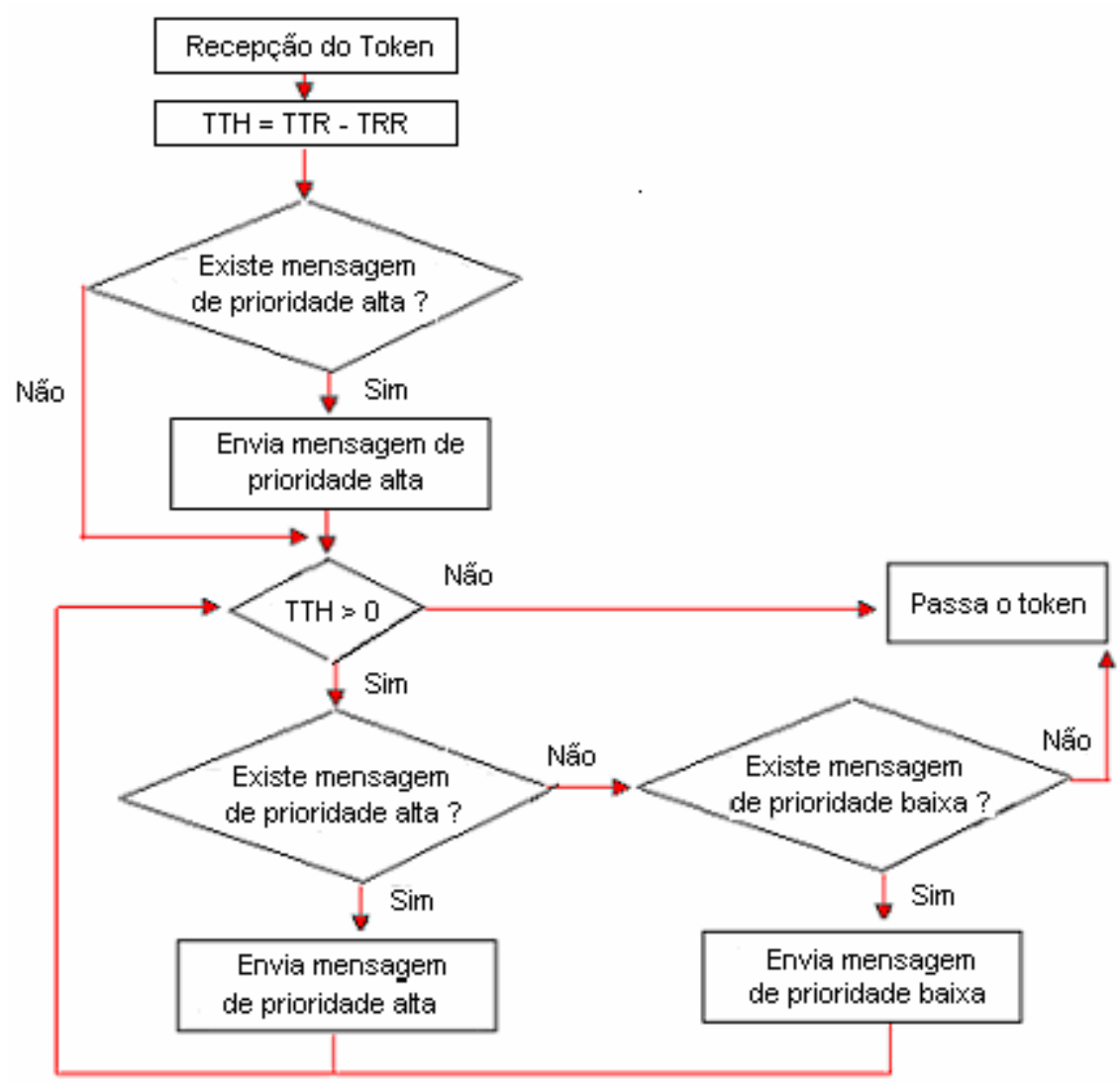

Figura 15 - Algoritmo de passagem do token 
O PROFIBUS define duas categorias de mensagens: prioridade alta e prioridade baixa. As mensagens com prioridade alta são transmitidas em intervalos regulares e devem ser entregues em tempos definidos, como por exemplo, atualização das variáveis de processo no sistema. Quanto às mensagens de prioridade baixa, estas não são periódicas e são utilizadas, por exemplo na parametrização dos dispositivos.

De acordo com a Figura 15, após a estação receber o token, o MAC calcula o tempo máximo que a estação pode transmitir mensagens no barramento antes de enviar o token para a próxima estação do anel. Esse período de tempo é representado pelo parâmetro $T T H$, do qual resulta da diferença entre os parâmetros TTR e TRR.

$$
\text { TTH }=\text { TTR }- \text { TRR }
$$

O parâmetro TTR contém o tempo desejado para que o token circule entre todas as estações do anel, enquanto que o parâmetro TRR possui o tempo real de rotação do token, medido através de dois recebimentos consecutivos do token em uma mesma estação.

- Independentemente do valor de TTH, a estação sempre pode transmitir uma mensagem com prioridade alta, mesmo se receber o token atrasado (TTH menor que zero). Quando TTH for maior que zero, ou seja, quando ainda existir tempo disponível, a estação verifica se há mensagem com prioridade alta no buffer de saída e a envia, caso não haja nenhuma, aí a estação verifica se há mensagem com prioridade baixa. Este processo é executado até que não haja mais mensagens com prioridade alta ou baixa a serem enviadas, ou até que TTH seja igual ou menor que zero. Quando ocorrer erro na transmissão da mensagem, independentemente do valor de TTH, a estação pode retransmiti-la até que receba a resposta ou até que o parâmetro retries (número de retransmissões) configurado pelo usuário tenha se expirado. Uma vez que o ciclo da mensagem é iniciado, este é sempre completado. 


\subsubsection{MÁQUINA DE ESTADOS DO FDL}

Dentro do processo de comunicação, apenas um dispositivo pode transmitir mensagens no barramento por vez, por isso cada estação deve cumprir um conjunto de requisitos definidos na norma para que não haja conflito entre estações durante a comunicação; cabe à estação, também, o cumprimento das exigências temporais e operacionais definidas na fase de configuração do sistema. Esta etapa é gerenciada pela máquina de estados do $F D L$, composta por 11 estados que descrevem as ações e transições das estações-mestres e escravas no transcorrer da comunicação (TRISTÃO, 2004).

.As próximas seções descrevem as ações de cada um dos estados da máquina, conforme representa a Figura 16:

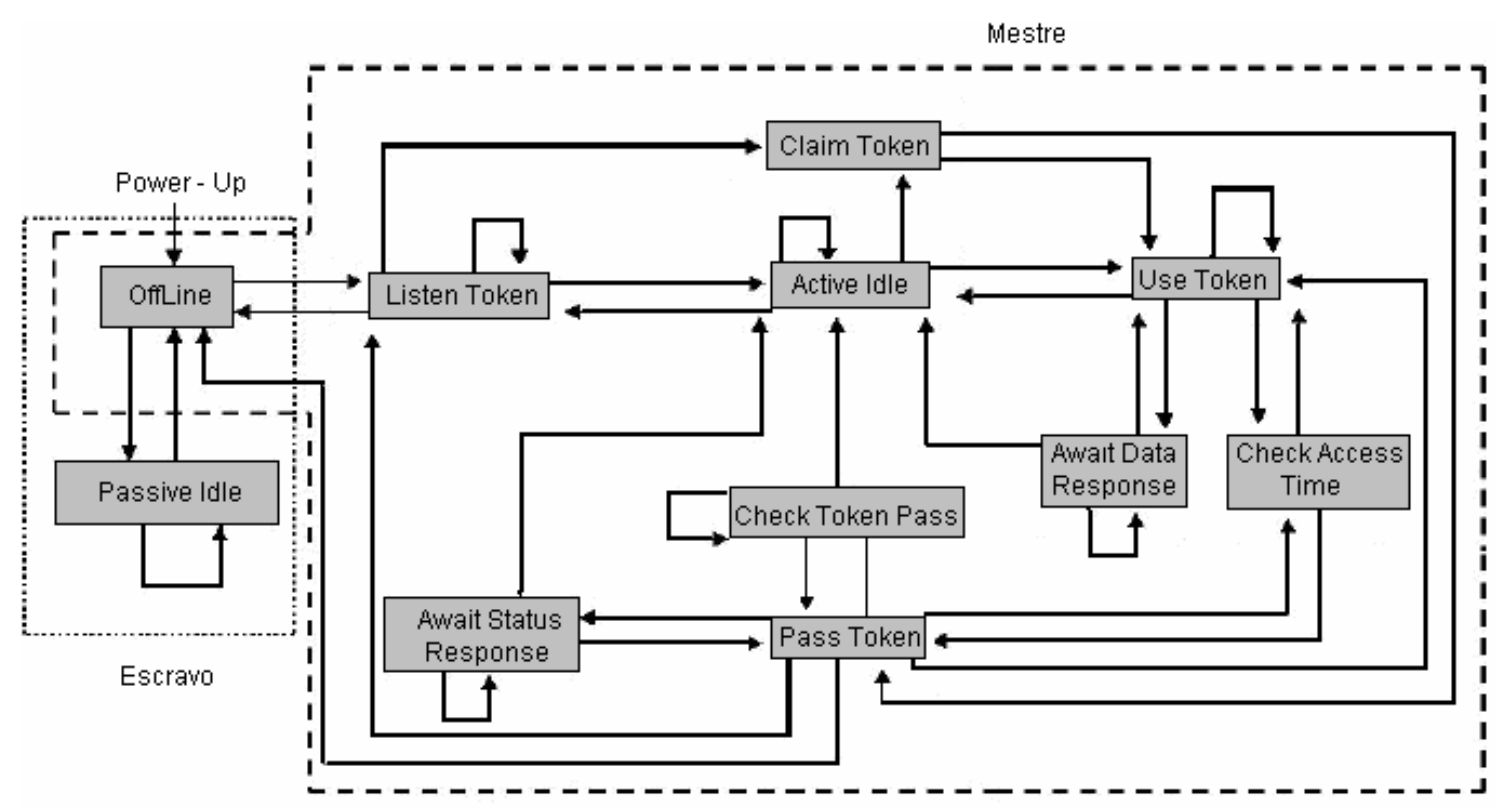

Figura 16 - Máquina de Estados do FDL

Fonte: TRISTÃO (2004) 


\section{- OFFLINE}

O estado offline ocorre na iniciação do sistema, ou após certas condições de erro.

Depois da iniciação, a estação-mestre assume o estado Listen Token, enquanto a estação-escrava assume o estado Passive Idle.

\section{- PASSIVE IDLE}

Neste item, a estação escrava monitora o barramento e responde ou confirma as mensagens recebidas como requerido, exceto as mensagens com endereço global (broadcast/multicast).

Na ocorrência de erros, o FDL retorna ao estado Offline.

\section{- LISTEN TOKEN}

No Listen Token a estação-mestre monitora o barramento, com a finalidade de elaborar as listas $L A S$ e GAPL.

Durante dois ciclos consecutivos completos de rotação do token, a estação-mestre responde aos Pedidos de status (RFL), como "não-pronta" e as demais mensagens recebidas não são reconhecidas e nem respondidas.

Após a finalização dos dois ciclos do token, a estação-mestre continua neste mesmo estado, e caso receba uma mensagem de Pedido de Status (RFL) da estação antecessora (PS), responde como "pronto para entrar no anel lógico". Depois disso, se receber uma mensagem de token, o FDL entra no estado Active Idle, caso a mensagem de token tenha sido enviada por uma estação diferente da sua antecessora, a estação, num primeiro momento, recusa o token e transmite uma mensagem de erro; mas se receber o token pela segunda vez consecutiva da mesma estação, ele é aceito e o novo endereço da PS é atualizado na $L A S$. 
Neste estado, a detecção de duas mensagens de token consecutivas com o endereço do remetente igual ao da estação-mestre indica que já existe uma estação ativa no anel lógico com o seu endereço; assim, o FDL gera uma mensagem de erro e retorna ao estado OffLine.

Se em um período de tempo conhecido como Timeout (TTO), não se detectar nenhuma atividade no barramento, o FDL entra no estado "Claim token".

\section{- ACTIVE IDLE}

No estado Active Idle a estação-mestre responde ou reconhece a mensagem recebida como requerido, e caso esta seja um token o FDL entra no estado Use Token, porém quando o endereço da estação que enviou o token for igual ao seu, um erro é reportado para a camada de aplicação e o FDL retorna ao estado Listen Token

Se em um período de tempo conhecido como Timeout (TTO), não se detectar nenhuma atividade no barramento, o FDL entra no estado Claim token

\section{- CLAIM TOKEN}

Este estado é assumido após a expiração do parâmetro Timeout (TTO) no estado Active Idle ou no Listen Token, neste caso, a estação-mestre assume que deve fazer uma iniciação no anel lógico e, a seguir transmite duas mensagens de token endereçadas a si mesma, e entra no estado Pass Token.

\section{- USE TOKEN}

Neste estado, a estação-mestre de posse do token pode transmitir mensagens num intervalo de tempo determinado, conforme descrito no tópico 2.4.3.3 (Algoritmo de passagem de token). Após a transmissão da mensagem, o FDL inicia o parâmetro Slot Time 
(TSL) e entra no estado Await Data Response. Quando se expira o parâmetro Slot Time (TSL) ou, seja, o prazo para recebimento de resposta/reconhecimento, o FDL entra no estado Check Access Time, com a finalidade de verificar se ainda há tempo disponível para continuar com o token.

\section{- AWAIT DATA RESPONSE}

Este estado é assumido pelo FDL após a transmissão da mensagem no estado Use Token. Quando a mensagem transmitida for do tipo SDN (mensagem sem reconhecimento), - FDL retorna imediatamente ao estado Use Token; caso contrário, a estação aguarda resposta, ou um reconhecimento ou até mesmo que o parâmetro Slot Time (TSL) se expire, e retorna para ao estado Use Token

Se uma mensagem válida é recebida mais de uma vez consecutiva, isso indica que um erro ocorreu, então a estação-mestre ignora a mensagem e entra no estado Active Idle

\section{- CHECK ACCESS TIME}

Neste estado, a estação-mestre verifica se ainda há tempo disponível para permanecer com o token, ou seja, se TTH é maior que zero, conforme descrito no tópico 2.4.3.3 (Algoritmo de passagem de token); caso haja tempo disponível e mensagens no buffer de saída o FDL retorna ao estado Use Token, mas quando ocorre o contrário o FDL entra no estado Pass Token.

\section{- PASS TOKEN}

No estado Pass Token a estação-mestre transmite o token para a próxima estaçãomestre do anel lógico, registrada na LAS como NS. 
Antes de passar o token, a estação-mestre verifica se ainda há tempo disponível e se o parâmetro TGUD expirou, caso ambas verificações sejam verdadeiras, o $F D L$ atualiza a GAP transmitindo uma mensagem de Pedido de Status (RFL) para o próximo endereço do GAPL e entra no estado Await Status Response; neste momento, se receber uma resposta indicando "pronto para entrar no anel lógico", o NS é atualizado no LAS e o token é transmitido para a nova estação.

Logo depois da transmissão do token, a estação-mestre monitora o barramento, com a finalidade de detectar a sua própria transmissão, e quando não a detecta, a estação estabelece que um erro fatal pode ter acontecido na transmissão ou no canal de recebimento, e assim o FDL entra no estado OffLine.

No caso da estação receber sua própria mensagem corrompida, tenta retransmitir o token, mas se voltar a receber uma mensagem inválida, o FDL entra no estado Listen Token.

Se a estação-mestre detectar a sua própria mensagem de token sem que esta esteja corrompida, o FDL entra no estado Check Token Pass.

\section{- CHECK TOKEN PASS}

No estado Check Token Pass, a estação-mestre aguarda o período de tempo referente ao parâmetro Slot Time (TSL) por uma resposta da estação na qual transmitiu a mensagem de token. Se uma mensagem válida ou inválida for recebida dentro deste intervalo de tempo, o FDL entra no estado Active Idle; caso o Slot Time (TSL) se expire e a estação não detecte atividade no barramento, considera-se que a estação sucessora (NS) não obteve o token e o FDL entra no estado Pass Token 


\section{- AWAIT STATUS RESPONSE}

Este estado é assumido pelo FDL após transmissão da mensagem de Pedido de Status (RFS) no estado Pass Token, assim o FDL aguarda um tempo referente ao parâmetro Slot Time (TSL) por uma resposta, caso receba a resposta indicando "pronto para entrar no anél lógico" atualiza o NS com o endereço da nova estação. Após isso retorna para o estado Pass Token.

\subsubsection{MÁQUINA DE ESTADOS DA ESTAÇÃO ESCRAVA}

As mensagens listadas na Poll-List são transmitidas para os dispositivos escravos somente quando estiverem parametrizados e configurados corretamente, desse modo, após a Poll-List ser elaborada, o DPM1 transmite uma mensagem de requisição de diagnóstico para todos os escravos da lista, com a finalidade de saber se estes já foram parametrizados e configurados por outro mestre. Caso não tenham sido, o DPM1 transmite uma mensagem de parametrização, informando aos escravos alguns comportamentos que devem obedecer durante a comunicação e, em seguida, transmite uma mensagem de configuração, especificando quais as variáveis dinâmicas devem ser trocadas ciclicamente entre eles, conforme definido na Poll-List. Para tanto, o dispositivo escravo deve estar preparado para receber os diferentes tipos de mensagens transmitidas pelos mestres. Nesta situação, utiliza-se uma máquina de estados para controlar a recepção da mensagem na estaçãoescrava, máquina está que contém 4 estados, os quais permitem que as transações entre eles sejam caracterizadas por eventos. 


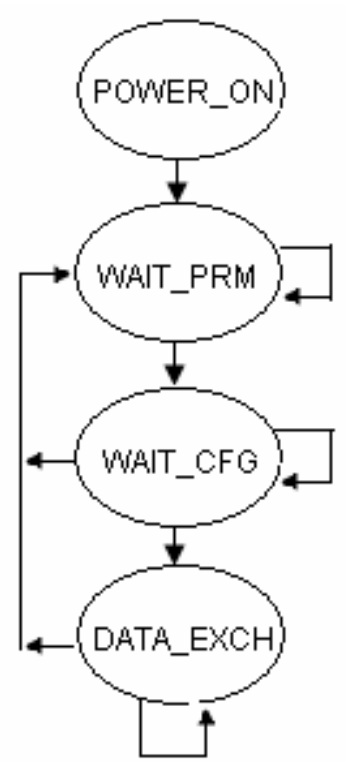

Figura 17 - Representação da máquina de estados da estação escrava

\section{- POWER_ON}

Depois de um start-up interno, a estação-escrava aguarda uma mensagem de alteração de endereço transmitida por uma estação DPM2, ou uma mensagem de requisição de diagnóstico, assim, passa a rejeitar todas as outras mensagens.

\section{- WAIT_PRM}

Neste estado, a estação escrava aguarda uma mensagem de parametrização, mas aceita também mensagens de requisição de diagnostico.

A mensagem de parametrização contém informações especificadas sobre 0 comportamento da estação-escrava, mas se as informações contidas na mensagem de parametrização não forem suportadas pela estação-escrava, esta deve ignorar a mensagem recebida e permanecer neste mesmo estado. 


\section{- WAIT_CFG}

No estado Wait_CFG o escravo aguarda uma mensagem de configuração, mas aceita também mensagens de requisição de diagnóstico e de parametrização.

A mensagem de configuração informa as variáveis a serem trocadas ciclicamente entre o DPM1 e o escravo, conforme Poll-List. Entretanto, se as informações contidas na mensagem de configuração forem incompatíveis com as mapeadas na estação-escrava, está deve ignorar a mensagem recebida.

\section{- DATA_EXCH}

O Data_Exch permite mensagens de troca de dados cíclicos (transmissão das mensagens definidas na Poll-List) entre o DPM1 e a estação-escrava, cuja operação caracteriza-se pela transmissão de mensagens de Data_exchange.

\subsection{TEMPOS DE OPERAÇÃO}

Segundo as normas PROFIBUS, para que a rede funcione de modo adequado, sem colisões, atraso ou tempo ocioso, é definido um grupo de parâmetros referente a tempo, que, obrigatoriamente, deve ser obedecido por todas as estações-mestres e estaçõesescravas da rede.

Estes parâmetros de tempo são usados pelo $F D L$ no gerenciamento do tráfego de mensagens no barramento; alguns deles são calculados pelo próprio $F D L$, enquanto outros são ajustados pelo usuário ou calculados automaticamente através de ferramentas de configuração.

A unidade usada na medição desses parâmetros é a tBIT, o que indica que qualquer outra unidade deve ser convertida para tBIT. 
- $\quad$ BIT TIME - tBIT

Bit Time é o tempo de transmissão de um bit, parâmetro diretamente relacionado ao baud rate em bit/s

$\mathrm{tBIT}=1 /$ baud rate $\quad$ (Baud rate in Bits/s)

- $\quad$ SLOT TIME (TSL)

O Slot Time (TSL) define o tempo máximo aguardado por um reconhecimento ou resposta, após transmissão da mensagem. Se esse tempo se expirar antes do reconhecimento ou resposta, a estação que fez a requisição deve repetir o pedido, respeitando o número de retransmissões suportadas.

\section{- TARGET ROTATION TIME (TTR)}

O parâmetro Target Rotation Time (TTR) define o tempo máximo esperado para que o token circule entre todas as estações-mestres do anel e retorne ao seu mestre inicial, no entanto, alguns fatores podem influenciar no tempo de ciclo do token, como por exemplo, o baud rate, número de mestres e de escravos com troca de dados cíclicos.

O ajuste do TTR deve ser feito pelo usuário ou automaticamente pela ferramenta de configuração e deve assegurar que cada estação-mestre do anel disponha de tempo suficiente para executar suas tarefas de comunicação. 


\section{- GAP UPDATE TIME (TGUD)}

O parâmetro Gap Update Time (TGUD) determina o momento em que se deve iniciar a atualização da GAPL. Se durante a rotação do token não houver tempo suficiente para manutenção da rede, deve-se atualizar o GAPL na próxima rotação do token.

TGUD $=$ GAPFATOR * TTR.

O parâmetro GAPFATOR deve ser configurado pelo o usuário que indicará o número de rotação do token, que deve ocorrer antes de se expirar o tempo do TGUD.

\section{- TIMEOUT TIME (TTO)}

Se no decorrer do tempo definido por este parâmetro nenhuma mensagem for transmitida no barramento, o temporarizador se expira e um erro ocorre. Normalmente, um valor diferente para esse parâmetro é definido para cada estação da rede, de acordo com o endereço das mesmas.

\subsection{ESTRUTURA DAS MENSAGENS}

O protocolo PROFIBUS disponibiliza cinco tipos de estruturas de mensagens, todas elaboradas conforme o serviço (Figura 18). 
Tamanho fixo sem campo de dados

\begin{tabular}{|l|l|l|l|l|l|}
\hline SD1 & DA & SA & FC & FCS & ED \\
\hline
\end{tabular}

Tamanho variável com campo de dados

\begin{tabular}{|l|l|l|l|l|l|l|l|l|l|}
\hline SD2 & LE & LEr & SD2 & DA & SA & FC & DATA UNIT & FCS & ED \\
\hline
\end{tabular}

Tamanho fixo com campo de dados

\begin{tabular}{|l|l|l|l|l|l|l|}
\hline SD3 & DA & SA & FC & DATA UNIT & FCS & ED \\
\hline
\end{tabular}

Token

\begin{tabular}{|l|l|l|}
\hline SD4 & DA & SA \\
\hline
\end{tabular}

Confirmaçẫo curta

$\mathrm{SC}$

Figura 18 - Representação da estrutura das mensagens

A Figura 19, a seguir mostra o significado de cada byte da mensagem.

\begin{tabular}{ll}
\hline \multicolumn{1}{c}{ SERVIÇO } & DESCRIÇÁO \\
\hline SD1,SD2,SD3,SD4,SC & Byte de Inicio (Indica o tipo de mensagem) \\
DA & Byte de endereço de destino \\
SA & Byte de endereço fonte \\
LE & Byte de comprimento \\
Ler & Byte de comprimento repetido \\
FC & Byte de controle \\
DATA UNIT & Bytes de campo de dados \\
FCS & Byte de checagem \\
ED & Byte finalizador \\
\hline
\end{tabular}

Figura 19 - Descrição dos bytes da mensagem 


\section{REVISÃO BIBLIOGRÁFICA}

Comparando-se as tecnologias atuais existentes na área de automação industrial com as de 20 anos atrás, observa-se um crescimento considerável nos sistemas de comunicação e nos instrumentos de campo (transmissores e atuadores). A evolução da comunicação no chão de fábrica, que vai desde a transmissão analógica por sinal pneumático até a moderna rede fieldbus foi descrita por Brandão (2000).

Fieldbus constitui-se numa rede de comunicação de dados utilizada no controle de plantas industriais, é formada por dispositivos, tais como: transmissores, atuadores e controladores (DOMINGUES, 2003).

As redes fieldbus diferem-se de outros tipos de redes por suas aplicações suportarem comunicação em tempo real; segundo os quais as mensagens precisam ser enviadas e recebidas em tempo inferior a um determinado limite; caso contrário, caracteriza-se falha de natureza temporal (TOVAR e VASQUES, 1999).

As aplicações em tempo real podem ser classificadas em dois tipos: Hard Real-Time e Soft Real-Time. As primeiras são aquelas que se um único requisito temporal não for cumprido, a aplicação é considerada inaceitável. Já nas aplicações Soft Real-Time; a nãoobservância de um limite de tempo é aceitável, uma vez que as conseqüências são mais restritas ou recuperáveis através de repetição (TRISTÃO, 2004).

Apesar de outros tipos de redes ainda não atenderem às exigências de tempo da indústria, uma tendência que vem se tornando realidade é a utilização da rede ETHERNET em plantas industriais. Essa tecnologia vem sendo gradualmente integrada ao PROFInet 
(protocolo derivado do PROFIBUS). De acordo com Albuquerque (2005), assim que as funcionalidades específicas da área de automação de processo forem transportadas para o PROFInet, estará bem próximo o uso de um padrão de rede industrial para todas as aplicações, com base na tecnologia ETHERNET.

\subsection{COMUNICAÇÃO EM REDES PROFIBUS}

Certamente, o atendimento aos requisitos temporais é fator determinante em rede fieldbus, por esse motivo, se o tráfego de mensagens não for gerenciado nem controlado apropriadamente, a rede induzirá atrasos que podem exceder os limites pré-definidos e, em conseqüência disso, os requisitos relacionados à performance do sistema não serão satisfeitos. (HONG e KIM ,1997)

De acordo com Tovar e Vasques (1998), para suportar comunicação em tempo real em redes fieldbus, deve-se assegurar que as mensagens com prioridade alta sejam transmitidas antes de seu deadline (tempo máximo permitido entre o momento em que a mensagem é colocada no buffer de saída e a sua completa transmissão).

Sob o mesmo ponto de vista, Lee et al. (2003c) afirmam que uma boa performance da rede pode ser assegurada se os tempos de atraso das mensagens forem mantidos abaixo do tempo permitido.

De uma forma geral, a performance da rede deve ser avaliada e planejada antes da sua implementação. Tradicionalmente, essa avaliação é feita por modelos analíticos (algoritmos matemáticos), simuladores ou dados experimentais. $\mathrm{O}$ desenvolvimento do modelo analítico, usualmente, requer várias suposições de operação do sistema e são usados como ferramentas de aproximação de análises. No caso dos simuladores, estes nem sempre requerem suposições, pois comportam - se como um sistema real de modo a tornar a análise mais exata (HONG e KIM ,1997).

Segundo Moro (2002), a implementação de um simulador é demorada e onerosa, porque requer a construção de um modelo com características e comportamentos criteriosos 
do protocolo. Quanto às ferramentas analíticas, são limitadas em relação à complexidade do sistema que está sendo modelado, mas sua utilização justifica-se pela simplicidade e rapidez com que os resultados são obtidos.

Sob esta representação e com a finalidade de estudar os diferentes aspectos e funcionalidades de uma rede fieldbus, alguns modelos analíticos, simuladores e experimentos foram propostos por pesquisadores como uma maneira de melhorar e otimizar as formas de comunicação dos fieldbuses. Dentre as propostas, encontram-se sugestões a serem utilizadas durante as fases de configuração e instalação da rede, bem como outras a serem empregadas na fase de operação do sistema e, por último, as propostas que envolvem mudanças no protocolo de comunicação.

Esta revisão bibliográfica descreve o estado da arte das pesquisas teóricas e das experimentais que tratam da comunicação em redes PROFIBUS.

De acordo com Pinelli (2006), alta velocidade na transferência de dados não é um critério suficiente para o sucesso de um sistema de comunicação de dados. Instalação, manutenção simples, boa capacidade de diagnóstico e a transmissão de dados segura e livre de erros são requisitos indispensáveis.

Segundo Lee et al. (2004), um fator fundamental para se garantir um bom desempenho em redes PROFIBUS é o ajuste dos parâmetros do sistema, parâmetros estes que precisam ser selecionados apropriadamente a fim de minimizar os atrasos de comunicação de forma que os critérios temporais requeridos pela aplicação sejam atendidos. Dentre os parâmetros, encontra-se o TTR (tempo de rotação do token), considerado muito importante, pois a partir dele calcula-se o parâmetro $T T H$, o qual determina o período de tempo que cada estação-mestre pode transmitir mensagens no barramento, quando de pose do token.

O TTR deveria ser escolhido pequeno, porém suficiente para satisfazer o mais estrito deadline. TOVAR e VASQUES (1998). 
O exemplo a seguir ilustra o comportamento das estações-mestres quando o TTR é configurado de forma inadequada: Considere uma rede PROFIBUS multi-mestre, na qual todas as estações-mestres estão configuradas com o mesmo valor de TTR. Num primeiro cenário, considere o TTR alto. Assim, de acordo com algoritmo de passagem do token descrito no tópico 2.4.3.3, o tráfego de mensagens com prioridade baixa pode, drasticamente, afetar o tráfego de mensagens com prioridade alta, pois conforme mostra Figura 20, a estação 1 após transmissão das mensagens com prioridade alta, possui tempo disponível para continuar com o token, assim, ela utiliza todo tempo disponível para transmitir mensagens com prioridade baixa, atrasando o tempo de rotação do token. Neste caso, os mestres subseqüentes (estação 2 e estação 3) recebem o token tardio, e por isso ficam limitados a transmitir somente uma mensagem com prioridade alta. (TOVAR e VASQUES, 1998a).

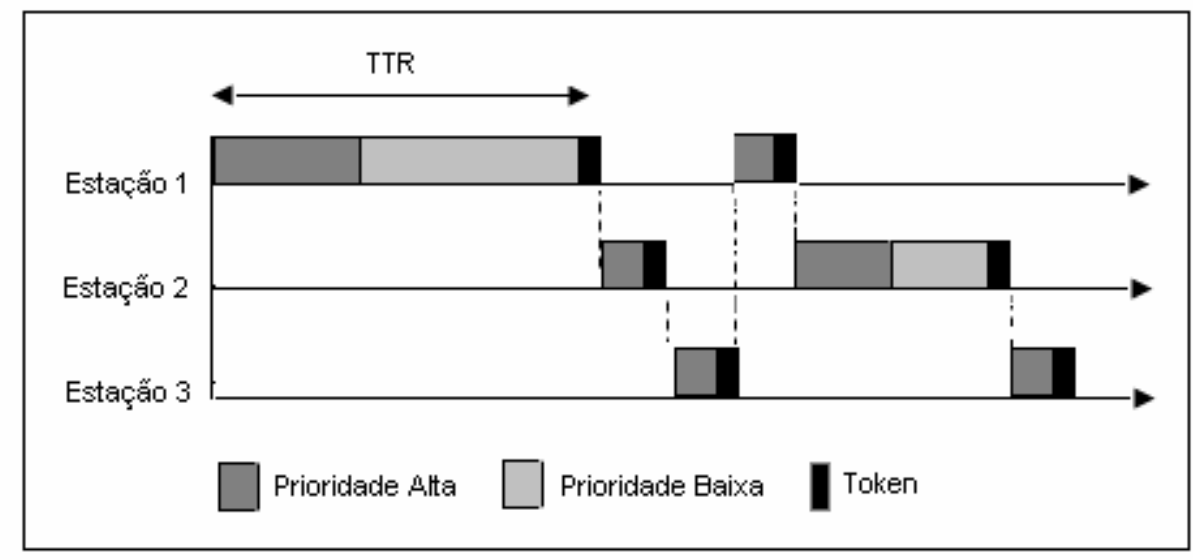

Figura 20 - Exemplo do ciclo do token com TTR alto

Num segundo cenário, considere uma situação oposta, onde o TTR é muito baixo. De acordo com algoritmo de passagem do token descrito no tópico 2.4.3.3, a estação será incapaz de transmitir mensagens com prioridade baixa, e o tráfico de mensagens com prioridade alta será afetado, pois a estação-mestre não terá tempo suficiente para transmitilas num único ciclo do token, como mostra a Figura 21. 


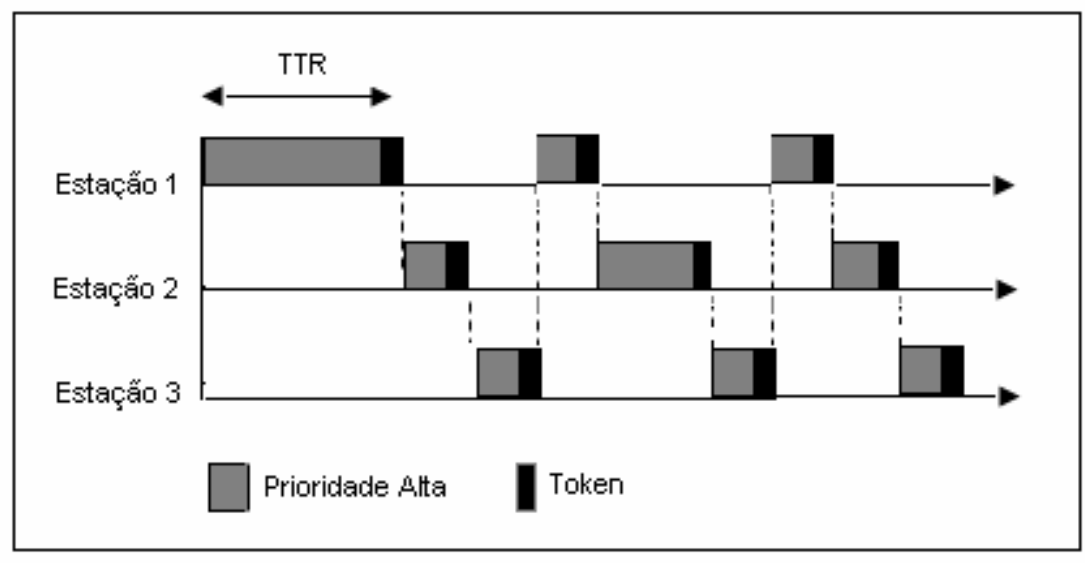

Figura 21 - Exemplo do ciclo do token com TTR baixo

Calcular um valor ideal para o parâmetro TTR é tarefa difícil, devido ás situações realísticas (LEE et al, 2003a). Para cálculo desse valor deve-se se levar em conta os seguintes fatores que influenciam na duração do ciclo do token:

- Quantidade de mensagens com prioridade alta e baixa de cada estação;

- Número de estações;

- Número de retransmissões;

- Velocidade de transmissão; (baud rate)

- Manutenção da rede;

- Deadlines quando fornecidos.

Segundo Vitturi (2004), a duração do ciclo do token normalmente é afetada pelo jitter (indesejadas variações) que ocorre por duas razões: retransmissão de mensagens e atividades acíclicas. O autor realizou uma análise detalhada e individual das probabilidades para cada fator responsável pelo jitter, e os resultados mostraram que $20 \%$ dos ciclos são afetados pelo jitter derivados de retransmissões.

Em outro trabalho, Vitturi (2003) apresentou um modelo matemático que calcula detalhadamente todos os parâmetros envolvidos na duração do ciclo do token, e apresentou 
os efeitos causados pelas atividades acíclicas. Para este autor, a duração do ciclo e o jitter são, provavelmente os fatores mais importantes de performance, e devem ser levados em consideração quando se analisar a operação de uma rede fieldbus. Segundo ele, a duração do ciclo deve ser mantida curta, o quanto possível, para assegurar o mais rápido e correto polling de sensores e atuadores; já o jitter deve ser baixo, especialmente em aplicações onde se exige boa sincronização como, por exemplo, nas aplicações de controle de movimento.

Bello e Mirabella (2001) constataram que o recebimento do token em estações onde não há mensagens a serem transmitidas, ou estações com apenas mensagens de prioridade baixa no buffer de saída, ocasiona aumento na duração do ciclo do token. Como alternativa para diminuir essa duração, os autores apresentaram uma nova estratégia que modifica o gerenciamento-padrão do token, segundo a qual este deve ser passado para a estação quando ela realmente tem dados para transmitir, e com mais freqüência para as estações que possuem mensagens com prioridade alta.

Com base na duração do ciclo do token, Lee et al. (2005), Lee et al. (2003d), Lee et al. (2003c), Lee et al. (2004) propuseram um algoritmo genético (GA) para ajustar o TTR de cada estação-mestre no barramento. Para os autores, o tempo de atraso permitido em cada estação-mestre de uma planta é diferente, pois algumas estações precisam satisfazer tempos mais rígidos que outras, por exemplo: uma estação que controla o processo deve atualizar suas variáveis mais rapidamente que uma outra que apenas monitora o processo; sendo assim, o TTR de cada estação deve ser configurado com valores diferentes, conforme requerimentos da aplicação.

Segundo este propósito, o algoritmo genético $(G A)$ calcula individualmente o valor do TTR para cada estação-mestre do anel lógico. Na iniciação do algoritmo gera-se aleatoriamente, um número de TTR, que constituirá uma população. Em seguida, calculamse os atrasos de comunicação de cada membro da população e selecionam-se os valores que apresentam menores atrasos (fitness); estes posteriormente, reproduzirão uma nova população (offspring), enquanto os demais valores serão descartados. Tal procedimento 
deve ser executado até que se obtenham os TTRs que satisfaçam os tempos requeridos pelo sistema.

Outros estudos baseados no ajuste do parâmetro TTR, foram proporcionados por Lee et al.(2003a) e Lee et al. (2003) ; LEE et al. (2003b) que introduziram um algoritmo matemático que calcula o tempo de comunicação das mensagens com prioridades altas e baixas. Esse tempo é relativo ao momento em que se gera a mensagem até a sua completa transmissão no barramento. Para tanto, com a finalidade de validar o algoritmo, os autores propuseram dois métodos. O primeiro apresenta-se na forma de diagrama (método presente somente nas duas últimas pesquisas), é eficaz para redes pequenas; quanto ao segundo, baseia-se em simulação e apresenta um bom desempenho em redes mais extensas. $O$ método de simulação quando executado em condições similares a de experimentos reais registra aproximadamente $10 \%$ de erro; ambos podem ser eficazes no ajuste do parâmetro TTR.

Segundo Tovar e Vasques (1999), quatro componentes estão envolvidos no tempo de comunicação da mensagem entre mestre e escravo, são eles:

- Tempo de Geração: Tempo decorrido entre a geração da mensagem de request na camada de aplicação da estação-mestre e a sua colocação no buffer de saída.

- Tempo de espera: Tempo que a mensagem aguarda no buffer de saída antes de ser transmitida.

- Tempo de transmissão: Tempo gasto para a mensagem de request ser transmitida no barramento + tempo de processamento da mensagem na estaçãoescrava + tempo de transmissão da mensagem de resposta.

- Tempo de entrega: Tempo decorrido entre o recebimento da mensagem de resposta e seu processamento na camada de aplicação da estação-mestre. 
Geralmente, as pesquisas que calculam o parâmetro TTR apresentam propostas para serem utilizadas na fase de design da rede, porém é importante enfatizar que mesmo depois da instalação e configuração da rede, pode haver necessidade de se ajustar o parâmetro $T T R$, isso porque os equipamentos podem ser adicionados ou removidos para sua manutenção ou conserto, durante a operação. Lee et al. (2000) propuseram um algoritmo baseado em lógica fuzzy que ajusta automaticamente o TTR de cada estação durante o funcionamento da rede (online). Deste modo, uma estação fica responsável por monitorar as mensagens transmitidas no barramento e verificar a performance das demais estações; caso o algoritmo detecte degradação em alguma estação, ele deverá calcular um novo valor de TTR e informar à estação degradada.

Uma alternativa para resolver problemas causados pelo atraso das mensagens listadas na Poll-List, devido à configuração inadequada do parâmetro TTR, foi proposta por Li (1996), Li e Stoeckli (1996) que desenvolveram um algoritmo que calcula o intervalo máximo de tempo entre duas transmissões consecutivas de um mesmo elemento contido em uma Poll-List. Este intervalo, denominado de polling-interval, é calculado individualmente para cada elemento da lista, no entanto, quando ele for maior que o tempo exigido, os autores propõem que se repita o elemento na Poll-List de maneira a reduzir o pollinginterval. Uma técnica de aproximação, conhecida como equi-distance, é usada para posicionar o elemento repetido na lista. A Figura 22 representa a Poll-List reorganizada de maneira a atender ao polling-interval do dispositivo D1 (elemento com o tempo mais restrito).

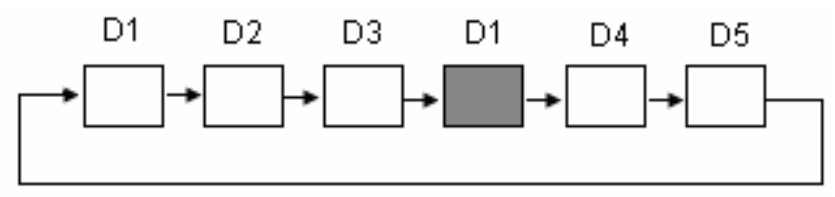

Figura 22 - Reorganização da Poll-List para atender o polling-interval 
Segundo Monforte et al. (2000), uma alternativa usada para checar se o valor do TTR atende aos requisitos do sistema é a de verificar se no pior cenário a execução das tarefas é menor que o admissível tempo de resposta.

Sobre tal hipótese, o pior cenário ocorre, quando no buffer de saída existem várias mensagens com prioridade alta e somente uma delas é transmitida por visita do token, ou seja, se houver $m$ mensagens no buffer, a última será despachada somente após $m$ chegadas do token. Todavia, o caso mais crítico acontece quando a mensagem com o menor valor de deadline, for a última do buffer de saída (TOVAR e VASQUES, 1999a).

De acordo com a Figura 23, as mensagens do buffer de saída seguem a seguinte ordem: M1, M2, M3, M4 e M5. Considerando que o deadline das mensagens são M5 < M4 < $\mathrm{M} 3<\mathrm{M} 2<\mathrm{M} 1$, a mensagem com o deadline mais estrito (M5) deverá aguardar cinco visitas do token para ser transmitida.

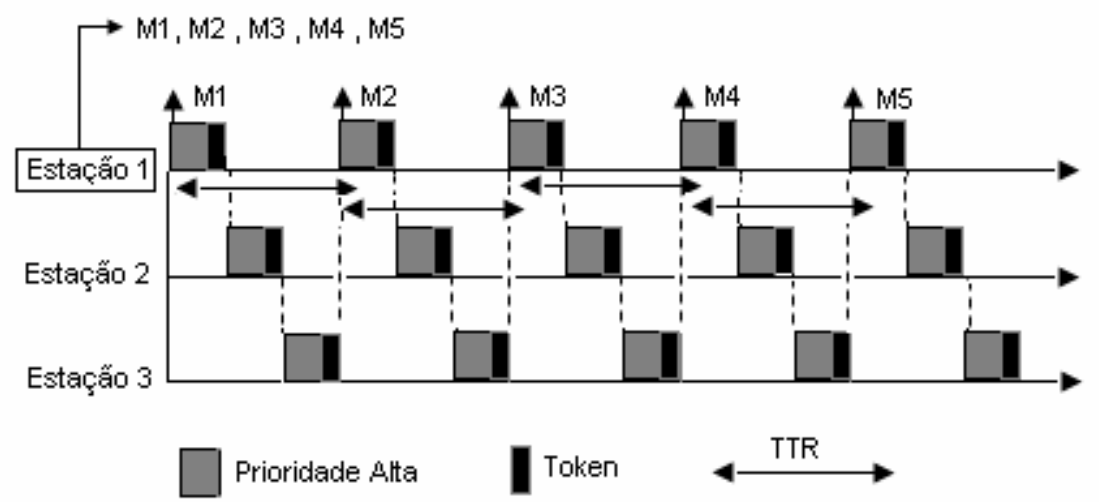

Figura 23 - Representação do pior cenário de ciclo do token

Com base neste conceito, várias pesquisas sobre análise do pior caso de tempo de resposta em redes PROFIBUS foram apresentadas, dentre as quais estão: (CAVALIERI et al. ,2002) , (MONFORTE et al, 2000), (MONFORTE et al. ,2002), (TOVAR e VASQUES ,1999a), ( TOVAR e VASQUES ,1999). A primeira pesquisa mencionada foi analisada em redes do tipo mono e multi-mestres; a segunda, em redes mono-mestre, e as quatro últimas 
em redes multi-mestres. Como resultados, os autores mostraram cenários e modelos matemáticos que representam o pior caso de tempo de ciclo do token. Para isso, os pesquisadores utilizaram como base o conhecimento da máxima duração do ciclo de mensagem, que é constituído pelo tempo de transmissão de um request e o correspondente reconhecimento ou resposta.

Tovar e Vasques (1999a) consideraram a mesma duração do ciclo de mensagem para todas mensagens em todos os mestres, diferentemente das demais pesquisas que calcularam a duração do ciclo de mensagem separadamente para cada mestre, levando em consideração, as diferenças no tamanho das mensagens de cada mestre. De uma maneira geral, todos os pesquisadores acima citados consideraram que o pior cenário ocorre quando uma única mensagem com prioridade alta é transmitida por ciclo do token, devido à indisponibilidade de tempo.

De modo a obter eficiência na análise do pior caso de tempo de resposta em redes PROFIBUS, Marcos et al. (2000) apresentaram uma ferramenta de simulação em temporeal, denominada Berta, que permite analisar vários métodos propostos por diferentes pesquisadores. Através de um ambiente de configuração, o usuário informa os parâmetros do método que deseja analisar e algumas informações sobre o sistema utilizado, como: dispositivos que compõem o sistema, prioridade das mensagens, deadline, etc.... A partir das informações fornecidas pelo usuário, a ferramenta Berta elabora um ambiente de simulação correspondente ao método utilizado.

Tovar e Vasques (1998), com base no pior caso de resposta, mostraram como configurar a rede de maneira a assegurar que a transmissão da mensagem seja realizada antes do seu deadline. O estudo foi realizado baseado em dois tipos de acesso ao buffer de transmissão, sendo eles: por prioridades (proposto pelo o artigo) e o outro por FIFO (definido por norma). Para tanto, se o TTR configurado não é suficiente para satisfazer o mais estrito deadline (considerando o pior caso), o tipo de acesso ao buffer é verificado, caso seja por prioridades, a mensagem com tempo mais estrito é deslocado para a primeira posição, caso contrário, o TTR deve ser recalculado. 
Em outro estudo, Tovar e Vasques (1999a) utilizaram os dois tipos de acesso ao buffer de transmissão (prioridades e FIFO), como base para calcular o tempo de ciclo do token sobre duas condições diferentes de gerenciamento do tráfego de mensagens com prioridade baixa, sendo:

- Não-Restrito (definido por norma): Em cada ciclo do token, as mensagens com prioridade baixa são transmitidas somente se a estação-mestre possui tempo disponível para permanecer com o token, de acordo com o tópico 2.4.3.3 (Algoritmo de passagem de token)

- Restrito (proposto pelo o artigo): As transmissões de mensagens com prioridade baixa são controladas pelo $M A C$ ou pela camada de aplicação. Tal técnica garante a transmissão de todas as mensagens com prioridade alta em cada ciclo do token.

Apesar de algumas limitações, o artigo demonstra que, em ambas condições, pode-se garantir comportamento de tempo real no tráfego de mensagens com prioridade alta, porém a primeira condição tem uma aproximação mais satisfatória para o sistema, isto porque a segunda é mais propicia ao aumento de transmissão de mensagens com prioridade baixa durante a pose do token.

O gerenciamento do tráfego de mensagens com prioridade baixa foi também proposto por Tovar e Vasques (1998a), porém neste artigo os autores analisaram apenas o acesso ao buffer de transmissão através da FIFO.

No que diz respeito aos aspectos de comunicação, o PROFIBUS é baseado em um simplificado protocolo chamado TT (Timed token), o qual apresenta boas soluções em sistemas com comunicação em tempo real. Entretanto, o PROFIBUS difere do protocolo TT 
pela ausência de sincronismo na alocação do bandwidth (quantia máxima de dados transmitida por unidade de tempo) (TOVAR e VASQUES, 1999a).

No protocolo TT, em cada ciclo do token, garante-se uma quantia mínima suficiente para transmissão de todas as mensagens com prioridade alta, enquanto que no PROFIBUS se um mestre recebe o token atrasado somente uma mensagem com prioridade alta é transmitida. (TOVAR e VASQUES, 1999a).

Segundo Hong, Kim (2000), quando o bandwidh estiver alocado de modo inadequado, a rede induz atrasos nas mensagens de tempo crítico, podendo exceder seus limites.

No trabalho proposto por Hong e Kim (2000), Hong e Kim (2002) é apresentado um método que tem como base a alocação de bandwith. Para tal, os autores classificaram as mensagens transmitidas no barramento em três tipos: tempo crítico, periódico e tempo disponível. As mensagens de tempo crítico são transmitidas em qualquer intervalo de tempo, enquanto que as demais são transmitidas conforme estratégia implementada no $F D L$ das estações-mestres. A estratégia utiliza o bit 7 da mensagem de token para indicar o tipo de mensagem (periódico ou tempo disponível) que as estações-mestres podem transmitir em cada pose do token, após a transmissão das mensagens de tempo crítico.

O método apresenta bons resultados somente se todas as estações-mestres estiverem sincronizadas. Contudo, ao se compararem os resultados com o PROFIBUS original observa-se que este método não somente satisfaz os tempos requeridos das mensagens de tempo crítico, mas também utiliza completamente os recursos de bandwidth das estações.

Hong e Kim (1997) analisaram por meio de simulação, o tempo de atraso da mensagem tanto na camada de enlace $(F D L)$ como na de aplicação de uma estação-mestre. Durante os experimentos, vários parâmetros do sistema foram modificados (tamanho da mensagem, período de geração da mensagem e TTR) e o atraso de ambas camadas foram medidas. Ao comparar os resultados, os autores concluíram que o atraso na camada de aplicação normalmente é maior que na camada de enlace. 
Dentre as pesquisas sobre redes PROFIBUS disponíveis na literatura, constatou-se uma nova abordagem de arquitetura para as redes industriais. Gradativamente, equipamentos WIRELESS (sem fio) estão sendo integrados em redes PROFIBUS já existentes (em operação).

O uso da comunicação WIRELESS dentro do ambiente industrial é atrativo, pois oferece benefícios, como: redução de fios, cabo, mobília e principalmente pela flexibilidade ocupacional dos equipamentos dentro da planta. Porém, as redes WIRELESS são mais propícias à perda ou corrupção de mensagens, se comparadas à uma rede com fios; por este motivo, questiona-se seu uso em aplicações industriais com tempo critico, mas, em aplicações onde ocasionalmente pode ocorrer perda de mensagem e o atraso não prejudica a performance do sistema, a tecnologia WIRELESS mostra-se interessante (WILLIG ,2003) .

Diversas pesquisas estão voltadas para as novas arquiteturas de redes PROFIBUS, onde é possível a junção de rede com fios já existente a uma rede sem fios. Dentre as pesquisas estão á proposta dos autores WILLIG (2003), FERREIRA (2004) e (TOVAR el at. ,2002). As duas últimas pesquisas, além da apresentação de todos os fatores que envolvem a arquitetura proposta, analisam também o pior tempo de resposta deste tipo de sistema.

Willig (1999) estudou o comportamento e o desempenho do PROFIBUS quando operado sobre uma rede WIRELESS e constatou que o fator que normalmente causa degradação, nesse tipo de rede, é a perda do token, devido à vulnerabilidade do protocolo.

A probabilidade de ocorrer perdas de token em redes WIRELESS é maior do que em uma rede convencional. Uma das conseqüências ocasionada por esse tipo de perda, é que após um número de retransmissão a estação que deixou de receber o token é excluída do anel lógico, causando degradação no sistema.

Dentro deste contexto, Willig (1999) realizou várias simulações em diferentes cenários e mediu os seguintes períodos de tempo:

- Tempo necessário para reintegrar no anel lógico uma estação que foi excluída;

- Fração de tempo que a estação fica no anel lógico. 
- Tempo entre a transmissão da mensagem e o recebimento dela na estação remota.

Por fim, o autor propôs ajustar apropriadamente o parâmetro TGUD para diminuir o tempo de reintegração da estação no anel, e enfatizou que se o TGUD é muito curto o bandwidth é desperdiçado (aumenta a quantidade de mensagens de manutenção) e se for longo o tempo de reintegração será maior.

O problema da perda do token em redes WIRELESS, foi também analisado por Willig e Wolisz (2001), que apresentaram três cenários, no qual ocasiona este tipo de perda. Para amenizar a instabilidade da rede e evitar perdas, os autores apresentaram um método que calcula o parâmetro TTO das estações-mestres. Segundo eles, tal parâmetro influência na reestruturação do anel, após a perda do token.

Em Carvalho et al. (2005), os autores propuseram uma ferramenta que simula vários comportamentos de falhas previstos no protocolo PROFIBUS, no qual são difíceis de ocorrerem em situações normais. Tal ferramenta injeta em tempos aleatórios, falhas no canal de comunicação, de acordo com o tipo de análise a ser realizada. Um dos cenários analisados pelo o artigo foi a perda do token, onde apresentaram os elementos responsáveis por esse tipo de falha.

\subsection{MOTIVAÇÃO}

$\mathrm{Na}$ revisão bibliográfica verifica-se que, há vasta pesquisa sobre análise de desempenho e otimização da comunicação em redes PROFIBUS. No entanto, observa-se que a maioria das pesquisas apresentadas, utilizam expressão matemática ou ferramenta de simulação para obter os resultados desejados.

Dentro deste universo, constata-se que o número de pesquisas envolvendo comunicação em tempo real em redes PROFIBUS é pequeno. Isto se deve, em parte, à 
escassez de ferramentas de suporte a projetos que enfoquem o trabalho na camada de enlace do protocolo PROFIBUS.

Diante deste cenário, ambas as análises realizadas através do MPA, conforme objetivos de número 3 e 4, visam complementar as pesquisas publicadas, nas quais envolvem análise de desempenho de redes PROFIBUS em tempo-real. Este tipo de análise normalmente apresenta resultados mais satisfatórios do que os obtidos por meio de modelo matemático ou ferramenta de simulação.

Em relação ao desenvolvimento do MPA, conforme objetivo de número 1, este visa suprir a escassez de ferramenta de suporte para projeto PROFIBUS. Além do cumprimento das exigências dos serviços da camada de enlace essenciais para operar como mestre da rede. O MPA engloba serviços que geralmente são disponibilizados por ferramentas comerciais, utilizadas na configuração do dispositivo mestre e durante operação da rede. A descrição dos serviços suportados pelo MPA é feita no capítulo 4 (Desenvolvimento). 



\section{DESENVOLVIMENTO}

O projeto MPA (Mestre PROFIBUS Analisador) apresentado neste trabalho, consiste de uma ferramenta computacional, desenvolvida na plataforma de programação Visual Basic da Microsoft, composta por funções e serviços descritos na norma PROFIBUS.

O MPA tem a tarefa de comporta-se como um mestre em redes PROFIBUS e complementarmente oferece um ambiente propício à realização de análises de desempenho da rede. Suas características são fundamentais para desempenhar o papel de mestre na rede. Assim, as funcionalidades descritas na norma PROFIBUS, que não apresentam impacto no funcionamento do mestre, nem no tráfego de mensagens na rede são descartadas.

O código fonte do MPA estrutura-se em módulos compostos por funções específicas de desenvolvimento, como mostra a Figura 24: 


\begin{tabular}{|c|c|}
\hline MÓDULO & DESCRIÇAO \\
\hline Mod_PollList & $\begin{array}{l}\text { Módulo responsável pela elaboração da Poll-List (lista } \\
\text { de mensagens que sẫo transmitidas sequencialmente } \\
\text { e ciclicamente pela estaçẫo DPM1). }\end{array}$ \\
\hline Mod_BusParameter & $\begin{array}{l}\text { Módulo responsável pela configuração dos } \\
\text { parâmetros usados pelo } \mathrm{FDL} \text { para controlar o tráfego } \\
\text { de mensagens no barramento. }\end{array}$ \\
\hline Mod_EstadoFDL & $\begin{array}{l}\text { Modulo responsável pelo gerenciamento da maquina } \\
\text { de estado do FDL. }\end{array}$ \\
\hline Mod_BuildMess & $\begin{array}{l}\text { Este módulo constrói as mensagens que sẫo } \\
\text { transmitidas no barramento. }\end{array}$ \\
\hline Mod_MessReceived & $\begin{array}{l}\text { Este módulo decodifica as mensagens recebidas no } \\
\text { barramento. }\end{array}$ \\
\hline Mod_BusAnalyse & $\begin{array}{l}\text { Este módulo elabora em tempo real uma lista com } \\
\text { todas as mensagens transmitidas no barramento. }\end{array}$ \\
\hline Mod_LiveList & $\begin{array}{l}\text { Este módulo elabora uma lista de todas as estaçốes } \\
\text { presentes no barramento. }\end{array}$ \\
\hline Mod_monit & $\begin{array}{l}\text { Este módulo monitora a variável de processo do(s) } \\
\text { dispositivo(s), definido(s) na Poll-List. }\end{array}$ \\
\hline Mod_Diagnosis & $\begin{array}{l}\text { Este módulo mostra o diagnóstico do(s) dispositivo(s) } \\
\text { definido(s) na Poll-List. }\end{array}$ \\
\hline Mod_ComCiclica & $\begin{array}{l}\text { Este módulo gerencia a transmissẫo de mensagem } \\
\text { cíclica no barramento. }\end{array}$ \\
\hline Mod_ComAciclica & $\begin{array}{l}\text { Este módulo gerencia a transmissẫo de mensagem } \\
\text { acíclica no barramento. }\end{array}$ \\
\hline Mod_General & Este módulo é composto por funçốes diversificadas \\
\hline
\end{tabular}

Figura 24 - Estrutura dos módulos de funções do MPA

A seguir, a descrição de cada módulo que compõe o MPA.

\subsection{MOD_POLLLIST}

No módulo Mod_PollList o usuário seleciona através de uma lista de transmissores, conversores e atuadores PROFIBUS PA do fabricante Smar (SMAR EQUIPAMENTOS INDUSTRIAIS, 2006), os dispositivos que devem participar da comunicação cíclica de dados (Poll-List). 


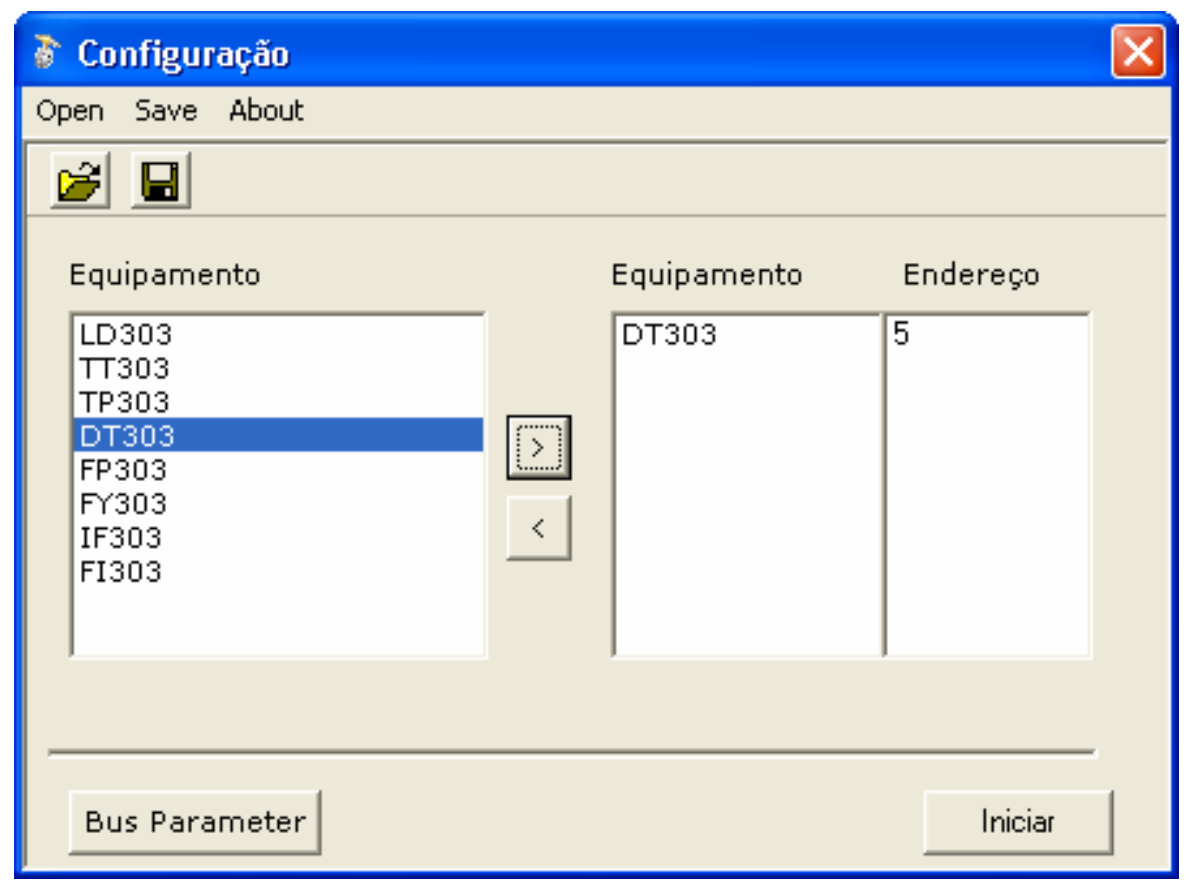

Figura 25 - Tela de configuração da Poll-List

Para cada dispositivo selecionado, o usuário deve informar o endereço do dispositivo no barramento.

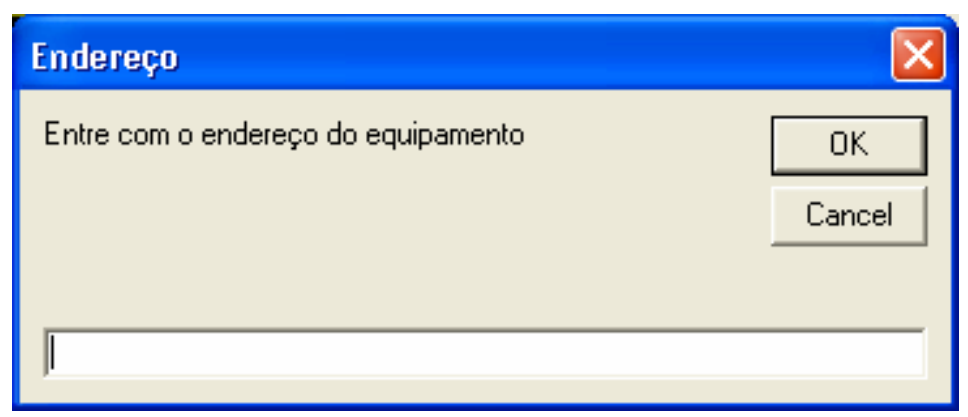

Figura 26 - Tela de entrada de endereço do equipamento

Após a escolha do(s) dispositivo(s), a Poll-List é construída pelo MPA e as seguintes informações são utilizadas em cada mensagem da lista:

- Endereço do dispositivo - Endereço do dispositivo no barramento. 
- Ident_Number - Número de Identificação do dispositivo. Está Informação é extraída do arquivo GSD, conforme norma PROFIBUS.

- Código de Acesso - Para cada variável que se deseja acessar ciclicamente, é necessário informar o código de acesso, que é mapeado no dispositivo e fornecido no arquivo GSD, conforme norma PROFIBUS.

A Figura 27 representa parte de um arquivo GSD de um dispositivo PROFIBUS PA, onde é extraído o código de acesso das variáveis.

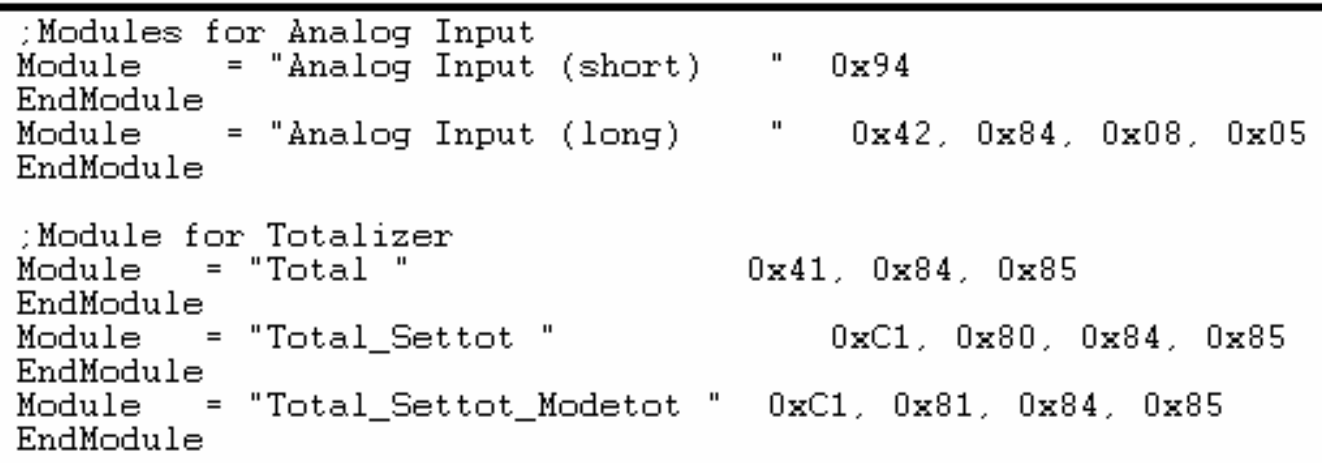

Figura 27 - Representação de parte de um arquivo GSD

De acordo com o GSD da Figura 27, o dispositivo possui dois blocos de funções, sendo eles: Analog Input e Totalizer. Na elaboração da Poll-List, é necessário respeitar a configuração mínima exigida por cada dispositivo da lista. No caso deste dispositivo, por exemplo, o bloco Analog Input é essencial na configuração, sendo assim o código de acesso deste bloco obrigatoriamente necessita ser indicado na mensagem da Poll-List, enquanto que o bloco Totalizer é opcional e se não for necessário para a aplicação, pode ser indicado na mensagem da Poll-List com o valor 0x00.

$\mathrm{Na}$ interpretação do GSD da Figura 27, por exemplo, o código de acesso "0x94" é referente a variável de saída do bloco Analog Input, enquanto que o código de acesso 
“0x42, 0x84, 0x08, 0x05” é referente a variável de saída do bloco Analog Input + o status da variável.

Caso o dispositivo tenha mais de um bloco de função do mesmo tipo, é necessário referenciar na mensagem da Poll-List, o mesmo código de acesso para cada bloco, por exemplo, suponha que o dispositivo representado pela Figura 27 tenha dois blocos Analog Input, sendo assim, na mensagem da Poll-List é necessário referenciar duas vezes o código de acesso do bloco Analog Input.

Em razão do MPA não possuir um interpretador de arquivo GSD, o código de acesso dos dispositivos listados na Figura 25 são fixos, e a configuração mínima exigida por cada dispositivo conforme GSD é respeitada (Figura 28):

\begin{tabular}{|c|c|c|}
\hline DISPOSITIVO & CÓDIGO DE ACESSO & VARIÁVEIS \\
\hline LD303 & $\begin{array}{l}0 \times 42,0 \times 84,0 \times 08,0 \times 05 \\
0 \times 00\end{array}$ & $\begin{array}{l}\text { Saida do bloco Al + Status } \\
\text { Bloco Totalizer (descartado) }\end{array}$ \\
\hline ТЗО1 & $\begin{array}{l}0 \times 42,0 \times 84,0 \times 08,0 \times 05 \\
0 \times 94\end{array}$ & $\begin{array}{l}\text { Saída do bloco Al1 + Status } \\
\text { Saida do bloco Al2 }\end{array}$ \\
\hline TP303 & $\begin{array}{l}0 \times 42,0 \times 84,0 \times 08,0 \times 05 \\
0 \times 00\end{array}$ & $\begin{array}{l}\text { Saida do bloco Al + Status } \\
\text { Bloco Totalizer (descartado) }\end{array}$ \\
\hline DT3П13 & $0 \times 42, \square \times 84,0 \times 08,0 \times 05$ & Saída do bloco Al + Status \\
\hline FP:303 & 0x82, $0 \times 84,0 \times 08,0 \times 05$ & Saída do bloco AO + Status \\
\hline $\mathrm{Fl} 30 \mathrm{O}$ & $\begin{array}{l}0 \times 82,0 \times 84,0 \times 08,0 \times 055 \\
0 \times A 4 \\
0 \times A 4\end{array}$ & $\begin{array}{l}\text { Saida do bloco AO1 + Status } \\
\text { Saida do bloco AO2 } \\
\text { Saída do bloco AO3 }\end{array}$ \\
\hline IF301 & $\begin{array}{l}0 \times 42,0 \times 04,0 \times 018,0 \times 05 \\
0 \times 00 \\
0 \times 94 \\
0 \times 00 \\
0 \times 94 \\
0 \times 00\end{array}$ & $\begin{array}{l}\text { Saida do bloco Al1 + Status } \\
\text { Bloco Totalizer1 (descartado) } \\
\text { Saida do bloco Al2 } \\
\text { Bloco Totalizer2 (descartado) } \\
\text { Saida do bloco Al3 } \\
\text { Bloco Totalizer3 (descartado) }\end{array}$ \\
\hline FYO103 & $0 \times 82,0 \times 84,0 \times 08,0 \times 05$ & Saida do bloco AO + Status \\
\hline
\end{tabular}

Figura 28 - Mapeamento das variáveis utilizadas pela Poll-List no MPA 


\subsection{MOD_BUSPARAMETER}

No módulo Mod_BusParameter o usuário configura alguns parâmetros do sistema que são utilizados pela máquina de estados do FDL no gerenciamento do tráfego de mensagens no barramento.

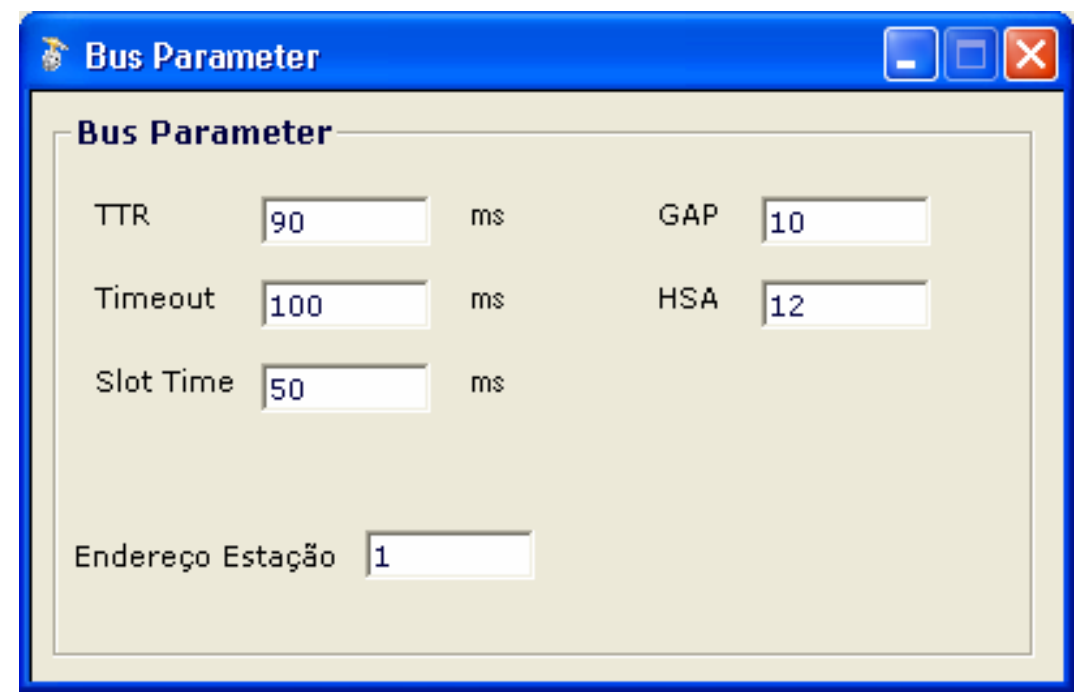

Figura 29 - Tela de configuração do Bus Parameter

- $\quad T T R$ - Tempo máximo esperado para que o token circule entre todas as estaçõesmestres do anel lógico e retorne para o MPA.

- Timeout (TTO) - Tempo máximo que o barramento pode ficar ocioso. Assim que esse parâmetro expira, o MPA assume que ocorreu algum problema na comunicação e uma ação correspondente é tomada, conforme descrito no módulo Mod_EstadoFDL.

- Slot Time (TSL) - Tempo máximo que o MPA aguarda depois da transmissão de uma mensagem por um reconhecimento ou resposta. 
- $\operatorname{GAP}(T G U D)$ - Define quantos TTRs são aguardados antes do MPA iniciar a atualização da GAPL.

- HSA - Determina o endereço da última estação, na qual o MPA deve transmitir mensagem de pedido de status (RFL).

- Endereço da Estação - Endereço do MPA no barramento.

Para controlar os parâmetros temporais da norma PROFIBUS, o MPA utiliza o componente Timer da plataforma Visual Basic. Devido o gerenciamento de tarefas do Sistema Operacional Windows, o componente Timer não funciona com determinismo. Em alguns momentos dependendo do PC utilizado, o tempo varia em até $20 \%$ do valor configurado. No entanto, apesar dos atrasos que podem ocorrer no componente Timer, é possível cumprir os requisitos temporais definidos na norma PROFIBUS.

\subsection{MOD_ESTADOFDL}

Para que não haja colisão de mensagem no barramento, cada estação deve respeitar as transições da Máquina de estados do FDL descrito no tópico 2.4.4 (Máquina de estados do FDL).

O módulo Mod_EstadoFDL é responsável pelo gerenciamento das transições de cada estado do FDL, que é feito através de funções especificas, conforme mostra a Figura 30. 


\begin{tabular}{ll}
\hline \multicolumn{1}{c}{ ESTADO } & \multicolumn{1}{c}{ FUNÇäo } \\
\hline Offline & Func_Est_OftLine \\
Listen Token & Func_Est_ListenToken \\
Active Idle & Func_Est_Activeldle \\
Claim Token & Func_Est_ClaimToken \\
Use Token & Func_Est_UseToken \\
Await Data Response & Func_Est_AwaitDataResponse \\
Check Access Time & Func_Est_CheckAcessTime \\
Pass Token & Func_Est_PassToken \\
Check Token Pass & Func_Est_CheckPassToken \\
Await Status Response & Func_Est_AwaitStatusResponse \\
\hline
\end{tabular}

Figura 30 - Funções do módulo Mod_EstadoFDL

De acordo com a norma PROFIBUS, em cada estado é verificada uma série de situações que podem ocorrer durante o funcionamento da rede, e para cada uma delas, uma ação correspondente é tomada. Em razão do MPA ser uma ferramenta de estudo, não existe a necessidade de executar todas as funcionalidades da máquina de estados do FDL descrita na norma PROFIBUS, sendo assim apenas as fundamentais são verificadas, conforme mostra a Figura 31. 


\begin{tabular}{|c|c|c|}
\hline FUNÇÄO & VERIFICAÇÄO & AÇÄO \\
\hline Func_Est_Off_line & & $\begin{array}{l}\text { (1) Inicia as variáveis do sistema, e } \\
\text { altera o estado para Listen Token }\end{array}$ \\
\hline Func_Est_Listen_token & $\begin{array}{l}\text { (1) Se o parâmetro timeout expirou. } \\
\text { (2) Se detectar novas estaçôes no } \\
\text { barramento. } \\
\text { (3) Se existe outra estação no } \\
\text { barramento com o mesmo endereço. } \\
\text { (4) Se terminou as duas primeiras } \\
\text { rotaçôes completas do token. } \\
\text { (5) Se houver Pedido de Status } \\
\text { (RFS), antes do segundo ciclo } \\
\text { completo do token. } \\
\text { (6) Se houver Pedido de Status } \\
\text { (RFS), depois da segunda execuçẫo } \\
\text { completa do token. } \\
\text { (7) Se receber o token da estação } \\
\text { antecessora ou se receber duas } \\
\text { vezes consecutivas o token de outra } \\
\text { estaçẫo que năo é da antecessora. }\end{array}$ & $\begin{array}{l}\text { (1) Altera o estado para Claim Token } \\
\text { (2) Executa a funçăo AddStationLAS } \\
\text { do módulo Mod_General. } \\
\text { (3) Altera o estado para Off Line } \\
\text { (4) A funçẫo FindPSNS do módulo } \\
\text { Mod_General é executada. } \\
\text { (5) O MPA responde o pedido de } \\
\text { status (RFS) como "Estaçẫo năo } \\
\text { pronta para entrar no anel lógico". } \\
\text { (6) O MPA responde o pedido de } \\
\text { status (RFS) como "Estaçăo pronta } \\
\text { para entrar no anel lógico" e altera o } \\
\text { estado para Active idie. } \\
\text { (7) Aceita o token e altera o estado } \\
\text { para Active idle }\end{array}$ \\
\hline Func_Est_Active_idle & $\begin{array}{l}\text { (1) Se Timeout expirou } \\
\text { (2) Se receber duas vezes } \\
\text { consecutivas o token de uma estação } \\
\text { aonde TS = NS } \\
\text { (3) Se receber o token da estação } \\
\text { antecessora } \\
\text { (4) Se houver Pedido de Status (RFS) }\end{array}$ & $\begin{array}{l}\text { (1) Altera o estado para Claim Token } \\
\text { (2) Altera o estado para Listen Token } \\
\text { (3) Altera o estado para Use Token } \\
\text { (4) O MPA responde o pedido de } \\
\text { Status (RFS) como "Estaçấo pronta } \\
\text { para entrar no anel lógico". }\end{array}$ \\
\hline Func_Est_Claim_token & & $\begin{array}{l}\text { (1) Atribui o seu endereço para o NS e } \\
\text { altera o estado Pass Token }\end{array}$ \\
\hline Func_Est_Use_token & $\begin{array}{l}\text { (1) Se há mensagem de prioridade } \\
\text { alta e TTH é maior que zero ou se é a } \\
\text { primeira mensagem a ser transmitida. } \\
\text { (2) Se năo há mensagem de } \\
\text { prioridade alta e há mensagem de } \\
\text { prioridade baixa e TTH é maior que } \\
\text { zero. } \\
\text { (3) Se näo existe mais mensagem a } \\
\text { ser transmitida ou TTH é menor ou } \\
\text { igual a zero. }\end{array}$ & $\begin{array}{l}\text { (1)Transmiti a mensagem de } \\
\text { prioridade alta e altera o estado para } \\
\text { Await Data Response. } \\
\text { (2) Transmiti a mensagem de } \\
\text { prioridade baixa e altera o estado para } \\
\text { Await Data Response. } \\
\text { (3) Altera o estado para Pass Token. }\end{array}$ \\
\hline Func_Est_Await_data_response & $\begin{array}{l}\text { (1) Se o parâmetro SlotTime expirou. } \\
\text { (2) Se recebeu uma resposta ou } \\
\text { reconhecimento. } \\
\text { (3) Se recebeu uma mensagem } \\
\text { corrompida ou de uma estação } \\
\text { diferente da esperada. }\end{array}$ & $\begin{array}{l}\text { (1) Altera o estado para Check } \\
\text { Access Time } \\
\text { (2) Altera o estado para Check } \\
\text { Access time } \\
\text { (3) Altera o estado para Active Idle }\end{array}$ \\
\hline Func_Est_Check_access_time & $\begin{array}{l}\text { (1) Se existe tempo disponivel (TTH é } \\
\text { maior que zero) } \\
\text { (2) Se năo existe tempo disponivel } \\
\text { (TTH é menor ou igual a zero). }\end{array}$ & $\begin{array}{l}\text { (1) Altera o estado para Use Token } \\
\text { (2) Altera o estado para Pass Token }\end{array}$ \\
\hline Func_Est_Check_Pass_token & $\begin{array}{l}\text { (1) Se o parâmetro SlotTime expirou e } \\
\text { o MPA nẵ detectou mensagem no } \\
\text { barramento } \\
\text { (2) Se detectou mensagem no } \\
\text { barramento }\end{array}$ & $\begin{array}{l}\text { (1) Altera o estado para Pass Token } \\
\text { (2) Altera o estado para Active Idie }\end{array}$ \\
\hline Func_Est_Pass_token & $\begin{array}{l}\text { (1) Se TTH é maior que zero e o } \\
\text { parâmetro GAP expirou. } \\
\text { (2) Se TTH é menor ou igual a zero ou } \\
\text { o parâmetro GAP nấo expioru. }\end{array}$ & $\begin{array}{l}\text { (1) Atualiza a GAPL. } \\
\text { (2) Passa o token para a estaçắ } \\
\text { sucessora e altera o estado para } \\
\text { Check Token Pass }\end{array}$ \\
\hline Func_Est_Await_status_response & & Nẵo é utilizado pelo o MPA \\
\hline
\end{tabular}




\subsection{MOD_LIVELIST}

O módulo Mod_LiveList apresenta uma lista de todas as estações presentes no barramento, de acordo com o endereço, tipo e o status de cada estação. Por meio desta funcionalidade o usuário consegue ter visibilidade das estações que estão operando na rede, sabendo portanto, quais endereços disponíveis para a inclusão de novos dispositivos.

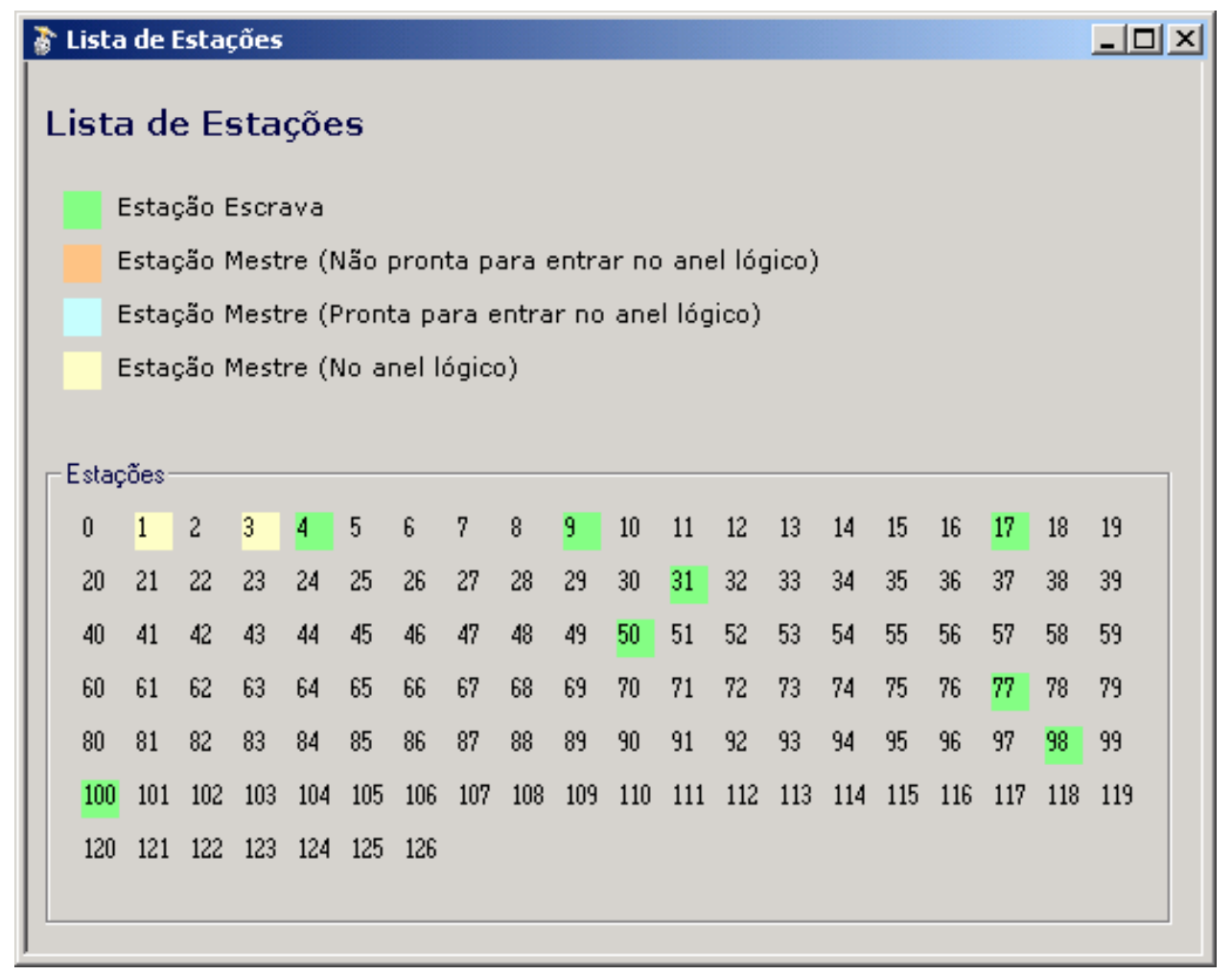

Figura 32 - Tela de representação da Lista de Estações presentes na rede

Tais informações são obtidas em tempo real na resposta da mensagem de pedido de status (RFS) durante a elaboração das listas: GAPL e LAS.

$O$ byte $F C$ da mensagem indica o tipo e o status da estação, como mostra a Figura 33: 


\begin{tabular}{ll}
\hline FC & STATUS \\
\hline 0×00 & Estaçẫo Escrava \\
$0 \times 10$ & Estaçẫo mestre (Nẫo pronta para entrar no anel lógico \\
$0 \times 20$ & Estaçẫo Mestre (Pronta para entrar no anel lógico) \\
$0 \times 30$ & Estaçẫo mestre (no anel lógico) \\
\hline
\end{tabular}

Figura 33 - Interpretação da resposta da mensagem de Pedido de status

\subsection{MOD_COMCICLICA}

Como mencionado anteriormente, o mestre DPM1 troca dados de processo com estações-escravas de maneira rápida, utilizando comunicação cíclica (Poll-List). No entanto, para que essa troca de dados seja possível, a estação-escrava precisa estar preparada, caso contrário, as mensagens de troca de dados são negadas.

De acordo com a máquina de estados da estação escrava descrita no tópico 2.4 .5 (Máquina de estados da estação escrava), o mestre DPM1 deve transmitir uma seqüência de mensagens, antes de transmitir mensagens de pedido de troca de dados cíclica (DataExchange). A Figura 34 mostra a seqüência de mensagens transmitidas pelo MPA para cada dispositivo escravo definido na Poll-List, conforme norma PROFIBUS. Este módulo é responsável por gerenciar essa seqüência de mensagens. 


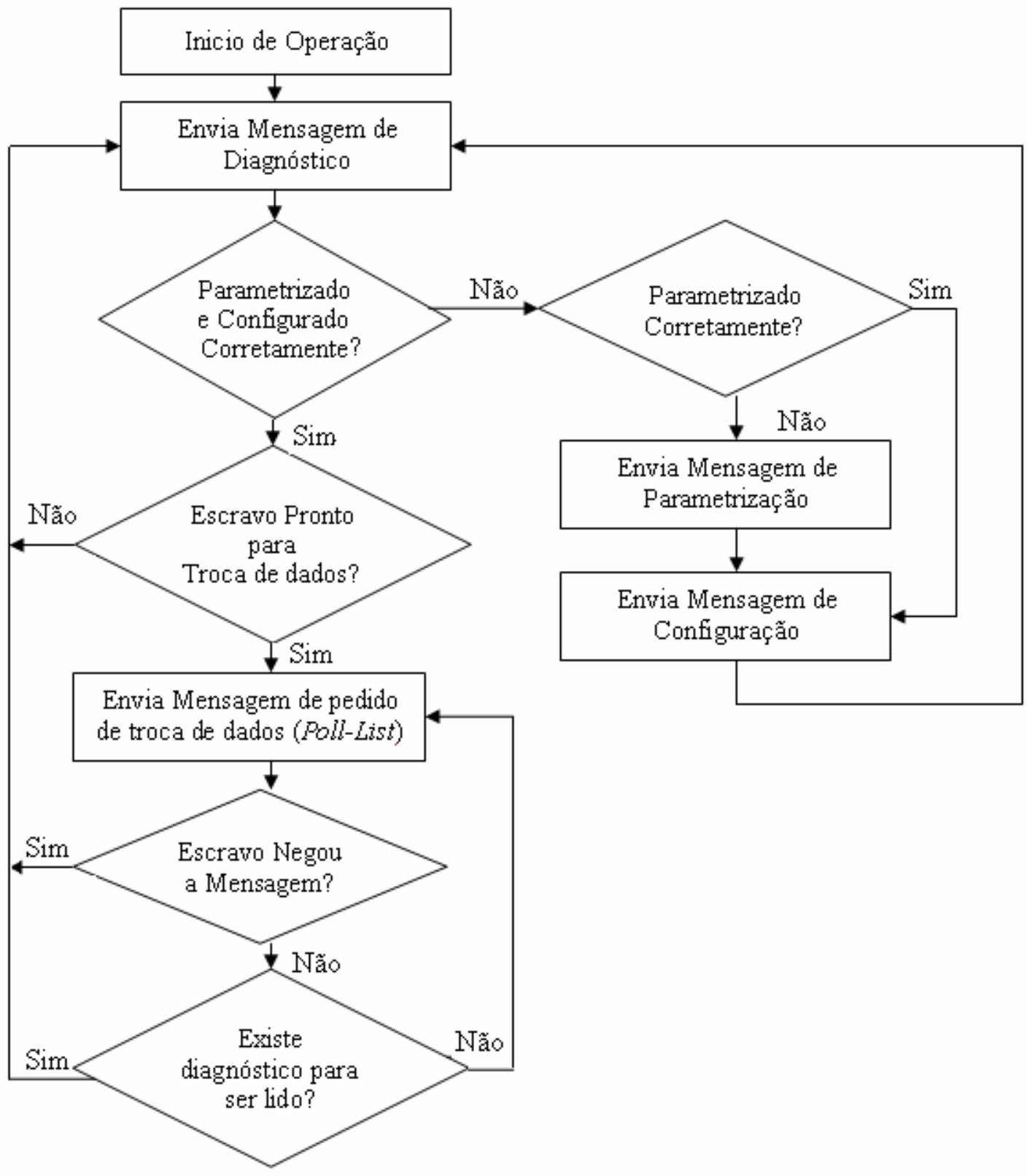

Figura 34 - Controle de transmissão de mensagens cíclicas

\subsection{MOD MONIT}

O módulo Mod_Monit monitora em tempo real o valor e o status da primeira variável de cada mensagem definida na Poll-List. Tal valor é obtido na resposta da mensagem de Data-Exchange. 


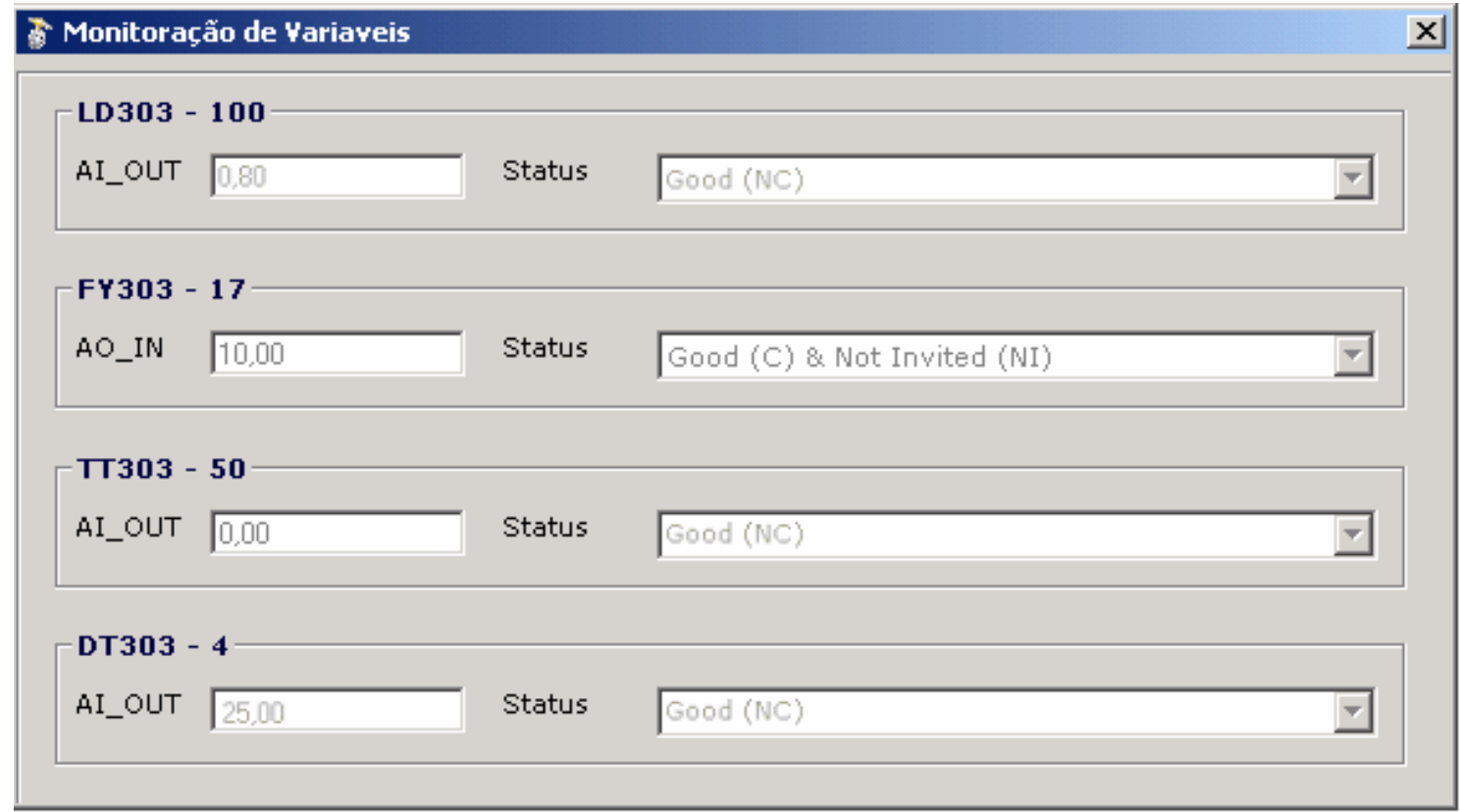

Figura 35 - Tela de Monitoração das variáveis definidas na Poll-List

O tipo de dado da variável monitorada é um DS-33, no qual é composto por um float (valor de processo) e 1 byte de status (qualidade da variável de processo). A função Converte_Data_Type do módulo Mod_General é usada na extração dos bytes do campo de dados da mensagem recebida e na conversão desses bytes no valor que é apresentado para o usuário.

A quantidade de dispositivos definidos na Poll-List varia de acordo com a configuração do usuário, sendo assim, á tela representada pela Figura 35 é flexível, pois mostra a variável e o status de cada mensagem da lista.

Para cada variável monitorada é mostrado: nome e endereço do dispositivo, valor e o status da variável.

\subsection{MOD_DIAGNOSIS}

O módulo Mod_Diagnosis mostra em tempo real o diagnóstico dos dispositivos definidos na Poll-List. Essa funcionalidade auxilia o usuário sobre a causa de possíveis problemas que podem ocorrer com o dispositivo.. 


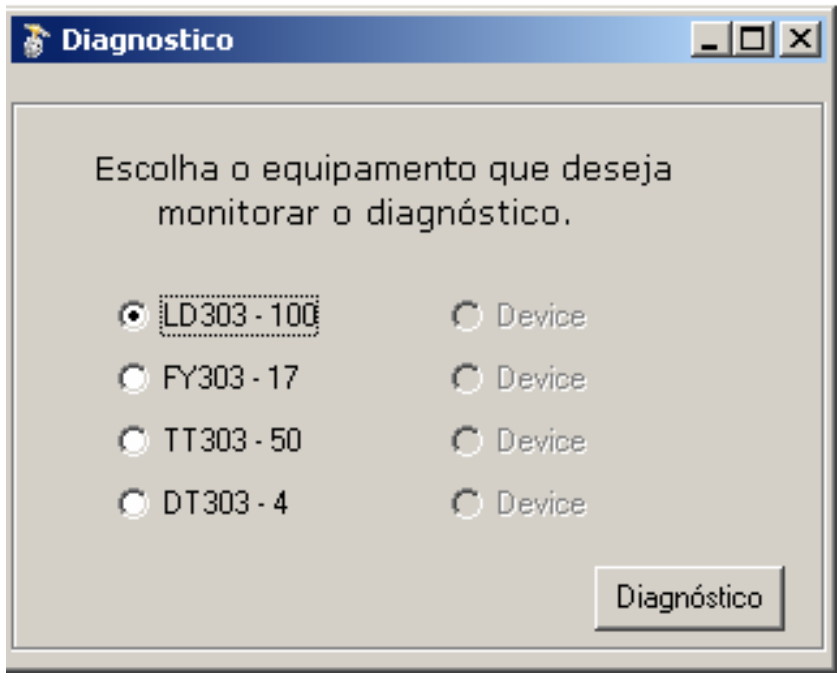

Figura 36 - Tela de escolha do equipamento para monitoração de diagnóstico

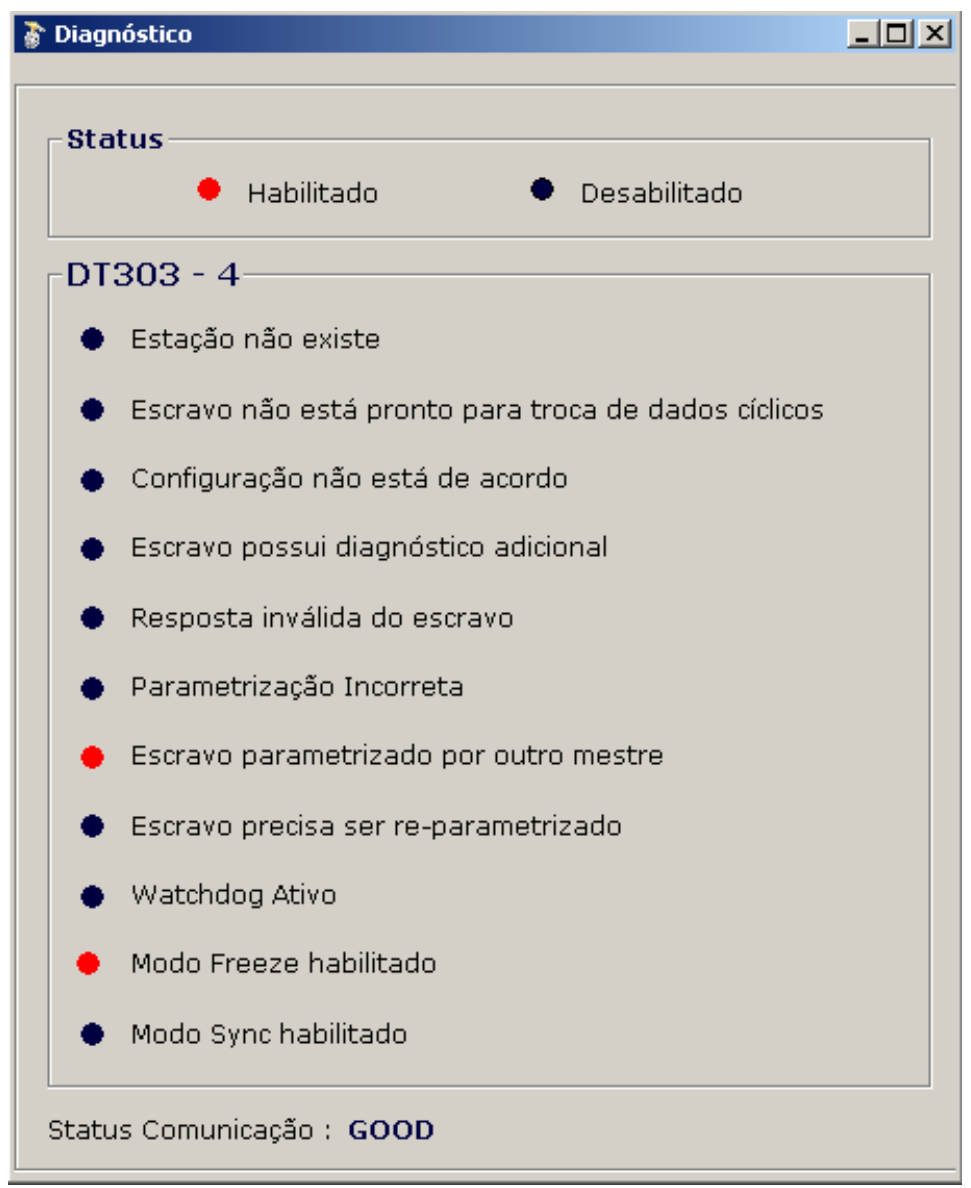

Figura 37 - Tela de diagnóstico 
As informações de diagnóstico são extraídas do campo de dados da mensagem de resposta de diagnóstico, e são interpretadas através da verificação dos bits de cada byte, conforme representa a Figura 38:

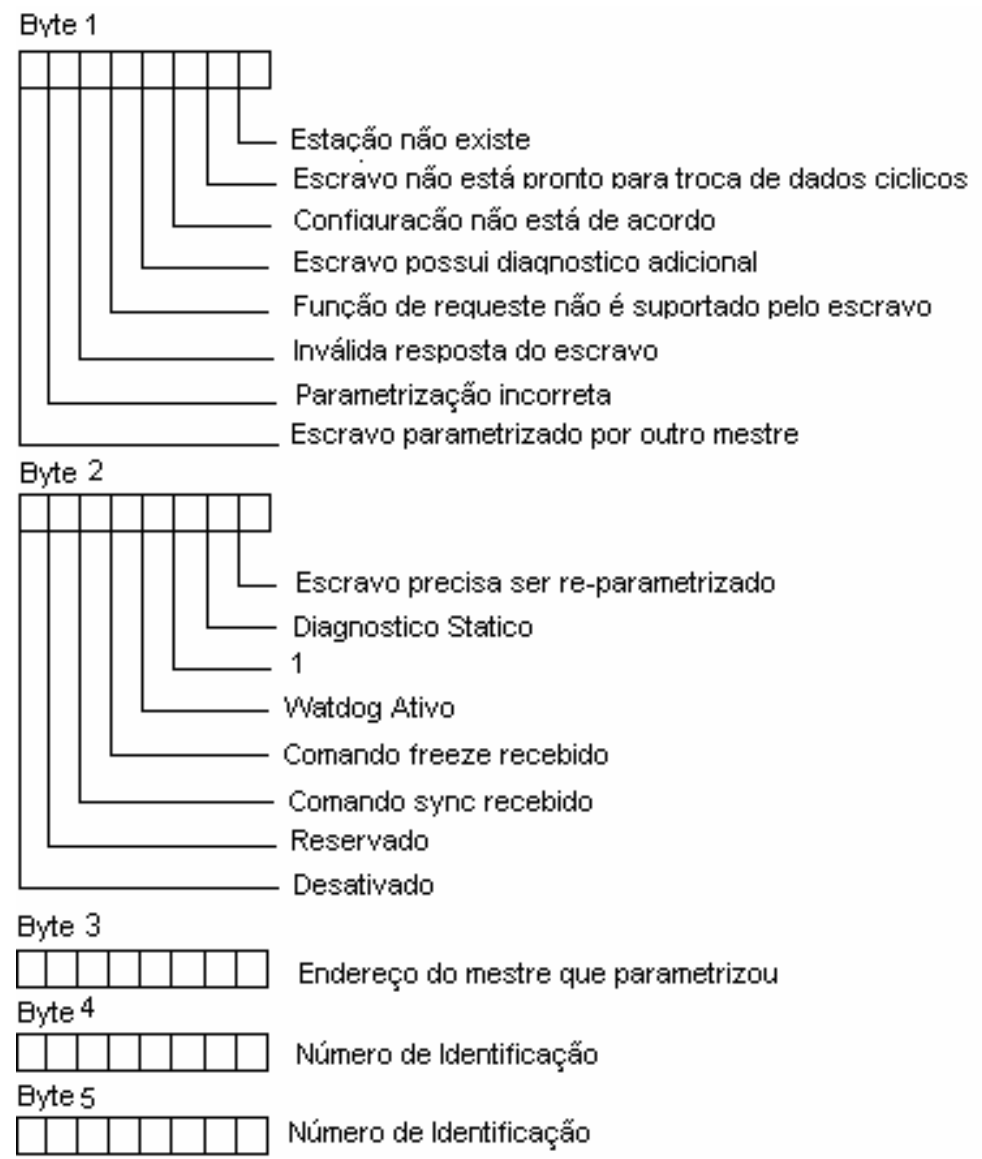

Figura 38 - Representação dos bytes de diagnostico da resposta do dispositivo

Os seis bytes mostrados na Figura 38 são genéricos, ou seja, são interpretados da mesma maneira para qualquer dispositivo, mas além desses bytes, a mensagem de resposta de diagnostico pode conter bytes adicionais que são específicos do dispositivo e precisam ser especificados no arquivo GSD. O MPA não interpreta os bytes adicionais da mensagem de diagnóstico. 


\subsection{MOD_COMACICLICA}

Conforme dito anteriormente a comunicação acíclica é feita aperiodicamente por estações-mestres DPM1 e DPM2, com a finalidade de parametrizar, configurar e diagnosticar dispositivos escravos. Este módulo é responsável por fazer leitura acíclica de alguns blocos padrões utilizados em dispositivos PROFIBUS PA.

Da mesma forma que na troca de dados cíclica, o dispositivo escravo precisa estar preparado para receber mensagens de leitura e escrita acíclica, sendo assim uma seqüência de mensagens deve ser transmitida pelo mestre, antes da mensagem de leitura ou escrita. A Figura 39 mostra a seqüência de mensagens transmitidas pelo MPA para cada dispositivo escravo antes da transmissão da mensagem de leitura, conforme norma PROFIBUS. 


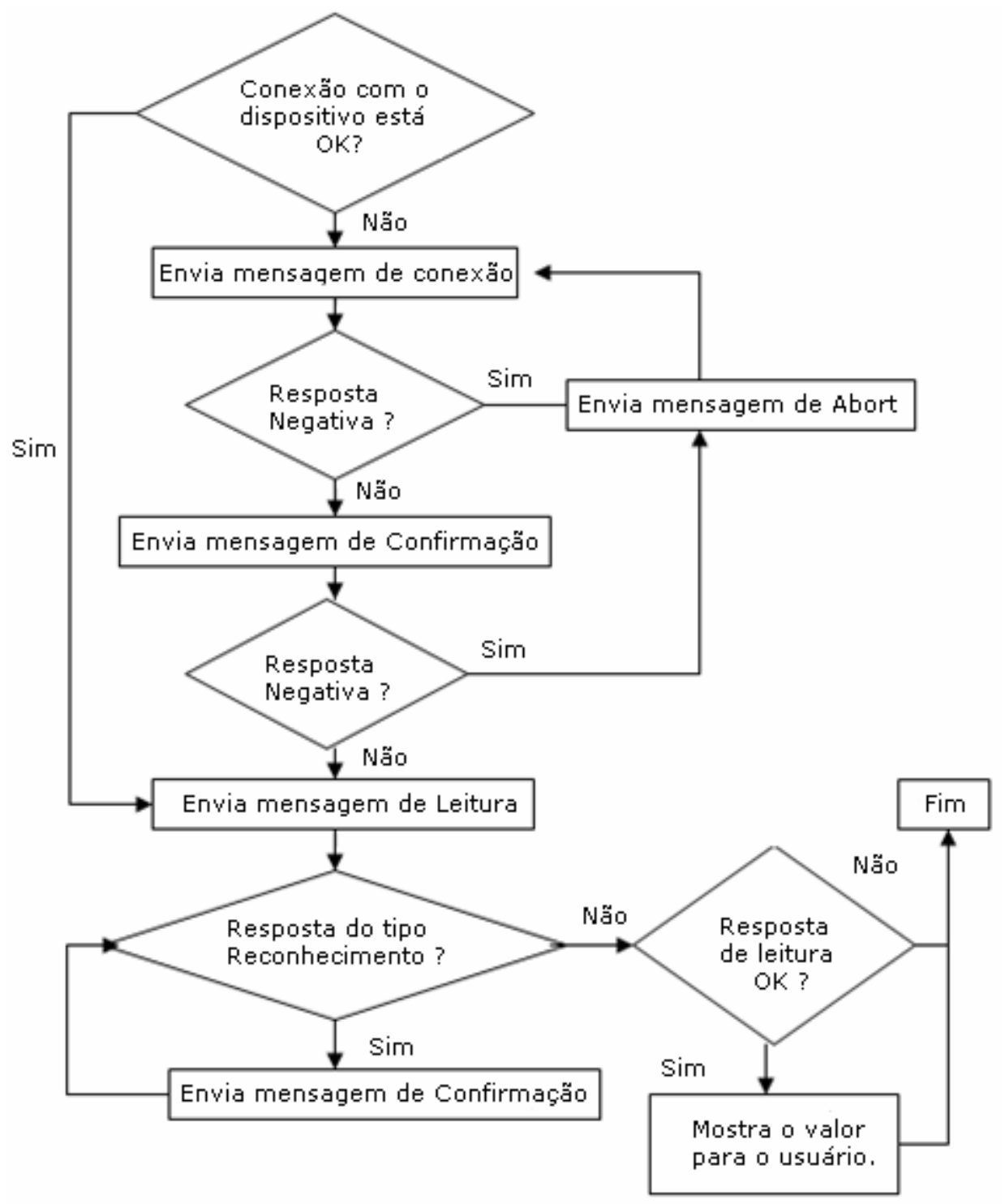

Figura 39 - Controle de transmissão de mensagens acíclicas

Antes de iniciar o ciclo de leitura, o usuário precisa escolher o dispositivo e o bloco que deseja ler. Caso o dispositivo selecionado não suporte o bloco selecionado, o usuário é informado com uma mensagem na tela. 


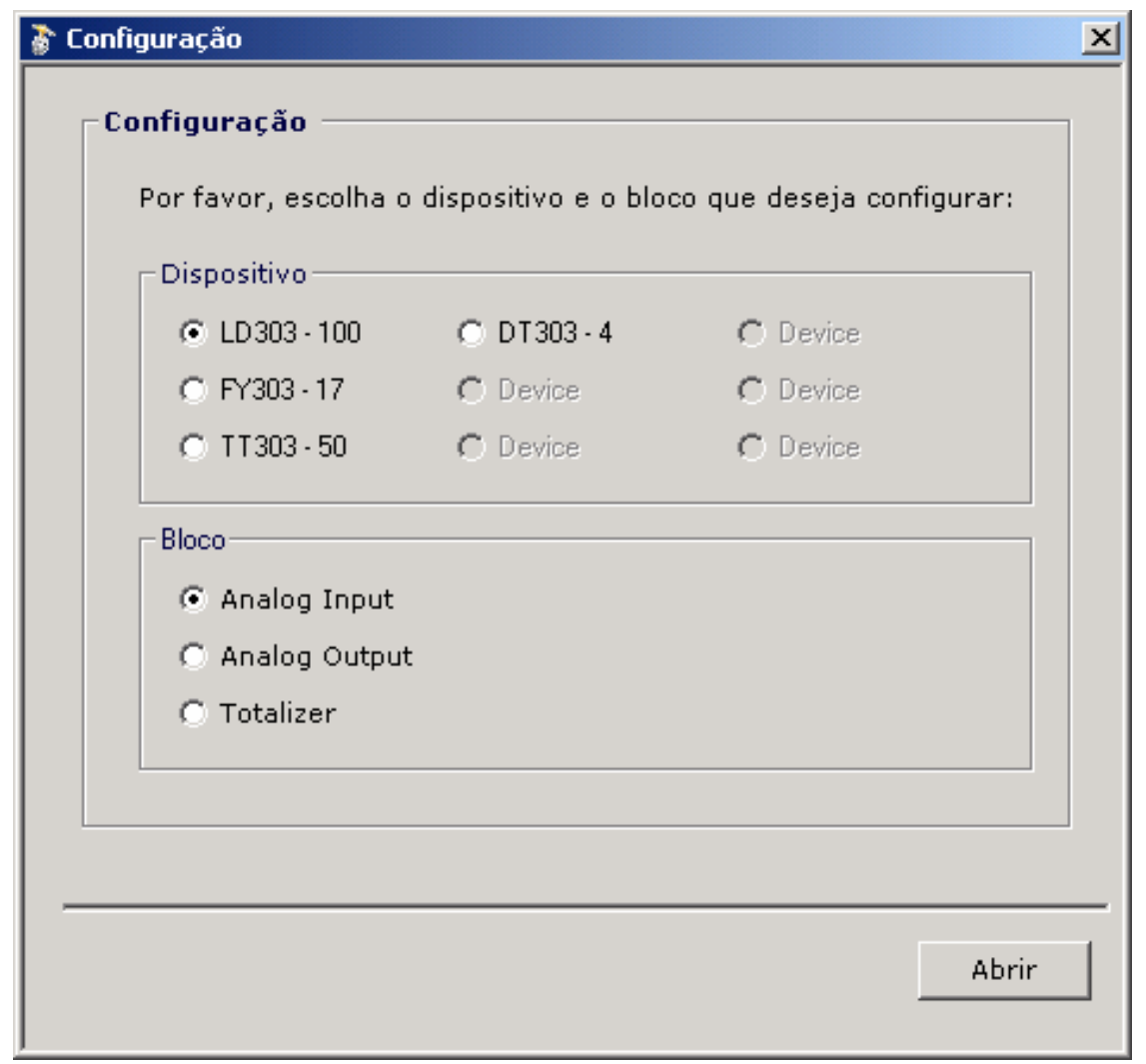

Figura 40 - Tela de configuração do dispositivo para transmissão acíclica

O MPA lê os principais parâmetros de cada bloco de função, como é mostrado pelas Figuras 41,42 e 43.

$\mathrm{Na}$ leitura de cada parâmetro, este módulo informa o Mod_BuildMess (Módulo responsável pela elaboração da mensagem) o slot do bloco e o index do parâmetro. Tais informações são obtidas pelo fabricante do equipamento. 


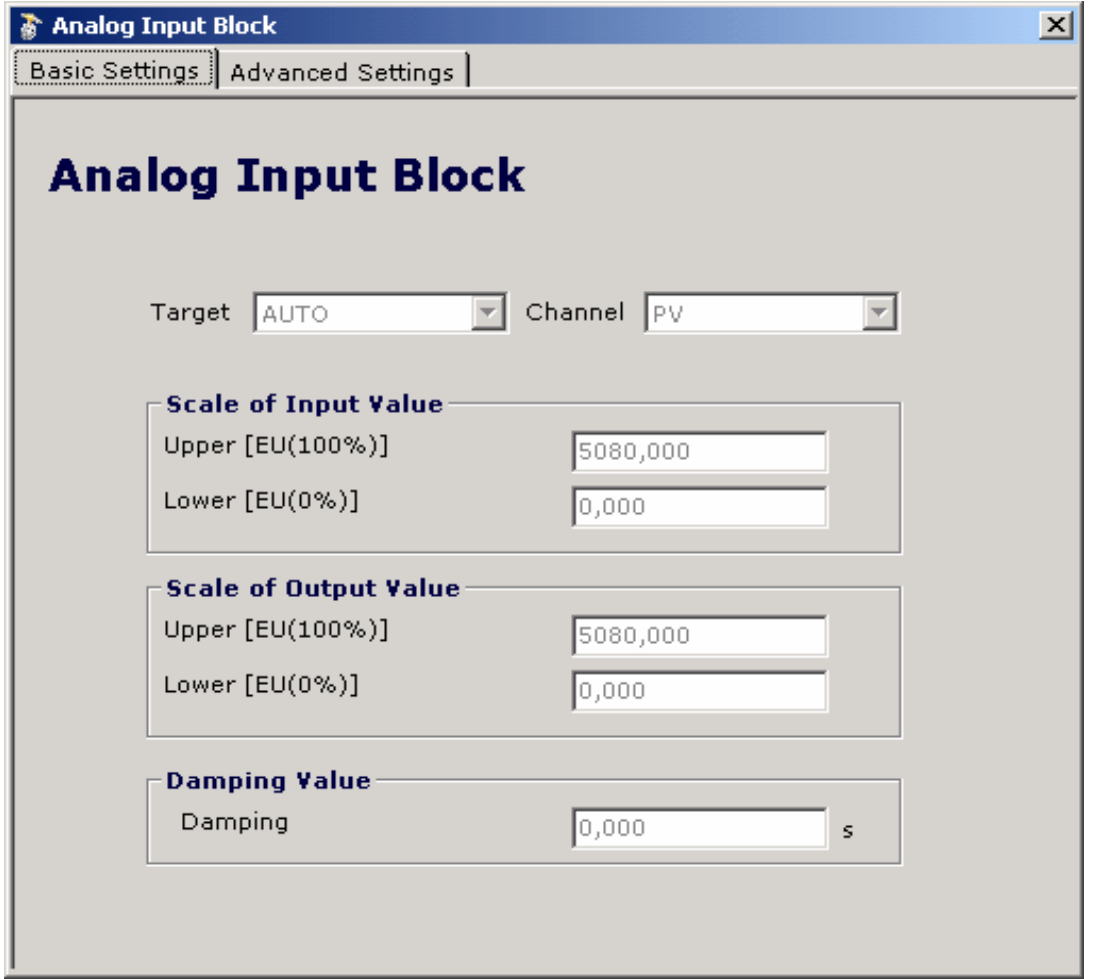

Figura 41 - Leitura acíclica do bloco Analog Input

Analog Dutput Block

Basic Settings Scales/Unit | Advanced Settings |

\section{Analog Output Block}

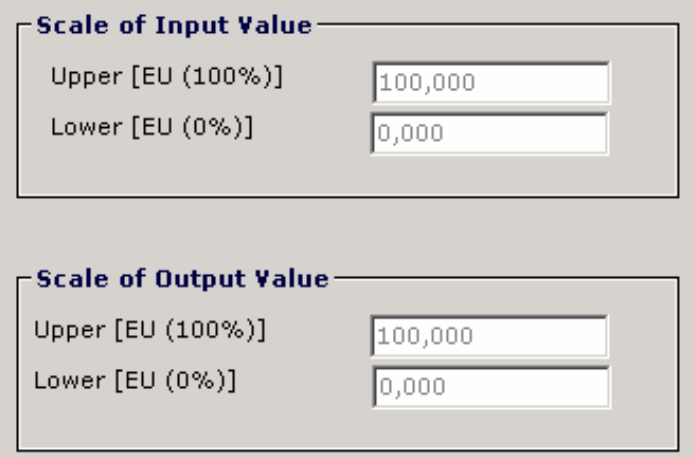

Figura 42 - Leitura acíclica do bloco Analog Output 


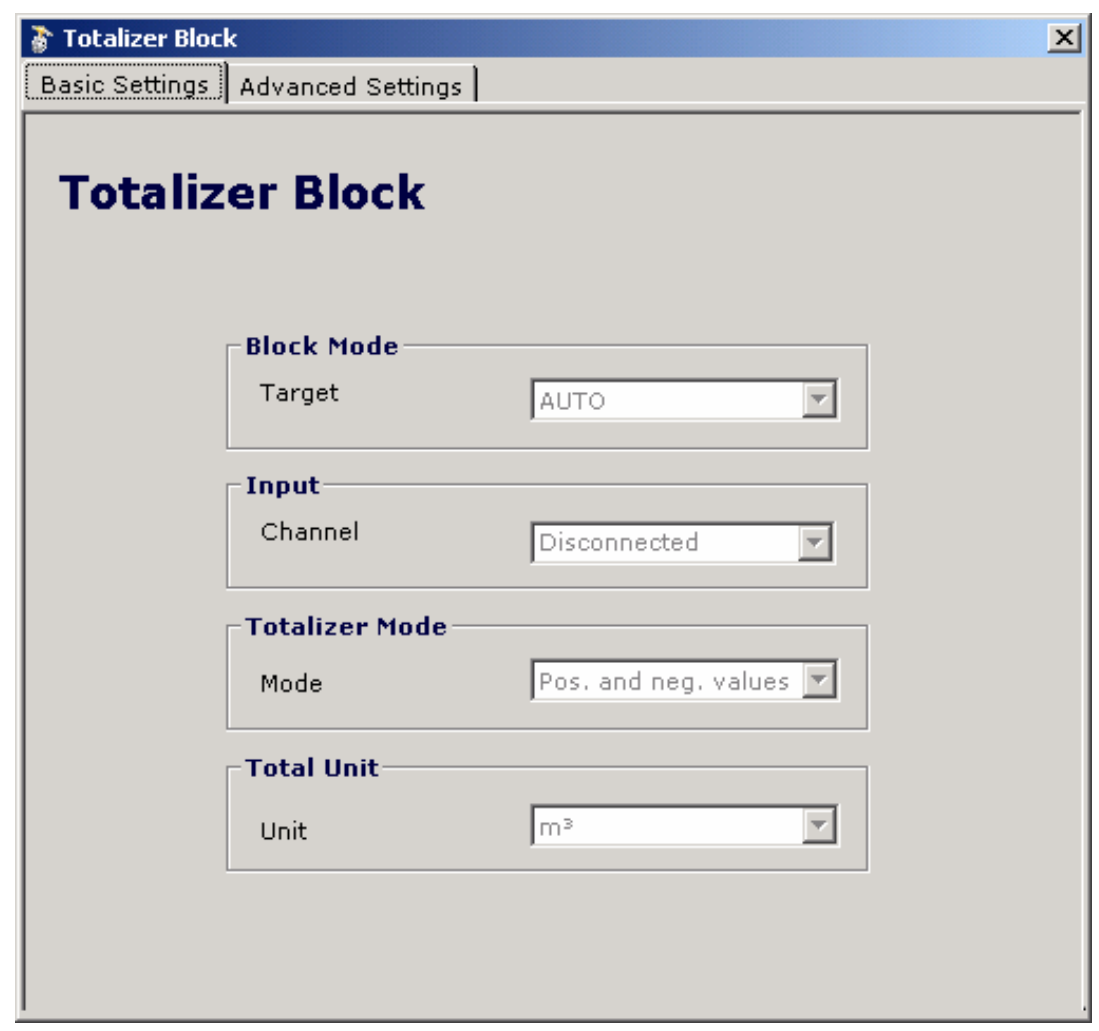

Figura 43 - Leitura acíclica do bloco Totalizer

\subsection{MOD_BUILDMESS}

O módulo Mod_BuildMess é responsável pela construção das mensagens que são transmitidas no barramento pelo MPA.

Algumas mensagens são diferenciadas no barramento pelo serviço de ponto de acesso $(S A P)$, no qual inclui dois bytes no campo de dados da mensagem (bytes DSAP e $S S A P$ ) e o bit mais significativo dos bytes $D A$ e $S A$ é setado para um, assumindo assim o formato 8x (POPP, 2003).

A Figura 44 mostra as mensagens transmitidas pelo MPA que utilizam o serviço $S A P$, junto com o valor dos bytes $D S A P$ e $S S A P$ de cada mensagem. 


\begin{tabular}{ccl}
\hline DSAP & SSAP & MENSAGEM \\
\hline $0 \times 3 \mathrm{C}$ & $0 \times 3 \mathrm{E}$ & Diagnóstico \\
$0 \times 3 \mathrm{D}$ & $0 \times 3 \mathrm{E}$ & Parametrizaçẫo \\
$0 \times 3 \mathrm{E}$ & $0 \times 3 \mathrm{E}$ & Configuraçẫo \\
\hline
\end{tabular}

Figura 44 - Serviço SAP

Sempre que uma mensagem é recebida ou transmitida pelo MPA, a função CalcCheckSum do módulo Mod_general é chamada. Tal função calcula o valor dos bytes FCS e ED da mensagem, esses bytes são verificados pela estação receptora da mensagem, como uma maneira de certificar que a mensagem foi recebida sem erro.

A seguir uma breve descrição de cada mensagem transmitida pelo MPA.

- Pedido de Status (RFS)

\begin{tabular}{|c|c|c|c|c|c|}
\hline $0 \times 10$ & $D A$ & 54 & $\mathrm{FC}$ & $\mathrm{FCS}$ & $\mathrm{ED}$ \\
\hline
\end{tabular}

Figura 45 - Mensagem de Pedido de Status (RFS)

A mensagem de Pedido de Status (RFS) é transmitida pelo MPA em duas condições diferentes:

$\checkmark$ Resposta: Resposta para um Pedido de Status (RFS) feito por outra estação mestre para o MPA.

- Se o MPA está pronto para entrar no anel lógico, o byte $F C$ é setado com o valor $0 \times 20$, caso contrário com o valor $0 \times 10$.

$\checkmark$ Request: Pedido de Status (RFS) feito pelo MPA para outra estação do barramento.

- O byte $F C$ é setado com o valor $0 \times 49$. 
- Pass Token

\begin{tabular}{|l|l|l|}
\hline $\mathrm{DXCO}$ & $\mathrm{DA}$ & $\mathrm{SA}$ \\
\hline
\end{tabular}

Figura 46 - Mensagem de token

Mensagem transmitida pelo MPA com a finalidade de passar o token para a estação sucessora do anel lógico, conforme LAS.

- Diagnosis

\begin{tabular}{|l|l|l|l|l|l|l|l|l|l|l|}
\hline $0 \times 68$ & $0 \times 05$ & $0 \times 05$ & $0 \times 68$ & DA & SA & FC & $0 \times 3 \mathrm{C}$ & $0 \times 3 \mathrm{E}$ & $\mathrm{FCS}$ & $\mathrm{ED}$ \\
\hline
\end{tabular}

Figura 47 - Mensagem de Requeste de Diagnóstico

$\mathrm{Na}$ iniciação do sistema, o MPA transmite uma mensagem de diagnóstico para cada dispositivo definido na Poll-List, conforme Figura 34.

A cada mensagem de diagnóstico, o byte $F C$ assume um valor diferente, sendo eles: 0x6D, $0 \times 5 \mathrm{D}$ ou $0 \times 7 \mathrm{D}$.

\section{- Parameterization}

\begin{tabular}{|l|l|l|l|l|l|l|l|l|l|l|l|l|l|l|l|l|l|}
\hline $0 \times 68$ & $0 \times 0 \mathrm{C}$ & $0 \times 0 \mathrm{C}$ & $0 \times 66$ & $\mathrm{DA}$ & $\mathrm{SA}$ & $\mathrm{FC}$ & $0 \times 3 \mathrm{D}$ & $0 \times 3 \mathrm{E}$ & $\mathrm{D} 1$ & $\mathrm{D} 2$ & $\mathrm{DS}$ & $\mathrm{D} 4$ & $\mathrm{D} 5$ & $\mathrm{D6}$ & $\mathrm{D} 7$ & $\mathrm{FCS}$ & $\mathrm{ED}$ \\
\hline
\end{tabular}

Figura 48 - Mensagem de Parametrização

Conforme Figura 34, após transmissão da mensagem de Diagnosis, o MPA transmite uma mensagem de Parameterization para informar o dispositivo sobre a maneira que ele deve comportar-se durante a comunicação. 
A cada mensagem de parametrização, o byte $F C$ assume um valor diferente, sendo: 0x6D, $0 \times 5 \mathrm{D}$ ou $0 \times 7 \mathrm{D}$.

A Figura 49 indica os valores setados pelo MPA em cada byte do campo de dados.

\begin{tabular}{|c|c|}
\hline $01-0 \times 80$ & $\mathrm{D} 2-0 \times 2 \mathrm{D}$ \\
\hline$[3-0 \times 01$ & $04-0 \times \square C$ \\
\hline \multicolumn{2}{|c|}{ [15 e D6 - Identificaçǟo } \\
\hline $07-0 \times 00$ & \\
\hline
\end{tabular}

Figura 49 - Bytes da mensagem de Parametrização

Os bits da Figura 50 informam sobre as opções de configuração disponíveis no byte D1.

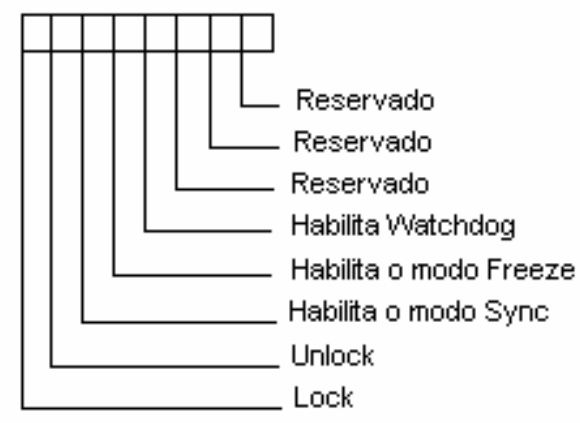

Figura 50 - Representação do byte de dados da mensagem de Parametrização

\begin{tabular}{|c|c|l|}
\hline Lock & Unlock & Descriçäo \\
\hline 0 & 0 & min TSDR deve ser sobrescrito \\
\hline 0 & 1 & Escravo está habilitado para outros mestres \\
\hline 1 & 0 & Escravo está desabilitado para outros mestres \\
\hline 1 & 1 & Escravo está habilitado para outros mestres \\
\hline
\end{tabular}

Figura 51 - Representação do bit Lock/Unlock na mensagem de Parametrização 
Os bytes D2 e D3 informam a base de tempo do parâmetro WATCHDOG do dispositivo escravo. O parâmetro WATCHDOG indica como forma de segurança, o tempo máximo a ser dispendido entre duas requisições de mensagens cíclicas transmitidas para o escravo.

O byte D4 configura o parâmetro TSDR do dispositivo. O parâmetro TSDR define o tempo que a estação deve aguardar antes de transmitir um reconhecimento ou uma mensagem de resposta para uma mensagem recebida.

Os bytes D5 e D6 indicam o número de identificação do dispositivo junto á associação PROFIBUS (Informação obtida no arquivo GSD do dispositivo)

O byte D7 indica o Group number (Indica se o dispositivo deve fazer parte de algum grupo específico. Tal informação é usada em comandos de Multicast).

\section{- Configuration}

\begin{tabular}{|c|c|c|c|c|c|c|c|c|c|c|c|}
\hline $0 \times 68$ & LE & LEr & $0 \times 68$ & DA & 54 & $\mathrm{FC}$ & $0 \times 3 \mathrm{E}$ & $0 \times 3 \mathrm{E}$ & DАТА & $\mathrm{FCS}$ & $\mathrm{ED}$ \\
\hline
\end{tabular}

Figura 52 - Mensagem de Configuração

Conforme Figura 34, após transmissão da mensagem de Parametrização, o MPA transmite uma mensagem de configuração para informar o dispositivo escravo quais as variáveis que devem ser trocados ciclicamente entre eles.

No campo DATA da mensagem podem ser transferidas até 16 bytes referentes ao código de acesso do dispositivo, conforme informação extraída do arquivo GSD e mostrado na Figura 28 do módulo Mod_PollList.

A cada mensagem de configuração, o byte $F C$ assume um valor diferente, sendo: 0x6D, 0x5D ou 0x7D.

Obs: Para garantir que as informações contidas nesta mensagem estão corretas, o escravo compara a configuração recebida com a sua própria configuração. 


\section{- Data_Exchange}

\begin{tabular}{|l|l|l|l|l|l|}
\hline DX10 & DA & SA & FC & FCS & ED \\
\hline
\end{tabular}

Figura 53 - Mensagem de troca de dados cíclico

Após o dispositivo escravo ser parametrizado e configurado, conforme Figura 34, o MPA pode iniciar a transmissão de mensagem de Data_Exchange, usada na troca de dados cíclico entre o dispositivo mestre e o dispositivo escravo.

A cada mensagem de Data_exchange, o byte $F C$ assume um valor diferente, sendo eles: 0x6D, 0x5D ou 0x7D.

- InitComm

\begin{tabular}{|c|c|c|c|c|c|c|c|c|c|c|c|c|c|c|c|}
\hline $0 \times 68$ & $0 \times 19$ & $0 \times 19$ & $0 \times 68$ & $\mathrm{DA}$ & SA & $\mathrm{FC}$ & D1 & $\mathrm{D} 2$ & D3 & D4 & D5 & D6 & D7 & D8 & D9 \\
\hline D10 & D11 & D12 & D13 & D14 & D15 & D16 & $\mathrm{D} 17$ & D18 & D19 & D20 & D21 & $\mathrm{D} 22$ & D23 & $\mathrm{FCS}$ & ED \\
\hline
\end{tabular}

Figura 54 - Mensagem de conexão acíclica

A mensagem InitComm é transmitida durante a comunicação acíclica de dados, para abrir uma conexão com o dispositivo escravo, conforme Figura 39.

A cada mensagem de InitComm o byte $F C$ assume um valor diferente, sendo: 0x6D, 0x5D ou $0 \times 7 D$.

A Figura 55 indica os valores setados pelo MPA em cada byte do campo de dados.

\begin{tabular}{|c|c|c|c|c|}
\hline$[1-0 \times 31$ & [12 - $0 \times 32$ & $\square 3-0 \times 57$ & {$[44-0 \times 000$} & [15 - 0×00 \\
\hline 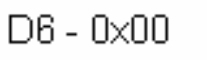 & $07-0 \times f f$ & DB - DXFF & $\square 9-\square \times 03$ & $010-0 \times 01$ \\
\hline $011-0 \times 00$ & $\square 12-\square \times \square 1$ & $013-0 \times 80$ & {$[14-0 \times 00$} & $015-0 \times 00$ \\
\hline$\square 16-0 \times 02$ & $017-0 \times 00$ & $018-0 \times 02$ & $019-0 \times 00$ & $020-0 \times 00$ \\
\hline$\square 21-0 \times 0 \square$ & 022 - $0 \times 00$ & $023-0 \times 000$ & & \\
\hline
\end{tabular}

Figura 55 - Bytes da mensagem de Conexão Acíclica 
- AbortComm

\begin{tabular}{|c|c|c|c|c|c|c|c|c|c|c|c|c|c|}
\hline $0 \times 60$ & $0 \times 08$ & $0 \times 08$ & $0 \times 66$ & DA & $S 4$ & $\mathrm{FC}$ & $\mathrm{D} 1$ & $\mathrm{D} 2$ & 03 & D4 & $\mathrm{D} 5$ & $\mathrm{FCS}$ & $\mathrm{ED}$ \\
\hline
\end{tabular}

Figura 56 - Mensagem de Abort

A mensagem AbortComm é transmitida durante comunicação acíclica de dados, quando deseja fechar uma comunicação, ou após uma conexão ser negada pelo dispositivo escravo, conforme Figura 39.

Em cada mensagem de Abort o byte $F C$ assume um valor diferente, sendo: 0x6D, 0x5D ou $0 \times 7 D$

A Figura 57 indica os valores setados pelo MPA em cada byte do campo de dados.

$$
\begin{aligned}
& \text { D1 - é um byte de controle que varia entre 0x2F e } 0 \times 30 \text {. } \\
& 02-0 \times 31 \quad \square 3-0 \times 58 \quad \square 4-0 \times 00 \quad \square 5-0 \times 20
\end{aligned}
$$

Figura 57-Bytes da mensagem de Abort

- Confirmation

\begin{tabular}{|l|l|l|l|l|l|l|l|l|l|l|}
\hline $0 \times 60$ & $0 \times 05$ & $0 \times 05$ & $0 \times 68$ & 04 & $S A$ & $F C$ & $D 1$ & 02 & $F C S$ & ED \\
\hline
\end{tabular}

Figura 58 - Mensagem de confirmação

A mensagem de Confirmação é transmitida durante a comunicação acíclica de dados, após a transmissão da mensagem de conexão, ou da mensagem de leitura ou escrita, para confirmar se a mensagem foi aceita pelo dispositivo escravo, conforme Figura 39.

A cada mensagem de confirmação, o byte $F C$ assume um valor diferente, sendo: 0x6D, $0 \times 5 \mathrm{D}$ ou $0 \times 7 \mathrm{D}$. 


$$
\begin{aligned}
& \text { 01 - byte de controle que varia entre } 0 \times 2 \mathrm{~F} \text { e } 0 \times 30 \text {. } \\
& 02-0 \times 32
\end{aligned}
$$

Figura 59 - Bytes da mensagem de Confirmação

\begin{tabular}{|c|c|c|c|c|c|c|c|c|c|c|c|c|c|c|}
\hline $0 \times 68$ & $0 \times 09$ & $0 \times 09$ & $0 \times 68$ & DA & $\mathrm{SA}$ & $\mathrm{FC}$ & D1 & $\mathrm{D} 2$ & D3 & D4 & D5 & D6 & $\mathrm{FCS}$ & $\mathrm{ED}$ \\
\hline
\end{tabular}

- Read_Parameter

Figura 60 - Mensagem de leitura de parâmetro

A mensagem Read_Parameter é transmitida durante a comunicação acíclica, para ler um ou mais parâmetros de um bloco de função, conforme Figura 39.

A cada mensagem de Read_parameter, o byte FC assume um valor diferente, sendo: $0 \times 6 \mathrm{D}, 0 \times 5 \mathrm{D}$ ou $0 \times 7 \mathrm{D}$.

A Figura 61 indica os valores setados pelo MPA em cada byte do campo de dados.

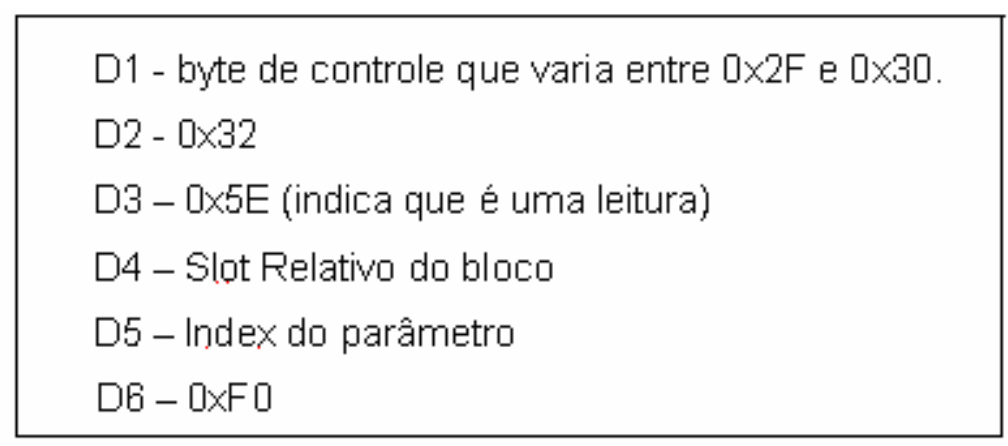

Figura 61 - Bytes da mensagem de leitura acíclica

\subsection{MOD_MESSRECEIVED}

No módulo Mod_MessReceived o MPA atribui para um buffer de entrada, as mensagens transmitidas no barramento por outras estações-mestres ou escravas. Sempre 
que um byte é detectado no barramento, um evento ocorre na porta serial do PC e o byte é recebido pelo MPA.

No entanto, antes do MPA atribuir o byte recebido para o buffer de entrada, é necessário verificar se este byte é o primeiro byte da mensagem, ou seja, se ele é igual a um dos bytes mostrado pela Figura 62.

\begin{tabular}{lll}
\hline BYTE & TIP0 & \multicolumn{1}{c}{ DESCRICÃo } \\
\hline 10h & SD1 & Mensagem de tamanho fixo sem campo de dados \\
68h & SD2 & Mensagem de tamanho variável com campo de dados \\
A2h & SD3 & Mensagem de tamanho fixo com campo de dados \\
DCh & SD4 & Mensagem de Token \\
E5 & SC & Mensagem de confirmaçẫo curta \\
\hline
\end{tabular}

Figura 62 - Tratamento do primeiro byte da mensagem

Caso o byte recebido seja o primeiro da mensagem e o buffer de entrada do MPA esteja vazio, o tipo da mensagem é definido de acordo com a Figura 62 e os próximos dois bytes recebidos são utilizados como indicador de tempo pelo MPA e não são adicionados no buffer de entrada.

Como dispositivo físico de acesso ao barramento, o MPA utiliza uma interface de comunicação chamada BC1 desenvolvida pela Smar Equipamentos Industriais (SMAR EQUIPAMENTOS INDUSTRIAIS, 2007), que interliga o PC via porta serial RS-232 a uma rede PROFIBUS PA, com velocidade de transmissão de $31,25 \mathrm{Kbits} / \mathrm{s}$ (PROFIBUS Descrição Técnica ,2000). O firmware original da interface BC1 foi substituído por um firmware adequado ao MPA com as seguintes funções:

- Transferir os bytes detectados no barramento para a porta serial do PC e vice-versa

- A BC1 possui um contador interno e sempre que detecta um byte vindo do barramento com o valor igual a um dos bytes da Figura 62, transfere para a porta serial do PC além do byte detectado, dois bytes adicionais contendo o valor do 
contador. O valor do contador é utilizado pelo MPA para controlar o momento que a mensagem foi recebida no barramento. Caso um dos bytes da Figura 62 for detectado após o inicio da mensagem, o MPA adiciona o byte no buffer de entrada e descarta os dois próximos bytes recebidos. A Figura 63 mostra o funcionamento da BC1.

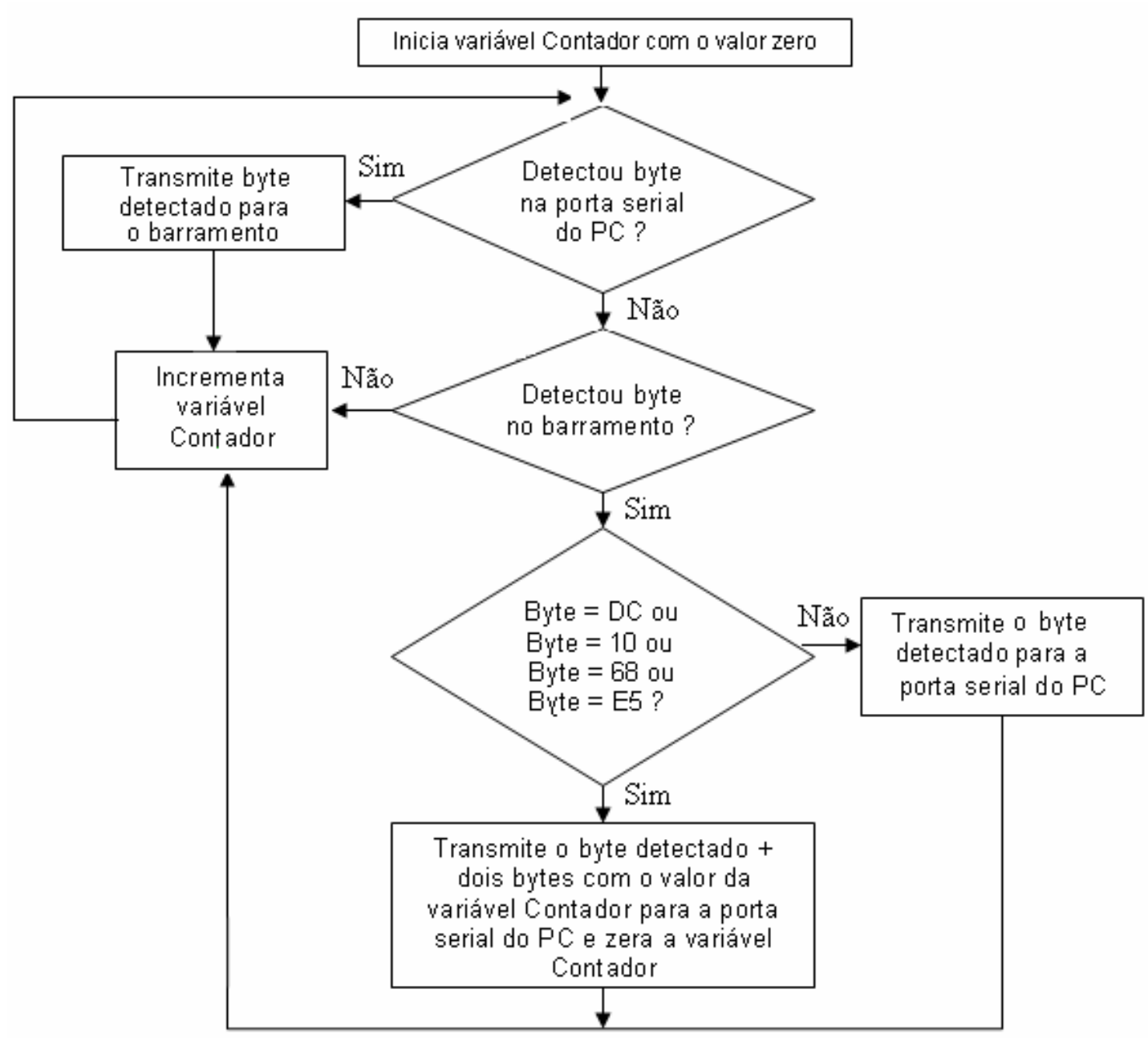

Figura 63 - Funcionamento da interface $B C 1$

Após definição do tipo da mensagem, o MPA já sabe o tamanho da mensagem e o tipo dos próximos bytes que devem ser recebidos, sendo assim, o MPA atribui o valor de cada byte recebido para uma variável correspondente, conforme mostra a Figura 64: 


\begin{tabular}{ll}
\hline VARIÁVEL & \multicolumn{1}{c}{ DESCRIÇÃo } \\
\hline FM & Formato da mensagem (SD1 _SD2,SD3,SD4,SC) \\
LE & Tamanho do DATA_UNIT \\
DA & Endereço de destino \\
SA & Endereço fonte \\
FC & Byte de controle \\
DSAP & Endereço de destino, no formato SAP. \\
SSAP & Endereço fonte, no formato SAP. \\
DATA_UNIT & Campo de dados \\
FCS & Byte de Checagem \\
ED & Byte finalizador \\
\hline
\end{tabular}

Figura 64 - Decodificação da mensagem recebida

Após a mensagem ter sido totalmente recebida, as mensagens com os bytes FCS e ED válidos e endereçados para o MPA, são verificadas através de alguns bytes específicos, e o tipo da mensagem recebida é definida, conforme Figura 65.

Na Figura 65 o endereço do MPA é representado pela variável EM e o endereço SAP pela variável ESM.

\begin{tabular}{ll}
\hline BYTES VERIFICADOS & TIPO DE MENSAGEM RECEBIDA \\
\hline$(\mathrm{FM}=\mathrm{SC})$ & Reconhecimento \\
$(\mathrm{FM}=\mathrm{S4})(\mathrm{DA}=\mathrm{EM})$ & Token \\
$(\mathrm{FM}=\mathrm{SD} 1)(\mathrm{DA}=\mathrm{EM})(\mathrm{FC}=49)$ & Resposta de Pedido de Status (RFS) \\
$(\mathrm{FM}=\mathrm{SD} 1)(\mathrm{DA}=\mathrm{EM})(\mathrm{FC}=03)$ & Resposta Ne gativa \\
$(\mathrm{FM}=\mathrm{SD} 2)(\mathrm{DA}=\mathrm{ESM})(\mathrm{DSAP}=3 \mathrm{E})(\mathrm{SSAP}=3 \mathrm{C})$ & Resposta de Diagnostico \\
$(\mathrm{FM}=\mathrm{SD} 2)(\mathrm{DA}=\mathrm{ESM})(\mathrm{DSAP}=3 \mathrm{E})(\mathrm{SSAP}=38)$ & Resposta de leitura cíclica \\
$(\mathrm{FM}=\mathrm{SD} 2)(\mathrm{DA}=\mathrm{ESM})(\mathrm{DSAP}=32)(\mathrm{SSAP}=31)$ & Resposta de conexẫo de mensagem acíclica \\
$(\mathrm{FM}=\mathrm{SD} 2)(\mathrm{DA}=\mathrm{ESM})(\mathrm{DSAP}=32$ ou $2 \mathrm{~F} / 30)$ & Resposta de confirmaçẫo de mensagem acíclica
\end{tabular}

Figura 65 - Verificação mensagem recebida 


\subsection{MOD_BUSANALYSE}

O módulo Mod_BusAnalyse disponibiliza em tempo real uma lista de todas as mensagens transmitidas no barramento. A finalidade do módulo é fornecer um ambiente propicio para realização de análise de desempenho da rede.

\begin{tabular}{|c|c|c|c|c|c|c|c|}
\hline \multicolumn{3}{|c|}{ Analisador Profibus } & & & & \multicolumn{2}{|c|}{$-\square x$} \\
\hline \multicolumn{8}{|c|}{ Live List View Conf Busca About } \\
\hline - & 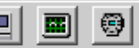 & Toke & & & & & \\
\hline Numero & Tempo & Mensagem & Tipo Mensagem & STX/ACK & Fonte & Destino & $0-1$ \\
\hline 32 & $09: 29: 16.278$ & $68000068011408000000004 C 000000004 C 18 \mathrm{Eg}$ & Resp. Leitura Poll-List & ACK & 20 & 1 & \\
\hline 33 & $09: 29: 16.290$ & $1009015 \mathrm{DCCA9}$ & Leitura Poll-List & STX & 1 & 9 & \\
\hline 34 & $09: 29: 16.295$ & $68080868010908000000004 C[2210$ & Resp. Leitura Poll-List & $\mathrm{ACK}$ & 9 & 1 & \\
\hline 35 & $09: 29: 16.306$ & DC 01018004 & Token & STX & 1 & 1 & \\
\hline 36 & $09: 29: 16.311$ & $10060149 \mathrm{BD} B 1$ & Pedido de Status [RFS] & STX & 1 & 6 & \\
\hline 37 & $09: 29: 16.327$ & 101401503294 & Leitura Poll-List & STX & 1 & 20 & \\
\hline 38 & $09: 29: 16.332$ & $68000068011408000000004 C 000000004 C 18 \mathrm{Eg}$ & Resp. Leitura Poll-List & ACK & 20 & 1 & \\
\hline 39 & $09: 29: 16.344$ & $1009017 \mathrm{D} 5318$ & Leitura Poll-List & STX & 1 & 9 & \\
\hline 40 & $09: 29: 16.349$ & $68080868010908000000004 C \mathrm{C} 210$ & Resp. Leitura Poll-List & ACK & 9 & 1 & \\
\hline 41 & $09: 29: 16.360$ & DC 01018004 & Token & STX & 1 & 1 & \\
\hline 42 & $09: 29: 16.366$ & $1014017 \mathrm{D} A \mathrm{D} 25$ & Leitura Poll-List & STX & 1 & 20 & \\
\hline 43 & $09: 29: 16.371$ & $68000068011408000000004 C 000000004$ C $18 \mathrm{Eg}$ & Resp. Leitura Poll-List & ACK & 20 & 1 & \\
\hline 44 & $09: 29: 16.383$ & $1009015 D$ CC A9 & Leitura Poll-List & STX & 1 & 9 & \\
\hline 45 & $09: 29: 16.388$ & $68080868010908000000004 C$ C2 10 & Resp. Leitura Poll-List & ACK & 9 & 1 & \\
\hline 46 & $09: 29: 16.400$ & DC 01018004 & Token & STX & 1 & 1 & \\
\hline 47 & $09: 29: 16.414$ & $1014015 \mathrm{D} 3294$ & Leitura Poll-List & STX & 1 & 20 & \\
\hline 48 & $09: 29: 16.420$ & $68000068011408000000004 C 000000004$ C $18 \mathrm{Eg}$ & Resp. Leitura Poll-List & ACK & 20 & 1 & \\
\hline 49 & $09: 29: 16.432$ & 100901705318 & Leitura Poll-List & STX & 1 & 9 & \\
\hline 50 & $09: 29: 16.437$ & $68080868010908000000004 C \mathrm{C} 210$ & Resp. Leitura Poll-List & ACK & 9 & 1 & \\
\hline 51 & $09: 29: 16.447$ & DC 01018004 & Token & STX & 1 & 1 & \\
\hline 52 & $09: 29: 16.453$ & $100801495 \mathrm{E} 16$ & Pedido de Status [RFS] & STX & 1 & 8 & \\
\hline 53 & $09: 29: 16.469$ & $1014017 \mathrm{D} A \mathrm{AD} 25$ & Leitura Poll-List & STX & 1 & 20 & \\
\hline 54 & $09: 29: 16.474$ & $68000068011408000000004 C 000000004 C 18 \mathrm{Eg}$ & Resp. Leitura Poll-List & ACK & 20 & 1 & \\
\hline 55 & $09: 29: 16.486$ & $1009015 D C C A 9$ & Leitura Poll-List & STX & 1 & 9 & \\
\hline 56 & $09: 29: 16.491$ & $68080868010908000000004 C$ C2 10 & Resp. Leitura Poll-List & ACK & 9 & 1 & \\
\hline 57 & $09: 29: 16.500$ & DC 01018004 & Token & STX & 1 & 1 & \\
\hline 58 & $09: 29: 16.508$ & $100901497 \mathrm{AAA}$ & Pedido de Status [RFS] & STX & 1 & 9 & \\
\hline 59 & $09: 29: 16.512$ & $10010900 \mathrm{~B} 103$ & Resp. Pedido de Status (RFS) & ACK & 9 & 1 & \\
\hline 60 & $09: 29: 16.521$ & 101401503294 & Leitura Poll-List & STX & 1 & 20 & \\
\hline 61 & $09: 29: 16.526$ & $68000068011408000000004 C 000000004 C 18 \mathrm{Eg}$ & Resp. Leitura Poll-List & ACK & 20 & 1 & \\
\hline 62 & $09: 29: 16.538$ & 100901705318 & Leitura Poll-List & STX & 1 & 9 & \\
\hline 63 & $09: 29: 16.543$ & $68080868010908000000004 C$ C2 10 & Resp. Leitura Poll-List & ACK & 9 & 1 & \\
\hline 64 & $09: 29: 16.554$ & DC 01018004 & Token & STX & 1 & 1 & \\
\hline 65 & $09: 29: 16.559$ & $10040149176 \mathrm{E}$ & Pedido de Status [RFS] & STX & 1 & 10 & \\
\hline 66 & $09: 29: 16.564$ & 100104003310 & Resp. Pedido de Status (RFS) & ACK & 10 & 1 & \\
\hline 67 & $09: 29: 16.571$ & C814017D AD 25 & Leitura Poll-List & STX & 1 & 20 & \\
\hline 68 & $09: 29: 16.578$ & $68000068011408000000004 \mathrm{C} 00000000$ 4C $18 \mathrm{Eg}$ & Resp. Leitura Poll-List & ACK & 20 & 1 & \\
\hline 69 & 09:29:16.590 & $1009015 D C C A 9$ & Leitura Poll-List & STX & 1 & 9 & \\
\hline 70 & $09: 29: 16.595$ & $68080868010908000000004 C$ C2 10 & Resp. Leitura Poll-List & ACK & 9 & 1 & \\
\hline 71 & $09: 29: 16.606$ & DC 01018004 & Token & STX & 1 & 1 & \\
\hline 72 & $09: 29: 16.611$ & $100 \mathrm{~B} 014933 \mathrm{D} 2$ & Pedido de Status [RFS] & STX & 1 & 11 & \\
\hline 73 & $09: 29: 16.627$ & $1014015 D 3294$ & Leitura Poll-List & STX & 1 & 20 & \\
\hline 74 & $09: 29: 16.632$ & $68000068011408000000004 C 000000004 C 18 \mathrm{Eg}$ & Resp. Leitura Poll-List & ACK & 20 & 1 & \\
\hline 75 & $09: 29: 16.644$ & 100901705318 & Leitura Poll-List & STX & 1 & 9 & \\
\hline 76 & $09: 29: 16.649$ & $68080868010908000000004 C$ C2 10 & Resp. Leitura Poll-List & ACK & 9 & 1 & \\
\hline 77 & $09: 29: 16.660$ & DC 01018004 & Token & STX & 1 & 1 & \\
\hline 78 & $09: 29: 16.666$ & $1014017 \mathrm{D} A \mathrm{D} 25$ & Leitura Poll-List & STX & 1 & 20 & \\
\hline 79 & $09: 29: 16.671$ & $68000068011408000000004 C 000000004 C 18 \mathrm{Eg}$ & Resp. Leitura Poll-List & ACK & 20 & 1 & \\
\hline 80 & $09: 29: 16.683$ & $1009015 D C C A 9$ & Leitura Poll-List & STX & 1 & 9 & \\
\hline 81 & $09: 29: 16.688$ & $68080868010908000000004 C C 210$ & Reso. Leitura Poll-List & ACK & 9 & 1 & $=$ \\
\hline
\end{tabular}

Figura 66 - Ambiente usado para analisar a rede

A lista é organizada pelos seguintes campos:

- Numero - Número seqüencial que identifica a mensagem 
- Tempo - Indica o momento que a mensagem foi recebida ou transmitida. ( tempo extraído do $2^{0}$ e $3^{0}$ byte da mensagem, conforme descrito no modulo Mod_MessReceived)

- Mensagem - Mensagem

- Tipo Mensagem - Indica o tipo da mensagem.

- $\quad$ STX/ACK - Indica se a mensagem é um request ou uma resposta/reconhecimento.

- Fonte - Endereço da estação que transmitiu a mensagem.

- Destino - Endereço de destino da mensagem.

As informações dos campos: "Tipo Mensagem" e "STX/ACK" são obtidas através da interpretação de cada byte da mensagem, conforme Figura 67.

\begin{tabular}{|c|c|c|}
\hline BYTES & TIPO DE MENSAGEM & STX/ACK \\
\hline$(\mathrm{FM}=\mathrm{SC})$ & Reconhecimento & ACK \\
\hline$(F M=S D 1)$ e $(F C=49)$ & Pedido de Status (RFS) & STX \\
\hline$(F M=S D 2)$ e $(F C=08)$ e $(D S A P=32)$ e $(S S A P=31)$ & Resp. Conexẫo Acíclica & ACK \\
\hline$(\mathrm{FM}=\mathrm{SD} 1)$ e $(\mathrm{FC}=5 \mathrm{R}$ ou $6 \mathrm{D}$ ou $7 \mathrm{D})$ & Leitura Poll-List & STX \\
\hline$(\mathrm{FM}=\mathrm{SD} 4)$ & Token & STX \\
\hline$(F M=S D 1)$ e $(F C=03)$ & Negativa & $\mathrm{ACK}$ \\
\hline$(\mathrm{FM}=\mathrm{SD} 1) \mathrm{e}(\mathrm{FC}=00)$ & Resp. Pedido de Status (RFS) & $\mathrm{ACK}$ \\
\hline$(F M=S D 2)$ e $(D S A P=3 E)$ e $(S S A P=3 C)$ & Resp. Diaanosis & $\mathrm{ACK}$ \\
\hline$(F M=S D 2)$ e $(D S A P=3 C)$ e $(S S A P=3 E)$ & Diaanosis & STX \\
\hline$(\mathrm{FM}=\mathrm{SD} 2)$ e $(\mathrm{DSAP}=3 \mathrm{E})$ e $(\mathrm{SSAP}=38)$ & Resp Leitura Pooll-List & $\mathrm{ACK}$ \\
\hline$(\mathrm{FM}=\mathrm{SD} 2)$ e $(\mathrm{DSAP}=38)$ e $(\mathrm{SSAP}=3 \mathrm{E})$ & Leitura Poll-List & TXT \\
\hline$(F M=S D 2)$ e $(F C=08)$ & Resp Leitura Poll-List & $\mathrm{ACK}$ \\
\hline$(F M=S D 2)$ e $(D S A P=32)$ e $(\operatorname{SSAP}=31)$ & Resn. Conexăo Acıclica & $\mathrm{ACK}$ \\
\hline$(F M=S D 2)$ e $(D S A P=32)$ e $($ DATA $(2)=5 E)$ & Resp Leitura Acıclica & $\mathrm{ACK}$ \\
\hline$(F M=S D 2)$ e $(D S A P=32)$ e $(D A T A(2)=5 F)$ & Resp Escrita Acíclica & $\mathrm{ACK}$ \\
\hline$(F M=S D 2)$ e $(S S A P=32)$ e $(D A T A(1)=5 E)$ & Leitura Acíclica & STX \\
\hline$(F M=S D 2)$ e $(S S A P=32)$ e $(D A T A(1)=5 F)$ & Escrita Acíclica & STX \\
\hline$(F M=S D 2)$ e $(D A=F F)$ & Multicast & STX \\
\hline
\end{tabular}




\subsection{MOD_GENERAL}

O módulo Mod_General é composto por funções diversificadas utilizadas por outros módulos, como descrito á seguir:

\section{- Função SendMessHigh}

Função responsável por organizar as mensagens com prioridade alta no buffer de saída, respeitando o algoritmo mostrado pela Figura 34 (Controle de transmissão de mensagens cíclicas)

Algumas mensagens possuem prioridades sobre outras, como mostra a Figura 68:

\begin{tabular}{l}
\hline MENSAGEM \\
\hline Diagnóstico \\
Parametrizaçẫo \\
Configuraçẫo \\
Data_Exchange
\end{tabular}

Figura 68 - Prioridades de mensagens (alta)

\section{- Função SendMessLow}

Função responsável por organizar as mensagens com prioridade baixa no buffer de saída, respeitando o algoritmo mostrado pela Figura 39 (Controle de transmissão de mensagens acíclicas)

Algumas mensagens possuem prioridades sobre outras, como mostra a Figura 69: 


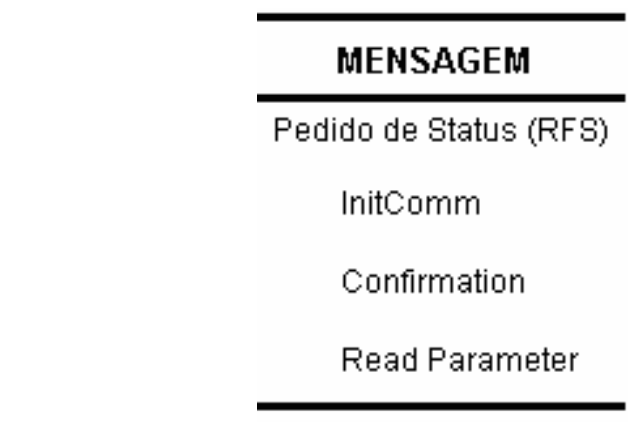

Figura 69 - Prioridades de mensagens (baixa)

- Função AddStationLAS

Esta função adiciona na $L A S$ as estações-mestres detectadas no barramento. Tal informação é adquirida através da resposta da mensagem de Pedido de Status (RFS).

\section{- Função FindPSNS}

Esta função procura na $L A S$ qual é a estação antecessora $(P S)$ e a estação sucessora (NS) do MPA.

\section{- Converte_Data_Type}

Quando o MPA recebe uma resposta da mensagem de Data_Exchange ou uma resposta da mensagem Read_parameter, essa função extrai os bytes do campo de dados da mensagem e converte no valor que é apresentado para o usuário.

À quantidade de bytes variam de acordo com o tipo de dado, em algumas mensagens são utilizadas estruturas de dados que contém um conjunto de parâmetros. É necessário um tratamento diferente para cada tipo de dado e estrutura. A Figura 70 mostra os tipos de dados e estruturas dos parâmetros lidos pelo MPA. 


\begin{tabular}{lcl}
\hline DADOS & QUANT.(BYTES) & ESTRUTURA \\
\hline Float & 4 & 1 Float \\
2 Float & 8 & 2 Float \\
Unsigned 8 & 1 & 1 unsigned 8 \\
Unsigned 16 & 2 & 1 Unsigned 16 \\
Unsigned 32 & 4 & 1 Unsigned 32 \\
DS33 & 5 & 1 Float + 1 Unsigned 8 \\
DS36 & 9 & 2 Float + 1 Unsigned 8 \\
DS37 & 3 & 3 Unsigned 8 \\
DS42 & 4 & 4 Unsigned 8 \\
\hline
\end{tabular}

Figura 70 - Tipos de dados

\section{- CalcCheckSum}

Esta função calcula através de um algoritmo os bytes FCS e ED da mensagem, no qual é usado na verificação da qualidade da mensagem.

\section{- GetStatus}

Essa função verifica através de uma lista, o status dos parâmetros do tipo DS33 (valor + status). 



\section{RESULTADOS}

Neste capítulo são apresentados os experimentos realizados e analisados através da ferramenta MPA, e os resultados obtidos.

Os experimentos foram realizados em uma rede PROFIBUS DP e PA, composta pelos seguintes elementos:

- 2 Mestres DF73 Smar, modelo HSE Profibus Gateway versão v1.00.06. (SMAR EQUIPAMENTOS INDUSTRIAIS, 2006).

- 1 Coupler Siemens modelo DP/PA Coupler SIMATIC S7 (SIEMENS ,2007).

- 1 BC1 modificada (O funcionamento desta interface de comunicação é apresentado pela Figura 63 do módulo Mod_MessReceived)

- 1 MPA

- 15 Equipamentos de campo PROFIBUS PA Smar, sendo eles: 1 DT303 (Transmissor de Densidade), 1 TP303 (Transmissor de Posição), 4 LD303 (Transmissor de Pressão), 1 LD293 (Transmissor de Pressão), 3 TT303 (Transmissor de Temperatura), 3 FY303 (Posicionador), 2 FP303 (Conversor de Fieldbus para Pressão).

A Figura 71 ilustra a estrutura da rede PROFIBUS utilizada nos experimentos. 


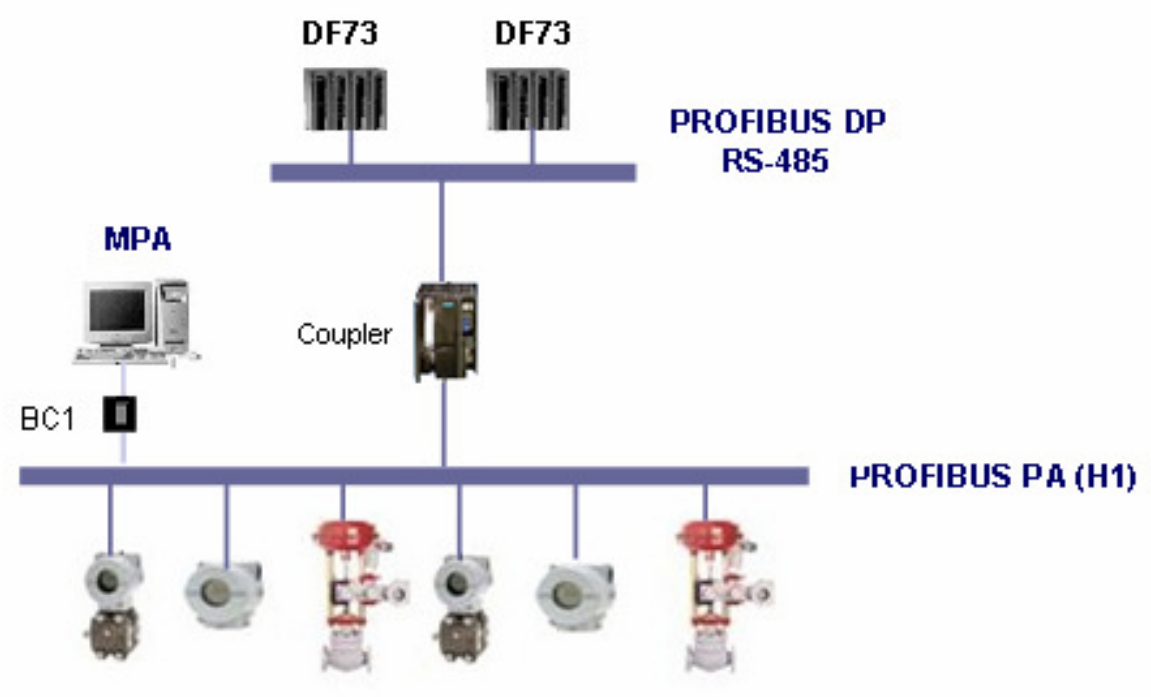

Figura 71 - Estrutura da rede PROFIBUS

Através da conexão à rede PROFIBUS PA, o MPA acessa também as mensagens transmitidas no barramento PROFIBUS DP.

\subsection{ANÁLISE DA INFLUÊNCIA DO PARÂMETRO TTR NO TEMPO DE POLLING DA MENSAGEM}

Neste experimento foi analisada a influência do parâmetro TTR no tempo de Polling das mensagens listadas na Poll-List, tempo esse medido através da transmissão consecutiva de uma mesma mensagem da lista. Na Figura 72, a variável T1 representa o tempo de Polling da mensagem do dispositivo D1 e a variável T2 o tempo de Polling da mensagem do dispositivo D2.

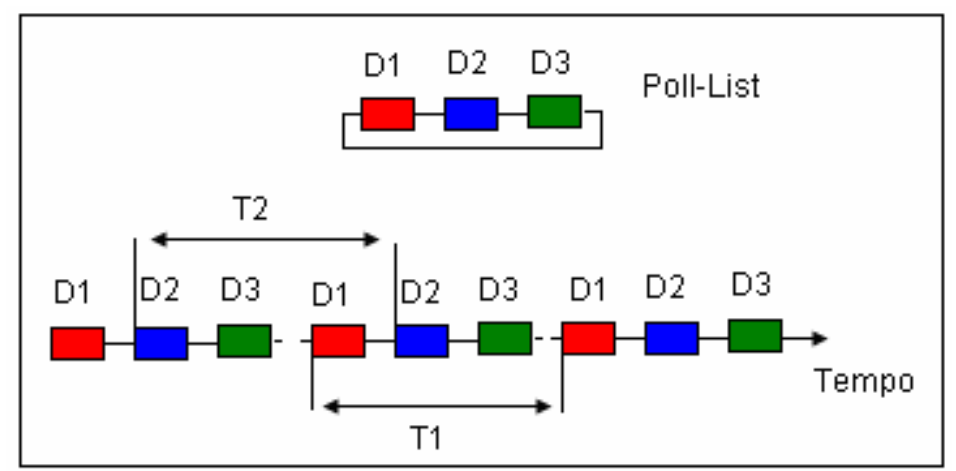

Figura 72 - Representação do tempo de Polling da mensagem 
O tempo de Polling da mensagem foi analisado analiticamente por Li (1996), que denominou este período de tempo, como, polling-interval. No entanto, Li não considerou em seu artigo alterações no parâmetro TTR, sendo assim, não existe o intuito de comparar os resultados obtidos por Li (1996) com os resultados obtidos neste experimento.

O tempo de Polling da mensagem é fator primordial em aplicações críticas de processo, pois determina a periodicidade de atualização das variáveis de processo, definindo assim a taxa de controle do sistema. Faz-se necessário saber se o maior tempo de Polling da mensagem está dentro do limite suportado pela a aplicação frente a determinado requisito de desempenho da(s) malha(s) de controle.

Sobre esta representação, o tempo de Polling da mensagem do equipamento TT303 (transmissor de temperatura) no endereço 7 foi analisado. Tal mensagem pertence à PollList do mestre MPA. A análise foi feita no ambiente apropriado fornecido pela ferramenta MPA, representado pela Figura 66 do módulo Mod_BusAnalyse, onde os dados foram extraídos manualmente.

A Figura 73 apresenta um exemplo do cálculo de tempo de Polling da mensagem do TT303, em uma rede composta por dois mestres: o DF73 no endereço 1 e o MPA no endereço 2.

\begin{tabular}{|c|c|c|c|c|c|c|}
\hline Numero & Tempo & Mensagem & Tipo Mensagem & STX/ACK & Fonte & Destino \\
\hline 429 & $15: 43: 28: 752$ & $\mathrm{DC} 02010217$ & Token & STX & 1 & MPA \\
\hline 431 & $15: 43: 28: 772$ & $68000068020708000000004 C 000000004 C 30 \mathrm{~A} 1$ & Resp. Leitura Poll-List & ACK & 7 & MPA \\
\hline 433 & $15: 43: 28: 797$ & $680 \mathrm{~B} 0 \mathrm{~B} 68020608000000001 \mathrm{~F} 000000986 \mathrm{~B}$ & Resp. Leitura Poll-List & ACK & 6 & MPA \\
\hline 434 & 15:43:28:815 & $1004024976 \mathrm{DA}$ & Pedido de Status [RFS] & STX & MPA & 4 \\
\hline 435 & $15: 43: 28: 819$ & $1002040065 \mathrm{~A} 1$ & Resp. Pedido de Status (RFS) & ACK & 4 & MPA \\
\hline 438 & $15: 43: 28: 858$ & 6808086801040800000000 4C E6 1F & Resp. Leitura Poll-List & ACK & 4 & 1 \\
\hline 439 & $15: 43: 28: 867$ & $100 \mathrm{C} 015 \mathrm{D} 7 \mathrm{AE} 5$ & Leitura Poll-List & STX & 1 & 12 \\
\hline 440 & $15: 43: 28: 874$ & $68080868010 \mathrm{C} 08000000004 \mathrm{C} 382 \mathrm{~B}$ & Resp. Leitura Poll-List & ACK & 12 & 1 \\
\hline 441 & $15: 43: 28: 882$ & DC 02010217 & Token & STX & 1 & MPA \\
\hline 442 & $15: 43: 28: 889$ & $10 \quad 07 \quad 02 \quad 5 D \quad A D \quad 1 D$ & Leitura Poll-List & STX & MPA & 7 \\
\hline 443 & $15: 43: 28: 897$ & $68000068020708000000004 C 000000004 C 30 \mathrm{A1}$ & Resp. Leitura Poll-List & ACK & 7 & MPA \\
\hline 444 & $15: 43: 28: 908$ & $10 \quad 06 \quad 02 \quad 50 \quad 89 \quad \mathrm{~A} 1$ & Leitura Poll-List & STX & MPA & 6 \\
\hline
\end{tabular}

Figura 73 - Cálculo de tempo do Polling da mensagem 
Observe-se que na Figura 73, após recebimento do token, o MPA transmite as mensagens da Poll-List, sendo a primeira para o endereço 7 (mensagem analisada) e a segunda para o endereço 6. Antes de transmitir o token para o DF73, o MPA transmite uma mensagem de Pedido de Status (RFS) para o endereço 4. Do mesmo modo, o DF73 recebe o token e transmiti as mensagens da Poll-List, sendo a primeira para o endereço 4 e a segunda para o endereço 6 , e por fim o DF73 retorna o token para o MPA, que inicia novamente a transmissão das mensagens da lista.

De acordo com a Figura 73, o tempo de Polling da mensagem do TT303 que está no endereço 7, é calculado pela diferença entre os tempos "15:43:28:889" e "15:43:28:764" do campo "Tempo", que aparecem entre os números 430 e 442 no campo "Número", resultando em $125 \mathrm{~ms}$.

É importante ressaltar, contudo, que apesar dos dispositivos mestres possuírem uma lista de mensagens periódicas (Poll-List), o tempo de Polling da mensagem não é constante, devido ás ocorrências de mensagens de Multicast, mensagens de Pedido de Status (RFS) (conforme definido nos parâmetros GAP e HSA) e resposta aos Pedidos de Status (RFS) caso haja um dispositivo ativo no endereço correspondente, além da variação de tempo de processamento da mensagem na camada de aplicação dos dispositivos. Tal fator deve ser evidenciado principalmente no MPA, em razão deste ser executado em PC onde os tempos não funcionam com determinismo.

De acordo com o algoritmo de passagem de token descrito no tópico 2.4.3.3, em cada recepção do token, o mestre possui uma quantidade de tempo diferente para transmitir mensagens no barramento, tal tempo é calculado pela diferença entre os parâmetros TTR e TRR. O valor do parâmetro TRR varia em cada ciclo do token e por esta razão, caso o parâmetro TTR esteja configurado com um valor baixo, ou seja, insuficiente para aplicação, o número de mensagens da Poll-List transmitida pelo mestre durante a pose do token não é fixa. Por exemplo, considere-se um mestre " $X$ " com 5 mensagens na Poll-List e com o parâmetro TTR configurado com um valor um pouco abaixo do valor considerado suficiente 
para a aplicação. Em alguns ciclos do token as 5 mensagens serão transmitidas, enquanto em outros ciclos apenas 4 ou 3 mensagens serão transmitidas, ou seja, eventualmente a Poll-List será executada completamente em um único ciclo do token ou finalizada em dois ciclos do token, dependendo do tempo que o mestre possui para transmitir mensagem no barramento quando de direito do token. Normalmente a quantidade de ciclos do token necessários para a execução completa da Poll-List é a mesma.

A Figura 74 expõe um exemplo do Polling da mensagem do TT303 que está no endereço 7, onde a completa transmissão das mensagens da Poll-List do MPA foi finalizada em dois ciclos do token.

\begin{tabular}{|c|c|c|c|c|c|c|}
\hline Numero & Tempo & Mensagem & Tipo Mensagem & STX/ACK & Fonte & Destino \\
\hline 5 & $16: 20: 23: 40$ & $\mathrm{DC} 02010217$ & Token & STX & 1 & MPA \\
\hline 6 & $16: 20: 23: 48$ & $10 \quad 07 \quad 02 \quad 5 D \quad A D \quad 1 D$ & Leitura Poll-List & STX & MPA & 7 \\
\hline 7 & $16: 20: 23: 56$ & $68000068020708000000004 C 000000004 C 30 \mathrm{~A} 1$ & Resp. Leitura Poll-List & $\mathrm{ACK}$ & 7 & MPA \\
\hline 8 & $16: 20: 23: 76$ & DC 0102 A.6 55 & Token & STX & MPA & 1 \\
\hline 9 & $16: 20: 23: 85$ & $10040170 \mathrm{DD} 7 \mathrm{~B}$ & Leitura Poll-List & STX & 1 & 4 \\
\hline 10 & $16: 20: 23: 92$ & 68080868010408000000004 C E6 1F & Resp. Leitura Poll-List & ACK & 4 & 1 \\
\hline 11 & $16: 20: 23: 101$ & $100 \mathrm{C} 015 \mathrm{D} 7 \mathrm{AE} 5$ & Leitura Poll-List & STX & 1 & 12 \\
\hline 12 & $16: 20: 23: 108$ & $68080868010 \mathrm{C} 08000000004 \mathrm{C} 382 \mathrm{~B}$ & Resp. Leitura Poll-List & ACK & 12 & 1 \\
\hline 13 & $16: 20: 23: 116$ & $\mathrm{DC} 02010217$ & Token & STX & 1 & MPA \\
\hline 14 & $16: 20: 23: 124$ & $10 \quad 06 \quad 02 \quad 5 D \quad 89 \quad A 1$ & Leitura Poll-List & STX & MPA & 6 \\
\hline 15 & $16: 20: 23: 133$ & $680 \mathrm{~B} 0 \mathrm{~B} 68020608000000001 \mathrm{~F} 000000986 \mathrm{~B}$ & Resp. Leitura Poll-List & ACK & 6 & MPA \\
\hline 16 & $16: 20: 23: 149$ & $1008024976 \mathrm{DA}$ & Pedido de Status [RFS] & STX & MPA & 4 \\
\hline 17 & $16: 20: 23: 153$ & $1002080065 A 1$ & Resp. Pedido de Status (RFS) & ACK & 4 & MPA \\
\hline 18 & $16: 20: 23: 177$ & DC $01 \quad 02 \quad A 655$ & Token & STX & MPA & 1 \\
\hline 19 & $16: 20: 23: 186$ & $10040170 \mathrm{DD} 7 \mathrm{~B}$ & Leitura Poll-List & STX & 1 & 4 \\
\hline 20 & $16: 20: 23: 193$ & 68080868010408000000004 C E6 1F & Resp. Leitura Poll-List & ACK & 4 & 1 \\
\hline 21 & $16: 20: 23: 202$ & $100 \mathrm{C} 01$ 5D 7A E5 & Leitura Poll-List & STX & 1 & 12 \\
\hline 22 & $16: 20: 23: 209$ & $68080868010 \mathrm{C} 08000000004 \mathrm{C} 382 \mathrm{~B}$ & Resp. Leitura Poll-List & ACK & 12 & 1 \\
\hline 23 & $16: 20: 23: 217$ & DC 02010217 & Token & STX & 1 & MPA \\
\hline 24 & $16: 20: 23: 225$ & $10 \quad 07 \quad 02 \quad 5 D \quad A D \quad 1 D$ & Leitura Poll-List & STX & MPA & 7 \\
\hline 25 & $16: 20: 23: 233$ & $68000 D 68020708000000004 C 000000004 \mathrm{C} 30 \mathrm{~A} 1$ & Resp. Leitura Poll-List & ACK & 7 & MPA \\
\hline 26 & $16: 20: 23: 254$ & DC $01 \quad 02 \quad A 655$ & Token & STX & MPA & 1 \\
\hline
\end{tabular}

Figura 74 - Polling da mensagem - dois ciclos do token

Sobre tal representação, o experimento foi realizado em duas etapas, sendo a primeira em uma rede PROFIBUS com dois mestres no barramento e a segunda com três mestres no barramento. Em cada conjunto estatístico de medidas composto por cinqüenta e uma amostras coletadas do tempo de Polling da mensagem do TT303 em regime de operação, foram ensaiados, diferentes valores do parâmetro TTR, combinados com quantidades crescentes de equipamentos escravo no barramento. O primeiro valor do TTR adotado é suficiente para que todas as mensagens da Poll-List do MPA sejam transmitida durante o ciclo do token (representado pela cor azul). O segundo valor do TTR é insuficiente 
para a transmissão de todas as mensagens da Poll-List do MPA, de forma que o processo normalmente requer dois ciclos do token para se completar (representado pela cor vermelha). O terceiro valor de TTR é menor ainda, de forma que a completa transmissão das mensagens da Poll-List do MPA normalmente é finalizada em três ciclos do token (representado pela cor verde). Para simplificar a análise, foram descartados os ciclos com mensagens acíclicas, ciclos com mensagem de erro e ciclos com retransmissão de mensagem, pois além de ocorrer ocasionalmente, aumentam o tempo de Polling da mensagem.

Para este experimento, o parâmetro TTR de ambos os DF73 foram configurados em 450ms, valor considerado suficiente para completa transmissão das mensagens da Poll-List de ambos os mestres durante o ciclo do token.

As Figuras 75 a 94, apresentam além do gráfico com os conjuntos de amostras coletadas, um quadro indicando quais os dispositivos utilizados no experimento, por exemplo, o quadro da Figura 75 indica que o experimento foi realizado em uma rede com dois mestres (DF73 no endereço 1 com uma mensagem na Poll-list, e o MPA no endereço 2 com duas mensagens na Poll-List). As Figuras $75,77,79,81,83,85,87,89,91$ e 93 representam os experimentos realizados com dois mestres $e$ as Figuras $76,78,80,82,84,86,88,90,92$ e 94 representam os experimentos realizados com três mestres. Os experimentos com três mestres utilizam a mesma configuração da Poll-List do experimento com dois mestres, apenas inclui o terceiro mestre que mantêm uma configuração da Poll-List fixa em todas as amostras. Salienta-se que em cada dois gráficos apresentados, é inserido um novo dispositivo na configuração, hora na Poll-List do MPA, hora na Poll-List do DF73.

As figuras 75 a 94 são representadas a seguir com a seguinte formatação:

$\boldsymbol{D}$ (mestre DF73 no endereço 1) + Número (quantidade de mensagem da Poll-List do DF73 no endereço 1) $+\boldsymbol{M}$ (mestre MPA no endereço 2) + Número (quantidade de mensagem da Poll-List do MPA). Nos gráficos com três mestres é incluso a letra $\boldsymbol{D}$ (mestre 
DF73 no endereço 2) + Número (quantidade de mensagem da Poll-List do DF73 no endereço 2).

- Configuração D1M2 - D1M2D3

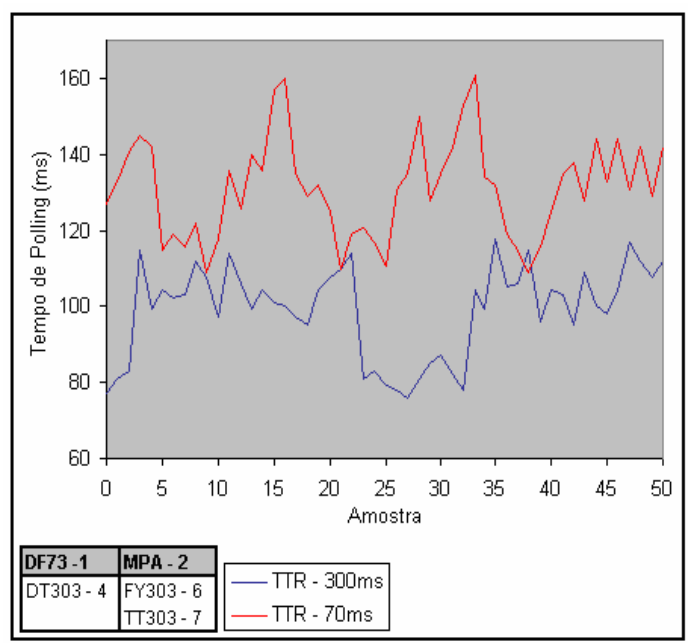

Figura 75- Configuração D1M2

- Configuração D2M2 - D2M2D3

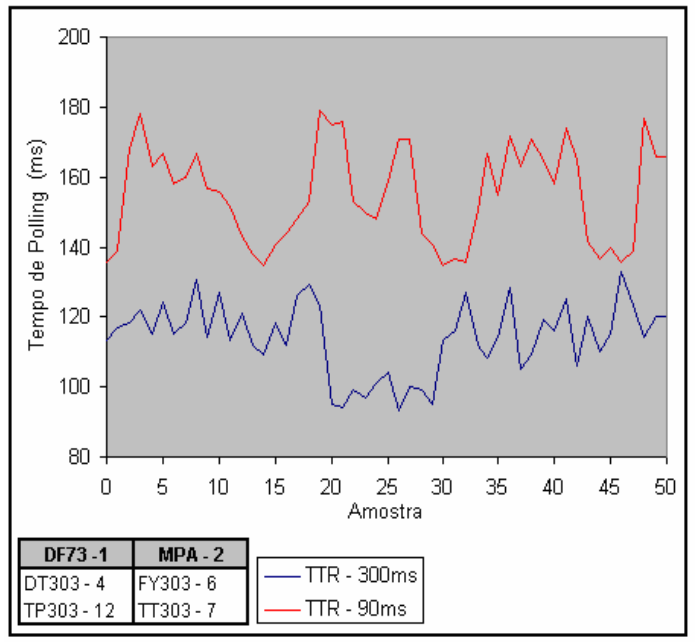

Figura 77- Configuração D2M2

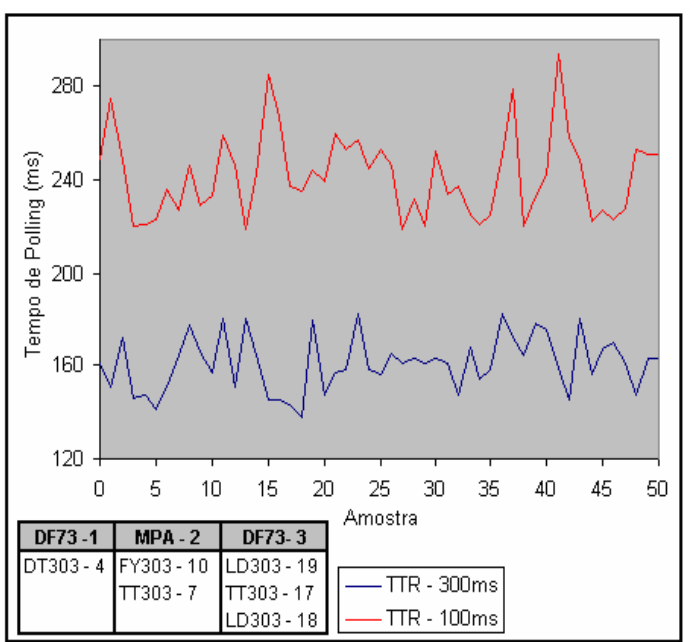

Figura 76 - Configuração D1M2D3

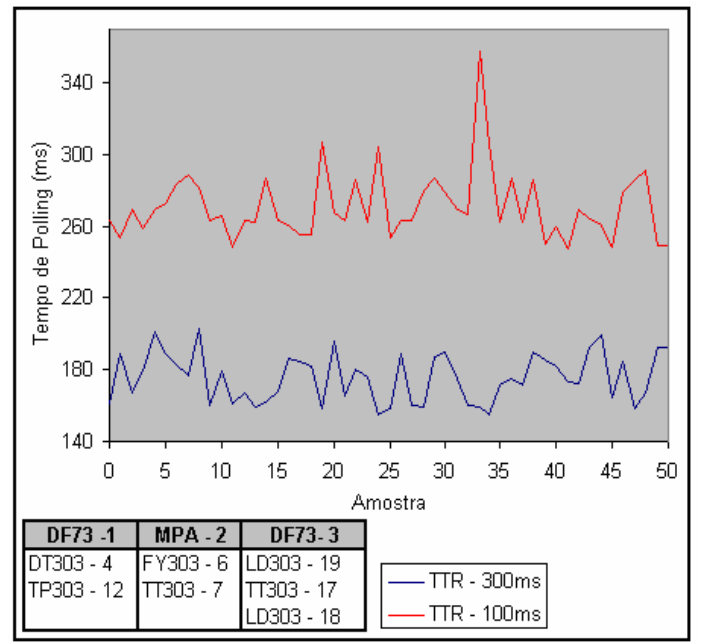

Figura 78 - Configuração D2M2D3 
- Configuração D2M3 - D2M3D3

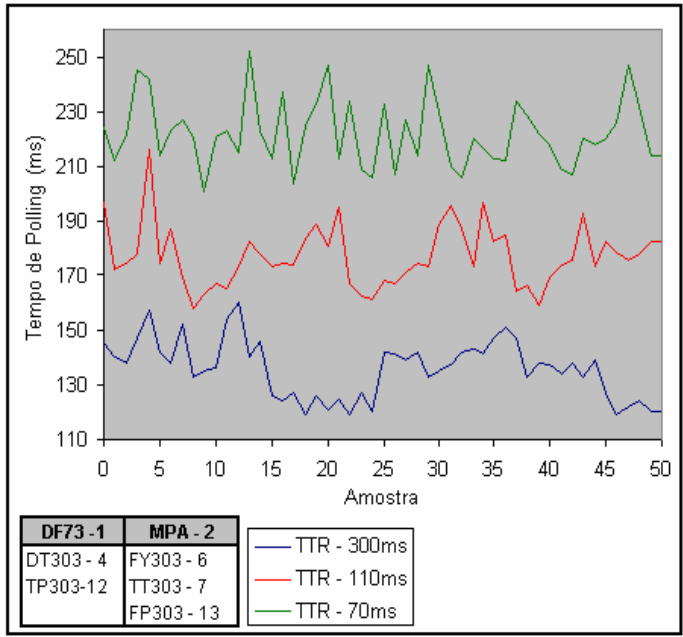

Figura 79- Configuração D2M3

- Configuração D3M3 - D3M3D3

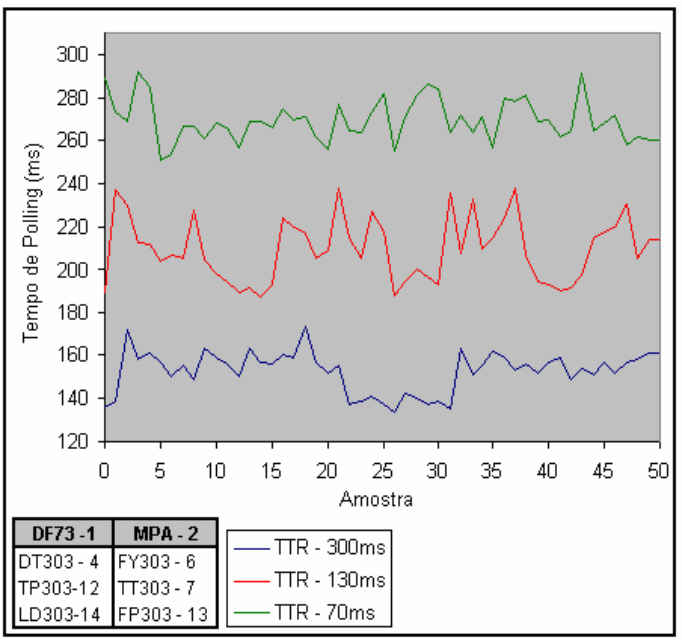

Figura 81 - Configuração D3M3

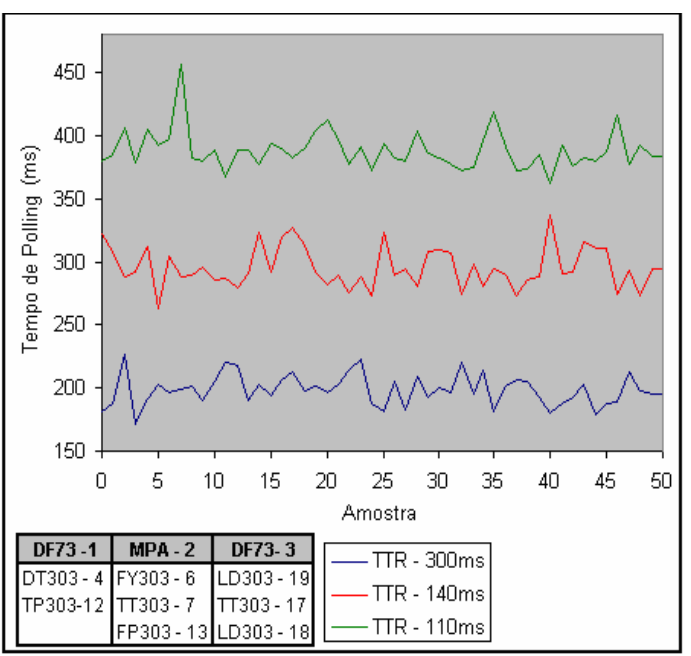

Figura 80 - Configuração D2M3D3

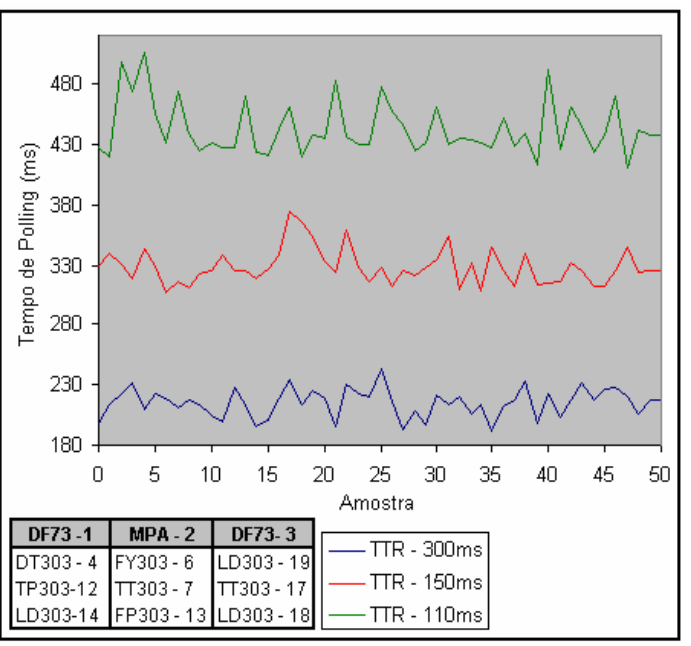

Figura 82 - Configuração D3M3D3 
- Configuração D3M4 - D3M4D3

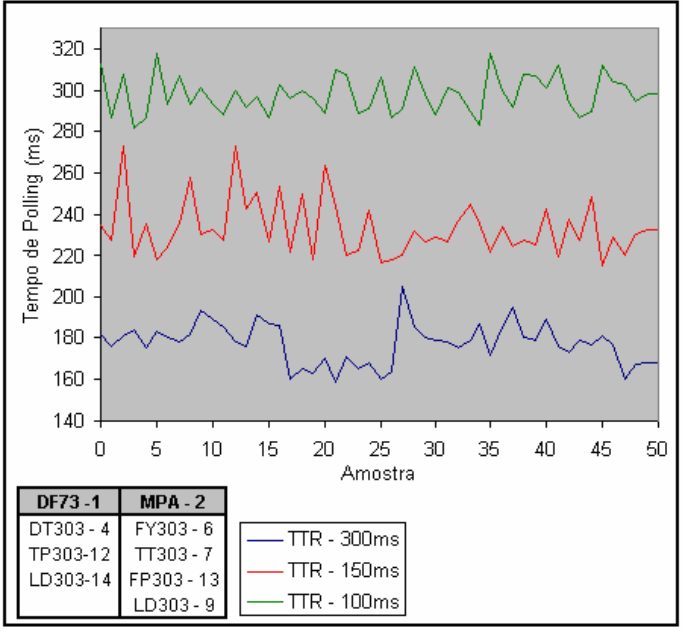

Figura 83 - Configuração D3M4

- Configuração D4M4 - D4M4D3

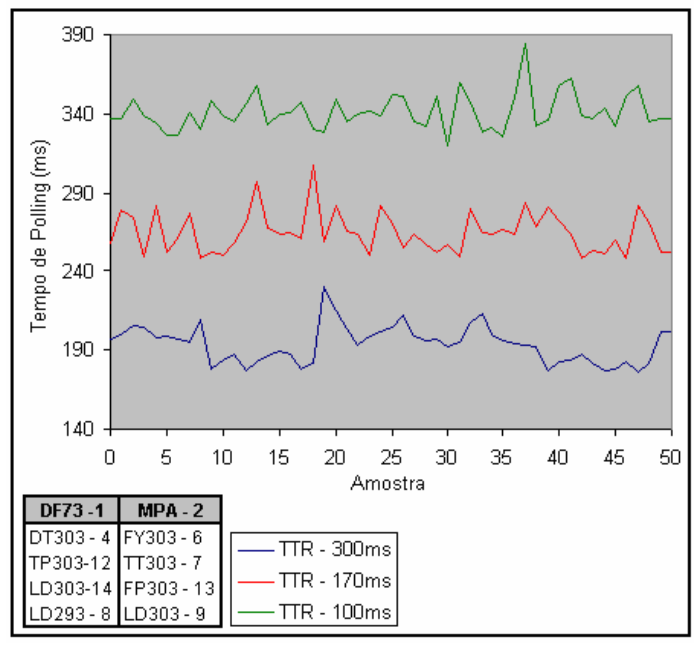

Figura 85 - Configuração D4M4

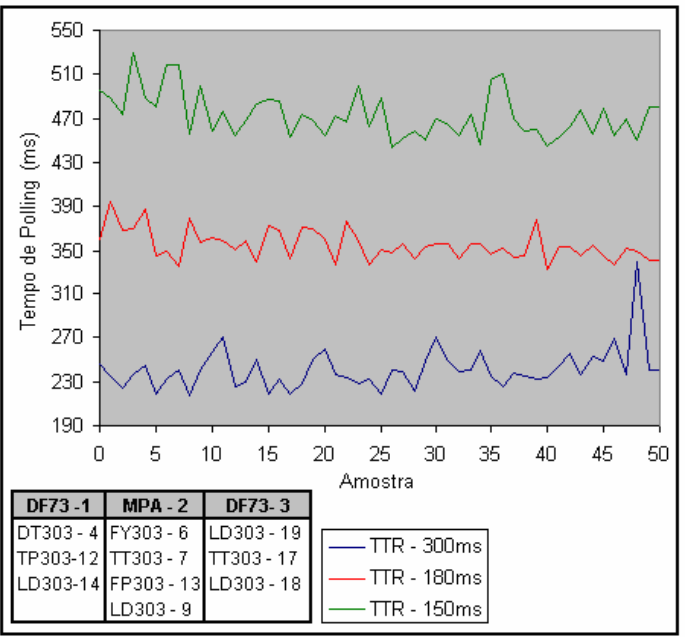

Figura 84 - Configuração D3M4D3

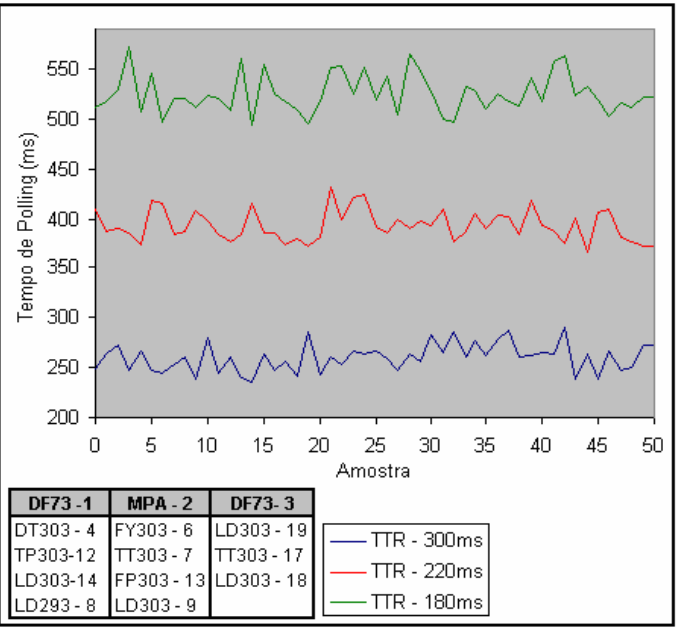

Figura 86 - Configuração D4M4D3 
- Configuração D4M5 - D4M5D3

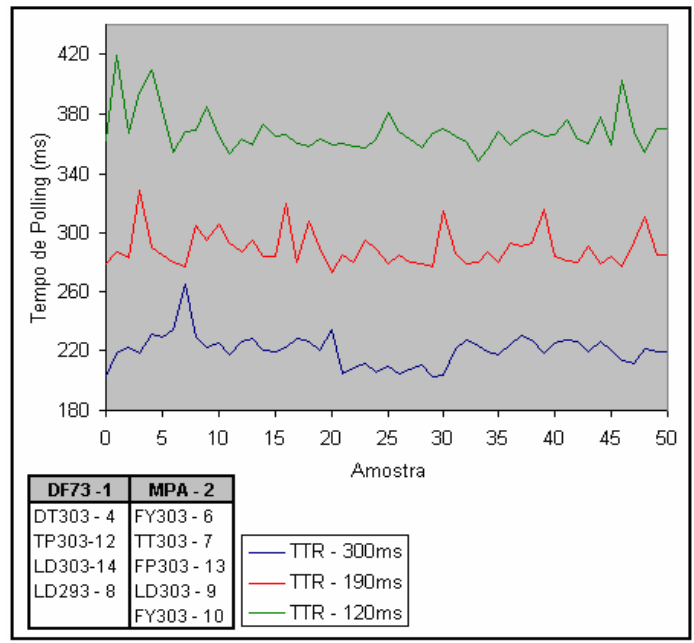

Figura 87 - Configuração D4M5

- Configuração D5M5 - D5M5D3

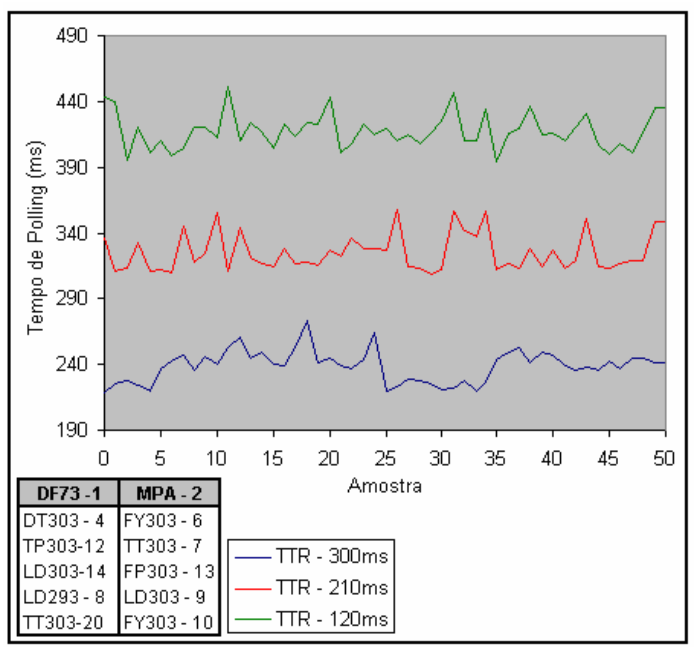

Figura 89 - Configuração D5M5

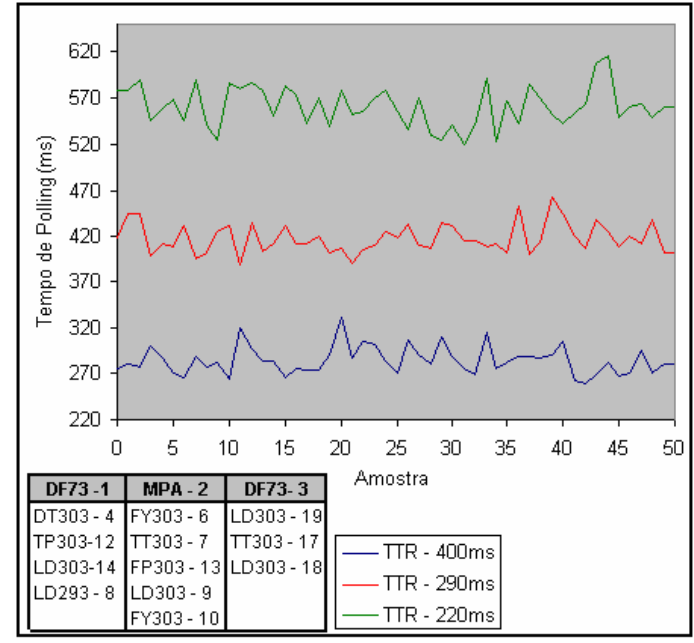

Figura 88 - Configuração D4M5D3

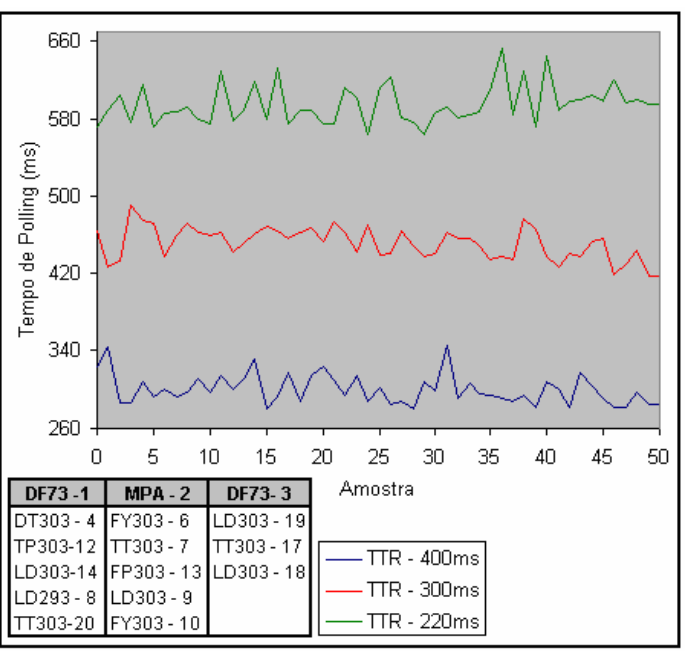

Figura 90 - Configuração D5M5D3 
- Configuração D5M6 - D5M6D3

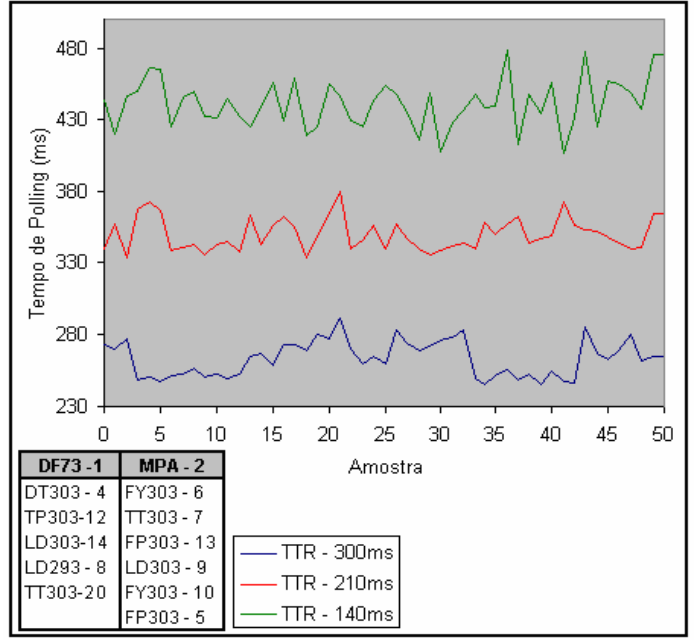

Figura 91 - Configuração D5M6

- Configuração D6M6 - D2M2D3

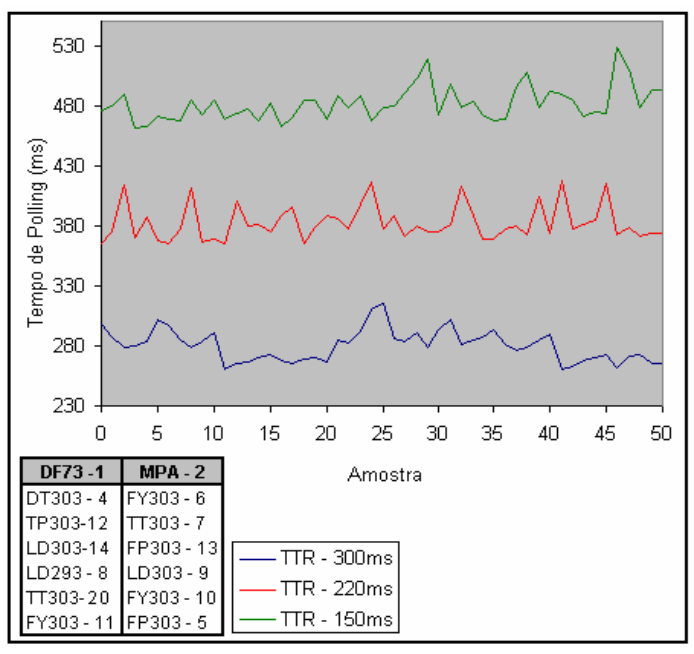

Figura 93 - Configuração D6M6

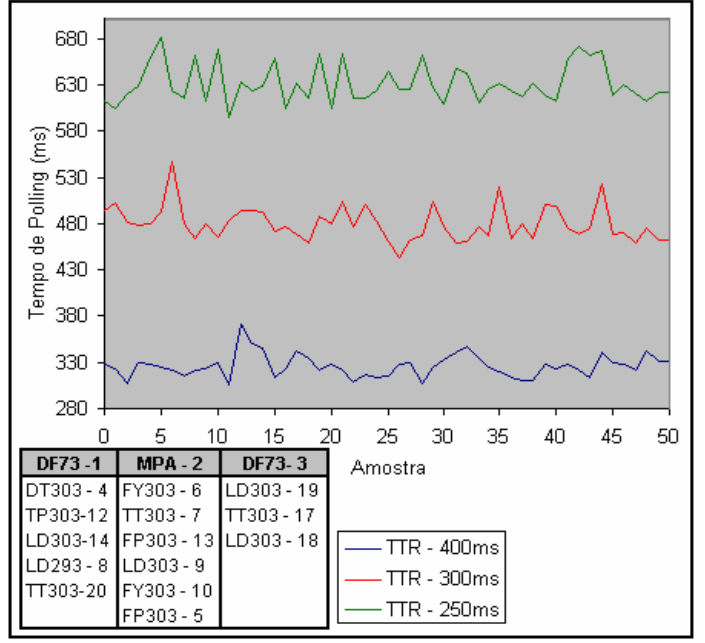

Figura 92 - Configuração D5M6D3

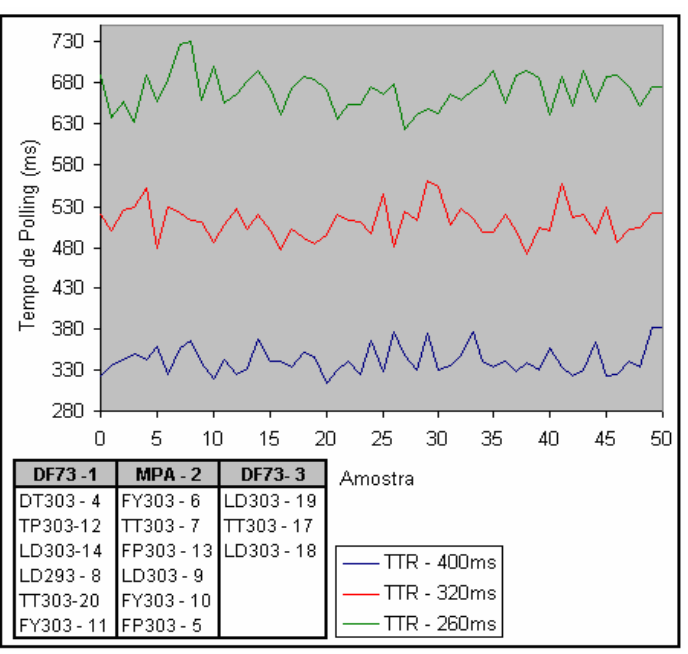

Figura 94 - Configuração D6M6D3

As tabelas 1 e 2 e a figura 95 mostram a média dos valores apresentados nos gráficos acima. 
Tabela 1 - Média do tempo de Polling da Mensagem do TT303 com dois mestres no barramento

\begin{tabular}{cccc}
\hline MESTRE (POLL-LIST) & TTR (ALTO) & TTR (MÉDIO) & TTR (BAIXO) \\
\hline D1M2 & 98,72 & 131 & \\
D2M2 & 113,74 & 155,12 & \\
D2M3 & 136,02 & 177,08 & 222,36 \\
D3M3 & 152,48 & 209,48 & 269,68 \\
D3M4 & 177,54 & 233,54 & 298,06 \\
D4M4 & 193,56 & 265,48 & 341,2 \\
D4M5 & 220,46 & 288,74 & 367,84 \\
D5M5 & 238,34 & 325,08 & 417,58 \\
D5M6 & 263,18 & 350,02 & 441,1 \\
D6M6 & 280,16 & 383,06 & 481,36 \\
\hline
\end{tabular}

Tabela 2 - Média do tempo de Polling da Mensagem do TT303 com três mestres no barramento

\begin{tabular}{cccc}
\hline MESTRE (POLL-LIST) & TTR (ALT0) & TTR (MÉDIO) & TTR (BAIX0) \\
\hline D1M2D3 & 160,72 & 241,8 & \\
D2M2D3 & 175,08 & 272,14 & \\
D2M3D3 & 198,28 & 295,42 & 388,62 \\
D3M3D3 & 214,98 & 328,26 & 443,14 \\
D3M4D3 & 240,96 & 355,2 & 472,88 \\
D4M4D3 & 259,96 & 393,92 & 525,6 \\
D4M5D3 & 284,18 & 418,14 & 561,16 \\
D5M5D3 & 300,44 & 452,74 & 595,08 \\
D5M6D3 & 325,7 & 480,92 & 631,68 \\
D6M6D3 & 341,42 & 511,6 & 670,54 \\
\hline
\end{tabular}




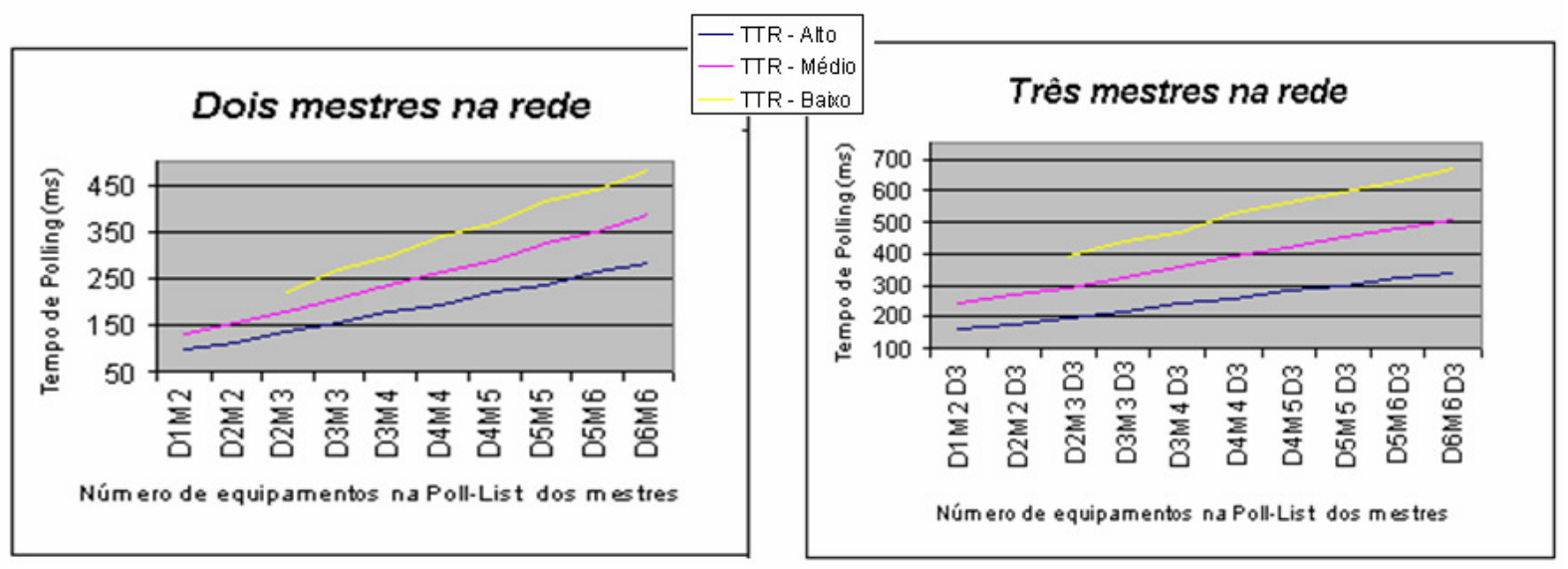

Figura 95 - Gráficos da Média do tempo de Polling da mensagem do TT303

Os seguintes fatores podem ser destacados nos resultados apresentados neste experimento:

- Quanto maior o número de ciclos do token necessários para o MPA transmitir as mensagens da Poll-List, maior é o tempo de Polling da mensagem. Basta comparar os valores das colunas de TTR (alto) referente a 1 ciclo do token, TTR (médio) referente a 2 ciclos do token e TTR (baixo) referente a 3 ciclos do token conforme tabelas 1 e 2.

Isto ocorre porque, durante o polling da mensagem do TT303, o DF73 recebe o token uma única vez no caso do TTR alto, duas vezes no caso do TTR médio e três vezes no caso do TTR baixo, onde transmite as mensagens da Poll-List, mensagem de Pedido de Status (RFS) e mensagem de multicast quando necessário. No experimento com três mestres (tabela 2) a diferença entre os valores das colunas de TTR (alto), TTR (médio) e TTR (baixo) é ainda maior, pois são dois DF73 que recebem o token durante o polling da mensagem do TT303. Nota-se também que essa diferença cresce conforme adiciona-se dispositivo na Poll-List dos mestres.

- Adição de dispositivo na Poll-List do DF73 representa um aumento maior no tempo de Polling da mensagem do TT303 quando comparado com a adição do mesmo dispositivo na Poll-List do MPA. 
Isto ocorre porque, durante o Polling da mensagem do TT303, o MPA transmite a mensagem uma única vez, enquanto o DF73 transmite a mensagem conforme o número de vezes que recebe o token.

Observe-se que no intervalo de Polling da mensagem do TT303 da Figura 74, o DF73 transmitiu duas vezes as mensagens da Poll-List, enquanto que o MPA transmitiu-as uma única vez. Com isso, evidencia-se que a adição de uma mensagem na Poll-List do MPA de 10 ms aumentará o tempo de Polling da mensagem em 10 ms, enquanto a adição da mesma mensagem no DF73 aumentará o tempo de Polling em 10 ms no caso do TTR (alto), 20 ms no TTR (Médio) e 30 ms no TTR (baixo).

A partir da análise realizada neste experimento, foi possível elaborar uma expressão matemática que represente o tempo de Polling das mensagens, representada pelo parâmetro TPM.

$$
T P M=T \_M A+T \_D M+T T+T P \_S t a t u s+T M
$$

Onde T_MA é o tempo necessário para transmitir e receber a resposta de todas as mensagens da Poll-List do mestre no qual possui a mensagem que está sendo analisada. T_DM é o tempo necessário para transmitir e receber a resposta de todas as mensagens referentes a Poll-List dos demais mestres do anel lógico. TT é o tempo necessário para transferir o token entre as estações do anel lógico. TP_Status é o tempo de manutenção na rede, ou seja, é o tempo necessário para que as estações-mestres transmitam e recebam a resposta da mensagem de Pedido de Status (RFS). TM é o tempo necessário para que as estações-mestres transmitam a mensagem de Multicast.

O parâmetro T_MA pode ser expresso como: 


$$
\text { T_MA }=\sum_{i=1}^{n} \operatorname{TMC}(i)
$$

Onde n é o número de mensagens na Poll-List do mestre que possui a mensagem que está sendo analisada. TMC (i) é o tempo necessário para transmitir e receber a resposta da ith mensagem da Poll-List.

O parâmetro T_DM pode ser expresso como:

$$
T_{-} D M=n *\left(\sum_{i=1}^{m} \sum_{j=1}^{p} T M C(i, j)\right)
$$

Onde $\mathrm{n}$ é o número de ciclos do token necessário para o mestre que possui a mensagem que está sendo analisada transmitir todas as mensagens da sua Poll-List. m é o número de mestres no anel lógico desconsiderando o mestre que possui a mensagem que está sendo analisada. p é o número de mensagens na Poll-List do ith mestre. TMC ( $\mathrm{i}, \mathrm{j})$ é o tempo necessário para transmitir e receber a resposta da jth mensagem da Poll-List no ith mestre.

O parâmetro TT pode ser expresso como:

$$
\mathrm{TT}=\left((\mathrm{NM}+1){ }^{*} \mathrm{NCiclos}\right){ }^{*} \mathrm{TM}_{-} \mathrm{T}
$$

Onde NM é o número de mestres no anel lógico desconsiderando o mestre que possui a mensagem que está sendo analisada e NCiclos é o número de ciclos do token necessário para o mestre que possui a mensagem que está sendo analisada transmitir todas as mensagens da sua Poll-List. TM_T é o tempo necessário para transmitir a mensagem de token. 
O parâmetro TP_Status pode ser expresso como:

$$
\text { TP_Status }=\sum_{i=1}^{n} \sum_{j=1}^{m} \operatorname{TMC}(i, j)
$$

Onde $\mathrm{n}$ é o número de ciclos do token necessário para o mestre que possui a mensagem que está sendo analisada transmitir todas as mensagens da sua Poll-List. m é o número de estações-mestres no anel lógico. TMC (i,j) é o tempo necessário para transmitir e receber a resposta da mensagem de Pedido de Status (RFS) do jth mestre no ith ciclo do token.

O parâmetro TM pode ser expresso como:

$$
\mathrm{TM}=\sum_{i=1}^{n} \mathrm{TM}_{-} \mathrm{M}_{\text {(i) }}
$$

Onde $n$ é o número de estações-mestres no anel lógico. TM_M (i) é o tempo necessário para transmitir a mensagem de Multicast do ith mestre.

De acordo com a norma PROFIBUS, o parâmetro TMC utilizado nas expressões acima, representa o tempo de ciclo da mensagem, composto pelo tempo de transmissão da mensagem de request + tempo de transmissão da mensagem de resposta. $O$ parâmetro TMC é expresso como:

$$
T M C=T S / R+T S D R+T A / R+T I D+2 T T D
$$

A composição e significado de cada parâmetro da expressão TMC pode ser encontrada em detalhes em PROFIBUS SPECIFICATION (1998). 
Para validar as expressões acima, o tempo de transmissão das mensagens referente ao conjunto de amostras do gráfico da Figura 88 (D4M5D3), onde o parâmetro TTR foi configurado em 290 ms foram substituídos na expressão TPM, como mostra a tabela 3. A Figura 96 compara os valores das amostras do gráfico da Figura 88 (D4M5D3) com os valores obtidos pela expressão TPM. 
Tabela 3 - Representação dos valores utilizados na expressão TPM

\begin{tabular}{|c|c|c|c|c|c|c|}
\hline Amostra & T MA ( $n=5)$ & T_DM $(n=2 ; m=2 ; p(1)=4 ; p(2)=3$ & TT (NM =2; Nciclos = 2; TMT = 9ms) & TP_STATUS ( $n=2 ; m=3)$ & TM $(m=3)$ & Total TPM \\
\hline 418 & $25,23,27,22,29$ & $15,14,16,11,17,19,15$ & 54 & $0,0,12,0,0,12$ & $0,0,0$ & 418 \\
\hline 445 & $28,24,29,21,27$ & $15,15,16,12,17,19,15$ & 54 & $0,0,13,0,0,12$ & $17,0,0$ & 443 \\
\hline 445 & $27,26,28,25,27$ & $15,15,16,12,16,19,15$ & 54 & $0,0,0,13,0,0,9$ & $0,0,17$ & 442 \\
\hline 398 & $27,26,29,23,27$ & $14,15,16,12,16,19,15$ & 54 & $0,0,0,0,0,0$ & $0,0,0$ & 400 \\
\hline 412 & $26,28,29,24,30$ & $16,15,16,13,16,19,15$ & 54 & $0,0,0,0,0,0$ & $0,0,0$ & 411 \\
\hline 409 & $25,25,26,21,26$ & $15,15,16,12,16,19,15$ & 54 & $0,0,0,0,0,13$ & $0,0,0$ & 406 \\
\hline 432 & $28,26,30,25,27$ & $15,15,17,12,16,19,15$ & 54 & $0,0,13,0,0,13$ & $0,0,0$ & 434 \\
\hline 400 & $23,22,25,21,24$ & $14,14,16,12,16,19,15$ & 54 & $0,0,12,0,0,12$ & $0,0,0$ & 405 \\
\hline 406 & $24,24,26,21,25$ & $15,14,16,12,16,19,14$ & 54 & $0,0,11,0,0,12$ & $0,0,0$ & 409 \\
\hline 425 & $26,25,30,23,28$ & $15,15,16,12,15,19,15$ & 54 & $0,0,13,0,0,12$ & $0,0,0$ & 425 \\
\hline 432 & $29,26,28,22,26$ & $15,16,16,12,16,20,15$ & 54 & $0,0,13,0,0,13$ & $0,0,0$ & 431 \\
\hline 391 & $23,22,24,20,24$ & $15,14,15,12,16,19,14$ & 54 & $0,0,9,0,0,8$ & $0,0,0$ & 394 \\
\hline 435 & $28,27,29,25,29$ & $15,15,16,13,16,19,15$ & 54 & $0,0,13,0,0,12$ & $0,0,0$ & 435 \\
\hline 404 & $24,23,24,21,25$ & $15,15,16,12,15,19,14$ & 54 & $0,0,12,0,0,11$ & $0,0,0$ & 406 \\
\hline 413 & $27,26,27,26,28$ & $15,15,16,12,16,19,16$ & 54 & $0,0,8,0,0,0$ & $0,0,0$ & 414 \\
\hline 431 & $29,26,29,27,31$ & $16,15,16,13,16,19,15$ & 54 & $0,0,0,0,0,0$ & $17,0,0$ & 433 \\
\hline 413 & $25,26,27,25,27$ & $15,15,16,12,16,18,15$ & 54 & $0,0,0,0,0,0$ & $0,0,16$ & 414 \\
\hline 415 & $25,27,26,24,25$ & $15,15,15,12,16,19,15$ & 54 & $0,0,12,0,0,11$ & $0,0,0$ & 418 \\
\hline 420 & $25,24,29,24,27$ & $15,15,16,12,15,18,15$ & 54 & $0,0,12,0,0,12$ & $0,0,0$ & 419 \\
\hline 402 & $24,21,24,22,24$ & $15,14,16,12,16,19,14$ & 54 & $0,0,12,0,0,12$ & $0,0,0$ & 405 \\
\hline 407 & $25,24,26,21,25$ & $14,15,15,12,16,19,15$ & 54 & $0,0,11,0,0,12$ & $0,0,0$ & 410 \\
\hline 393 & $23,22,23,20,24$ & $15,14,15,12,15,19,14$ & 54 & $0,0,12,0,0,11$ & $0,0,0$ & 391 \\
\hline 406 & $24,25,24,22,24$ & $15,15,15,12,16,19,14$ & 54 & $0,0,13,0,0,9$ & $0,0,0$ & 407 \\
\hline 410 & $24,28,24,23,25$ & $15,15,16,12,16,19,14$ & 54 & $0,0,8,0,0,12$ & $0,0,0$ & 412 \\
\hline 425 & $22,28,30,24,28$ & $15,14,16,12,15,19,15$ & 54 & $0,0,12,0,0,12$ & $0,0,0$ & 422 \\
\hline 418 & $23,25,28,23,29$ & $15,15,16,12,16,18,15$ & 54 & $0,0,13,0,0,8$ & $0,0,0$ & 417 \\
\hline 427 & $29,26,29,27,34$ & $16,15,16,13,16,21,15$ & 54 & $0,0,0,0,0,0$ & $0,0,0$ & 423 \\
\hline 411 & $25,27,29,25,31$ & $15,15,16,13,16,19,16$ & 54 & $0,0,0,0,0,0$ & $0,0,0$ & 411 \\
\hline 408 & $23,25,26,23,27$ & $14,15,17,12,16,19,15$ & 54 & $0,0,0,0,0,12$ & $0,0,0$ & 406 \\
\hline 435 & $25,24,27,23,27$ & $15,15,16,12,16,19,15$ & 54 & $0,0,12,0,0,12$ & $16,0,0$ & 436 \\
\hline 432 & $23,22,26,24,27$ & $15,15,16,12,15,19,15$ & 54 & $0,0,12,0,0,11$ & $17,0,0$ & 430 \\
\hline 415 & $24,22,26,24,27$ & $15,15,16,12,16,19,15$ & 54 & $0,0,12,0,0,12$ & $0,0,0$ & 417 \\
\hline 416 & $23,23,25,21,28$ & $15,14,16,12,16,19,15$ & 54 & $0,0,12,0,0,13$ & $0,0,0$ & 413 \\
\hline 409 & $23,25,24,21,27$ & $15,15,16,12,16,19,14$ & 54 & $0,0,12,0,0,11$ & $0,0,0$ & 411 \\
\hline 413 & $23,26,28,22,29$ & $15,15,16,12,15,19,15$ & 54 & $0,0,8,0,0,8$ & $0,0,0$ & 412 \\
\hline 402 & $24,21,25,21,24$ & $15,15,16,12,14,19,15$ & 54 & $0,0,12,0,0,12$ & $0,0,0$ & 405 \\
\hline 453 & $27,27,35,29,34$ & $17,15,16,12,17,20,15$ & 54 & $0,0,12,0,0,12$ & $0,0,0$ & 454 \\
\hline 399 & $27,22,28,20,26$ & $15,14,15,12,15,19,14$ & 54 & $0,0,0,0,0,12$ & $0,0,0$ & 397 \\
\hline 414 & $24,28,29,26,30$ & $16,15,16,13,16,19,16$ & 54 & $0,0,0,0,0,0$ & $0,0,0$ & 413 \\
\hline 455 & $28,27,36,28,42$ & $16,15,16,12,17,20,15$ & 54 & $0,0,0,0,0,13$ & $0,0,0$ & 450 \\
\hline 442 & $26,27,30,27,30$ & $15,15,16,13,16,20,15$ & 54 & $0,0,13,0,0,12$ & $0,0,0$ & 439 \\
\hline 421 & $25,24,29,23,28$ & $14,15,16,12,15,19,15$ & 54 & $0,0,12,0,0,12$ & $0,0,0$ & 419 \\
\hline 408 & $22,25,28,20,26$ & $15,16,15,11,16,18,15$ & 54 & $0,0,12,0,0,12$ & $0,0,0$ & 411 \\
\hline 439 & $23,25,27,25,28$ & $15,15,16,13,16,19,15$ & 54 & $0,0,12,0,0,11$ & $17,0,0$ & 440 \\
\hline 426 & $22,24,27,23,27$ & $15,14,16,12,16,18,15$ & 54 & $0,0,12,0,0,12$ & $16,0,0$ & 429 \\
\hline 409 & $23,26,27,22,25$ & $15,15,15,12,16,19,14$ & 54 & $0,0,13,0,0,8$ & $0,0,0$ & 410 \\
\hline 420 & $24,25,29,24,27$ & $15,15,15,12,15,19,15$ & 54 & $0,0,12,0,0,12$ & $0,0,0$ & 419 \\
\hline 412 & $24,27,24,23,26$ & $15,15,16,12,16,19,14$ & 54 & $0,0,9,0,0,13$ & $0,0,0$ & 414 \\
\hline 438 & $26,27,35,27,29$ & $16,15,15,13,16,19,17$ & 54 & $0,0,13,0,0,0$ & $0,0,0$ & 433 \\
\hline
\end{tabular}

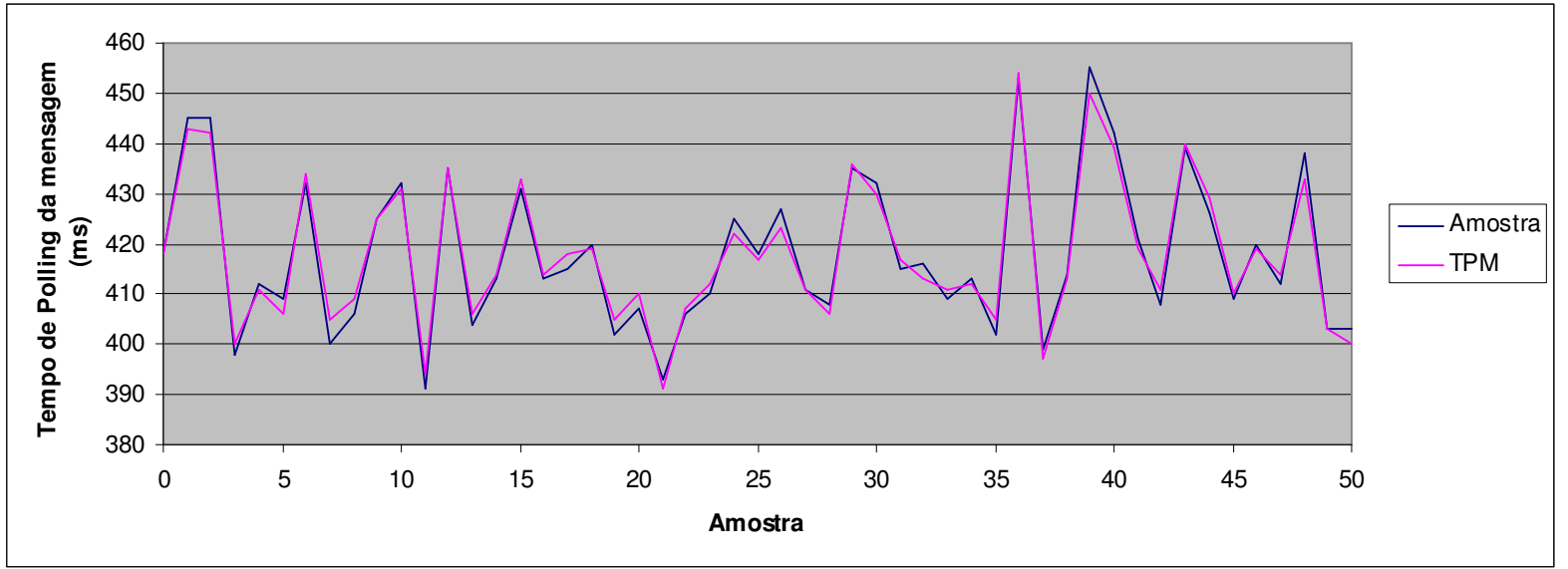

Figura 96 - Gráfico de comparação entre amostra e TPM 


\subsection{ANÁLISE DO TEMPO DE REINTEGRAÇÃO DA ESTAÇÃO-MESTRE NO BARRAMENTO APÓS PERDA DE MENSAGEM DE TOKEN}

Durante operação da rede, as estações-mestres trabalham de modo sincronizado, onde o token é passado entre elas de maneira seqüencial e periódica. Esta sintonia pode ser quebrada por um período de tempo, caso haja retirada de um dos dispositivos mestres da rede, ou a perda de mensagem de token.

A perda de mensagem de token pode causar instabilidade no sistema, pois após o número de retransmissão definido no parâmetro retries, a estação que deixou de responder a mensagem de token é excluída do anel lógico, e o tempo de sua reintegração pode ser oneroso e prejudicial para aplicação caso o sistema não esteja configurado adequadamente. Este tipo de falha de comunicação é mais comum em redes WIRELESS, por serem mais susceptível á perda ou corrupção de mensagens quando comparadas com uma rede com fios (WILLIG, 2003).

O tempo de reintegração da estação-mestre no anel lógico, após perda de mensagem de token foi analisado através de ferramenta de simulação por Willig (2003), que aplicou dois modelos de erros que são utilizados em redes WIRELESS, sendo eles: "Independent model errors" e "Gilbert/Elliot model errors". Em razão de Willig (2003) utilizar outro tipo de rede, não existe o intuito de comparar os resultados obtidos por Willig (2003) com os resultados obtidos neste experimento.

A Figura 97 apresenta um exemplo de perda de mensagem de token em uma rede composta por dois mestres: MPA no endereço 1 e o DF73 no endereço 2. 


\begin{tabular}{|c|c|c|c|c|c|c|}
\hline Numero & Tempo & Mensagem & Tipo Mensagem & STX/ACK & Fonte & Destino \\
\hline 350 & $07: 27: 06: 886$ & DC $0102 A 655$ & Token & STX & 2 & MPA \\
\hline 351 & $07: 27: 06: 901$ & DC $0102 \mathrm{A6} 55$ & Token & STX & 2 & MPA \\
\hline 352 & $07: 27: 06: 916$ & $\mathrm{DC} 02022446$ & Token & STX & 2 & 2 \\
\hline 353 & $07: 27: 06: 922$ & $10040250 \mathrm{COD9}$ & Leitura Poll-List & STX & 2 & 4 \\
\hline 354 & $07: 27: 06: 929$ & $68080868020408000000004 C$ AB $6 A$ & Resp. Leitura Poll-List & ACK & 4 & 2 \\
\hline 355 & $07: 27: 06: 938$ & $100 \mathrm{C} 025 \mathrm{D} \mathrm{F} 8 \mathrm{FG}$ & Leitura Poll-List & STX & 2 & 12 \\
\hline 356 & $07: 27: 06: 945$ & $68080868020 \mathrm{C} 08000000004 \mathrm{C} 755 \mathrm{E}$ & Resp. Leitura Poll-List & ACK & 12 & 2 \\
\hline 357 & $07: 27: 06: 953$ & $100 \mathrm{E} 025 \mathrm{D}$ B1 8E & Leitura Poll-List & STX & 2 & 14 \\
\hline 358 & $07: 27: 06: 961$ & $68080868020 \mathrm{E} 08000000004 \mathrm{C} 42 \mathrm{D} 3$ & Resp. Leitura Poll-List & $\mathrm{ACK}$ & 14 & 2 \\
\hline 359 & $07: 27: 06: 969$ & $1003024989 \mathrm{EE}$ & Pedido de Status[RFS] & STX & 2 & 3 \\
\hline 360 & $07: 27: 06: 973$ & $10020300 \mathrm{FGFC}$ & Resp. Pedido de Status(RFS] & ACK & 3 & 2 \\
\hline 361 & $07: 27: 06: 982$ & DC 02022446 & Token & STX & 2 & 2 \\
\hline 362 & $07: 27: 06: 988$ & $10040250 \mathrm{COD9}$ & Leitura Poll-List & STX & 2 & 4 \\
\hline 363 & $07: 27: 06: 995$ & $68080868020408000000004 C \mathrm{AB} 6 \mathrm{~A}$ & Resp. Leitura Poll-List & STX & 4 & 2 \\
\hline 364 & $07: 27: 07: 004$ & $100 \mathrm{C} 025 \mathrm{DF} F \mathrm{FG}$ & Leitura Poll-List & STX & 2 & 12 \\
\hline 365 & $07: 27: 07: 011$ & $68080868020 \mathrm{C} 0800000000$ 4C 75 5E & Resp. Leitura Poll-List & STX & 12 & 2 \\
\hline 366 & $07: 27: 07: 020$ & $100 \mathrm{E} 025 \mathrm{D}$ B1 $8 \mathrm{E}$ & Leitura Poll-List & STX & 2 & 14 \\
\hline 367 & $07: 27: 07: 027$ & $68080868020 \mathrm{E} 08000000004 \mathrm{C}$ & Resp. Leitura Poll-List & STX & 14 & 2 \\
\hline 368 & $07: 27: 07: 035$ & $1004024976 \mathrm{DA}$ & Pedido de Status[RFS] & STX & 2 & 4 \\
\hline 369 & $07: 27: 07: 040$ & $1002040065 A 5$ & Resp. Pedido de Status(RFS] & STX & 4 & 2 \\
\hline 370 & $07: 27: 07: 048$ & DC 02022446 & Token & STX & 2 & 2 \\
\hline
\end{tabular}

Figura 97 - Perda de Token - Dois mestres no barramento

Observe-se que na Figura 97, o MPA ignora as duas mensagens de token transmitidas consecutivamente pelo DF73 (mensagens de número 350 e 351). Com isso, o DF73 considera que o MPA foi retirado da rede e transmite a mensagem de token para si mesmo em razão de sua LAS estar vazia (mensagem de número 352). Após o DF73 receber a sua própria mensagem de token, ele inicia a transmissão das mensagens da PollList (mensagem de número 353) e em seguida transmite uma mensagem de Pedido de Status (RFS) para o primeiro endereço da GAPL (Mensagem de número 359), e por fim, transmite novamente o token para si mesmo (mensagem de número 361).

Em cada ciclo do token o DF73 transmite uma mensagem de Pedido de Status (RFS) para um endereço da GAPL. Assim, o MPA deve ser reintegrado ao anel lógico, somente após receber a mensagem de Pedidos de Status (RFS) do DF73, no qual deve responder como "Estação pronta para entrar no anel lógico" em razão de sua LAS já estar pronta. Após isso, o DF73 transmite a mensagem de token para o MPA e a sintonia entre as estaçõesmestres volta a ser a mesma de antes da perda de token.

O parâmetro HSA configurado pelo usuário indica o endereço da última estação da rede, na qual o DF73 deve transmitir a mensagem de Pedido de Status (RFS). No experimento representado pela Figura 97, o parâmetro HSA foi configurado em 20, assim a 
GAPL do DF73 contém 20 endereços, como mostra a Figura 98. Deste modo, conforme GAPL do DF73 o MPA será reintegrado ao anel lógico após 20 ciclos do token..

\section{\begin{tabular}{|l|l|l|l|l|l|l|l|l|l|l|l|l|l|l|l|l|l|l|l|}
\hline 3 & 4 & 5 & 6 & 7 & 8 & 9 & 10 & 11 & 12 & 13 & 14 & 15 & 16 & 17 & 16 & 19 & 20 & 0 & 1 \\
\hline
\end{tabular}}

Figura 98 - GAPL do DF73 no endereço 2

A Figura 99 apresenta um exemplo de perda de mensagem de token, em uma rede composta por três mestres: MPA no endereço 1, DF73 no endereço 2 e outro DF73 no endereço 3.

\begin{tabular}{|c|c|c|c|c|c|c|}
\hline Numero & Tempo & Mensagem & Tipo Mensagem & STX/ACK & Fonte & Destino \\
\hline 350 & $09: 15: 03: 300$ & DC 0103 BB 9A & Token & STX & 3 & MPA \\
\hline 351 & $09: 15: 03: 315$ & DC 0103 BB 9A & Token & STX & 3 & MPA \\
\hline 352 & $09: 15: 03: 329$ & DC 02033989 & Token & STX & 3 & 2 \\
\hline 353 & $09: 15: 03: 335$ & $10040250 \mathrm{COD9}$ & Leitura Poll-List & STX & 2 & 4 \\
\hline 354 & $09: 15: 03: 342$ & 6808086802040800000000 4C AB $6 A$ & Resp. Leitura Poll-List & ACK & 4 & 2 \\
\hline 355 & $09: 15: 03: 350$ & $100 \mathrm{C} 025 \mathrm{DF} F \mathrm{~F}$ & Leitura Poll-List & STX & 2 & 12 \\
\hline 356 & $09: 15: 03: 357$ & $68080868020 \mathrm{C} 08000000004 \mathrm{C} 75 \mathrm{5E}$ & Resp. Leitura Poll-List & ACK & 12 & 2 \\
\hline 357 & $09: 15: 03: 366$ & $100 E 0250$ B1 8E & Leitura Poll-List & STX & 2 & 14 \\
\hline 358 & $09: 15: 03: 374$ & $68080868020 \mathrm{E} 08000000004 \mathrm{C} 42 \mathrm{D} 3$ & Resp. Leitura Poll-List & ACK & 14 & 2 \\
\hline 359 & $09: 15: 03: 382$ & $\mathrm{DC} 0302 \mathrm{AE} \mathrm{F} 2$ & Token & STX & 2 & 3 \\
\hline 360 & $09: 15: 03: 389$ & 100503607810 & Leitura Poll-List & STX & 3 & 5 \\
\hline 361 & $09: 15: 03: 397$ & $680808680305084248000080 \mathrm{C} 5 \mathrm{FC}$ & Resp. Leitura Poll-List & $\mathrm{ACK}$ & 5 & 3 \\
\hline 362 & $09: 15: 03: 405$ & $1009036 \mathrm{D} 4 \mathrm{~B}$ CF & Leitura Poll-List & STX & 3 & 9 \\
\hline 363 & $09: 15: 03: 412$ & 6808086803090800000000 4C 8F 65 & Resp. Leitura Poll-List & ACK & 9 & 3 \\
\hline 364 & $09: 15: 03: 420$ & $100 A 036 D$ C9DC & Leitura Poll-List & STX & 3 & 10 \\
\hline 365 & $09: 15: 03: 427$ & 680808680304084120000080 A9 B0 & Resp. Leitura Poll-List & ACK & 10 & 3 \\
\hline 366 & $09: 15: 03: 435$ & $10040349 \mathrm{~F} 2 \mathrm{A9}$ & Pedido de Status[RFS] & STX & 3 & 4 \\
\hline 367 & $09: 15: 03: 439$ & 100304003099 & Resp. Pedido de Status(RFS] & ACK & 4 & 3 \\
\hline 368 & $09: 15: 03: 447$ & DC 02033989 & Token & STX & 3 & 2 \\
\hline
\end{tabular}

Figura 99 - Perda de mensagem de token com três mestres na rede

Dentre as diferenças de funcionamento do sistema após a perda de mensagem de token em uma rede com dois mestres, representado pela Figura 97, e uma rede com três mestres, representado pela Figura 99, destacam-se os seguintes fatores:

- Na Figura 99, o DF73 que teve as duas mensagens de token ignorada pelo MPA (mensagem de número 350 e 351), ao invés de transmitir a mensagem de token para si mesmo, transmite para o outro DF73 que está no endereço 2 (endereço da estação sucessora na $L A S$ ) (mensagem de número 352). Deste modo, o DF73 que 
está no endereço 2 transmite as mensagens da Poll-List (mensagem de número 353) e retorna o token para o DF73 no endereço 3 (mensagem de número 359).

- Na Figura 99, após a perda de mensagem de token, apenas o DF73 que está no endereço 3 transmite mensagem de Pedido de Status (RFS) no barramento, pois a GAPL do DF73 que está no endereço 2 está vazia.

- Na Figura 99, o tempo de reintegração do MPA no anel lógico é proporcional a 19 ciclos do token. O ciclo do token engloba as mensagens transmitidas por ambos os mestres: DF73 no endereço 2 e DF73 no endereço 3. A Figura 100 apresenta a seqüência de endereço da GAPL do DF73 que está no endereço 3.

\begin{tabular}{|l|l|l|l|l|l|l|l|l|l|l|l|l|l|l|l|l|l|l|}
\hline 4 & 5 & 6 & 7 & 8 & 9 & 10 & 11 & 12 & 13 & 14 & 15 & 16 & 17 & 18 & 19 & 20 & 0 & 1 \\
\hline
\end{tabular}

Figura 100 - GAPL do DF73 no endereço 3

Sobre está representação, neste experimento foi analisado o tempo de reintegração do mestre MPA no barramento, após perda de mensagem de token. Para realização do experimento, a máquina de estado do FDL do MPA foi adaptada para que em períodos de tempo aleatórios a mensagem de token recebida por outro mestre seja rejeitada, o botão "token" que aparece na Figura 66 do módulo Mod_BusAnalyse permite ativar ou desativar essa funcionalidade. A análise foi feita no ambiente apropriado fornecido pelo MPA, também representado pela Figura 66, onde os dados foram extraídos manualmente.

O experimento foi realizado em duas etapas, sendo a primeira em uma rede PROFIBUS com dois mestres no barramento e a segunda com três mestres no barramento. O TTR de ambos os DF73 foram configurados em $450 \mathrm{~ms}$, tempo considerado suficiente para a completa transmissão da Poll-List + transmissão da mensagem de Pedido de Status (RFS) em cada ciclo do token.

Em cada conjunto estatístico de medidas composto por dez amostras coletadas do tempo de reintegração do MPA no anel lógico, após perda de mensagem de token, foram 
ensaiados diferentes valores do parâmetro HSA, combinados com quantidades crescentes de equipamentos escravos no barramento. O tempo de reintegração do MPA no anel lógico é calculado entre o instante que o DF73 transmite o token para si mesmo ou para o próximo mestre listado na LAS após recusa do token pelo MPA e o instante que o DF73 transmite o token para o MPA após o MPA responder a mensagem de Pedido de Status (RFS) do DF73 como "Estação pronta para entrar no anel lógico". Para simplificar a análise, foram descartados os ciclos com mensagens acíclicas, ciclos com mensagem de erro e ciclos com retransmissão de mensagem, pois além de ocorrer ocasionalmente, aumentam o tempo de reintegração do MPA no anel lógico.

As Figuras 101 a 112, apresentam além do gráfico com os conjuntos de amostras coletadas, um quadro indicando quais os dispositivos utilizados no experimento, por exemplo, o quadro da Figura 101 indica que o experimento foi realizado em uma rede com dois mestres (MPA no endereço 1 com duas mensagens na Poll-List e o DF73 no endereço 2 com duas mensagens na Poll-List). As Figuras 101, 103, 105, 107, 109 e 111 representam os resultados dos experimentos realizados com dois mestres no barramento, enquanto as Figuras 102, 104, 106, 108, 110 e 112 os experimentos realizados com três mestres no barramento.

As Figuras 101 a 112 são representadas a seguir com a seguinte formatação:

$\boldsymbol{D}$ (mestre DF73 no endereço 2) + Número (quantidade de mensagem da Poll-List do DF73 no endereço 2) $+\boldsymbol{M}$ (mestre MPA no endereço 1) + Número (quantidade de mensagem da Poll-List do MPA). Nos gráficos com três mestres é incluso a letra $\boldsymbol{D}$ (mestre DF73 no endereço 3) + Número (quantidade de mensagem da Poll-List do DF73 no endereço 3). 
- Configuração D1M2 - D1M2D3

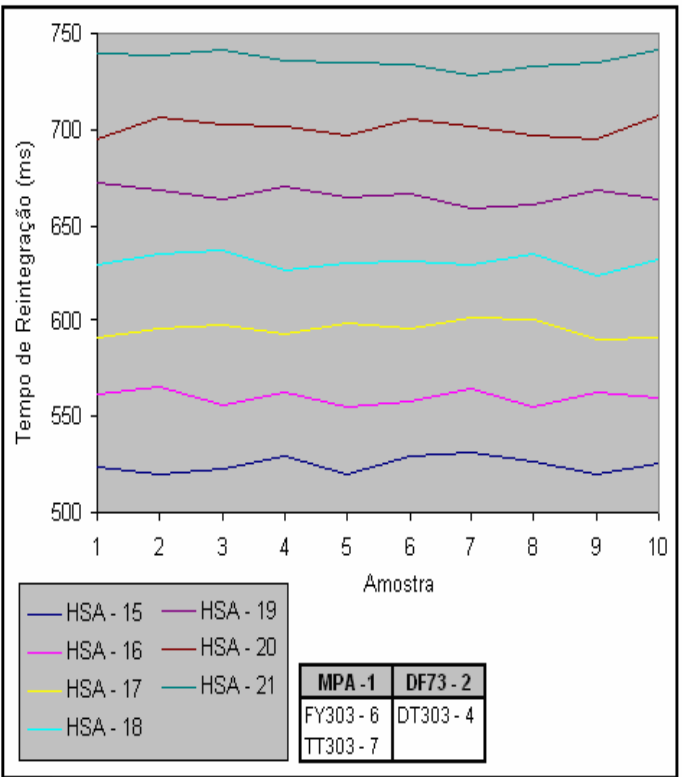

Figura 101 - Configuração D1M2

- Configuração D2M2 - D2M2D3

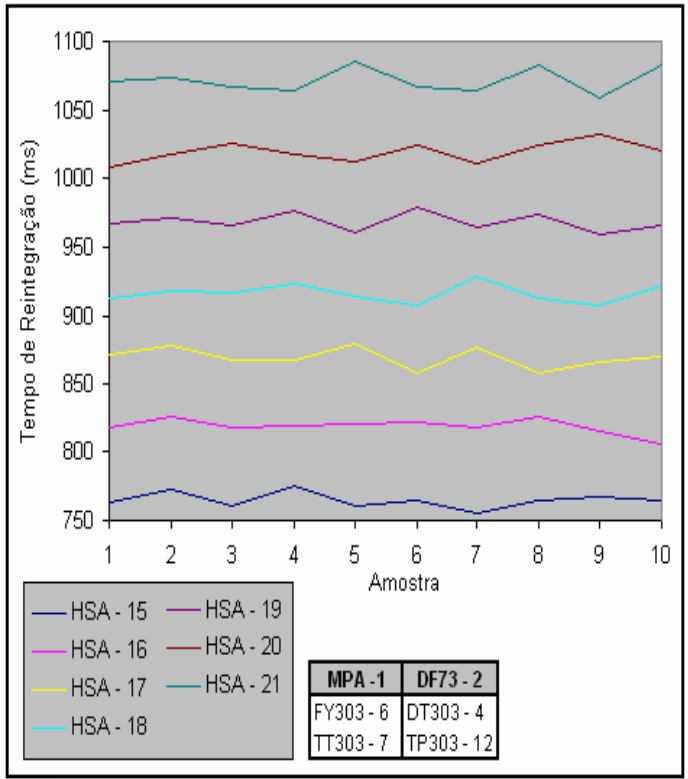

Figura 103 - Configuração D2M2

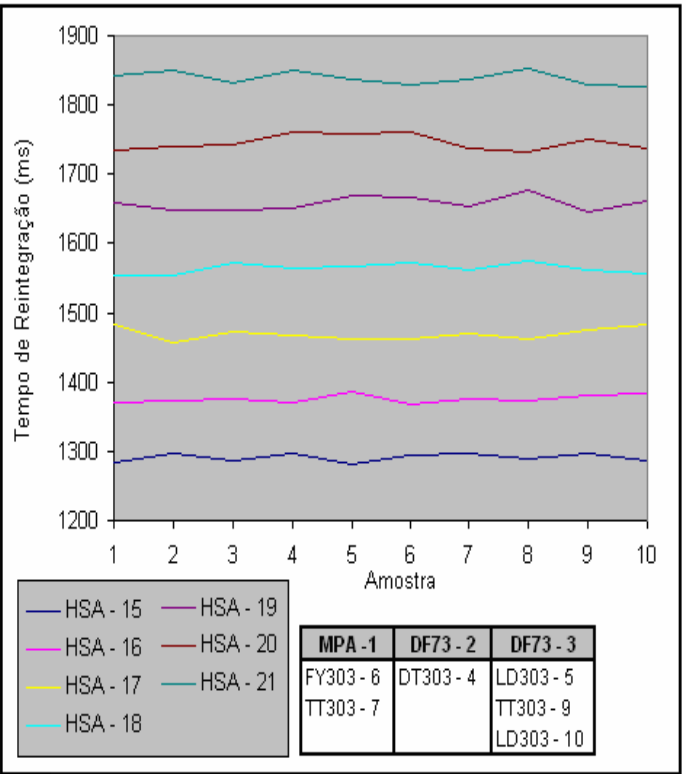

Figura 102 - Configuração D1M2D3

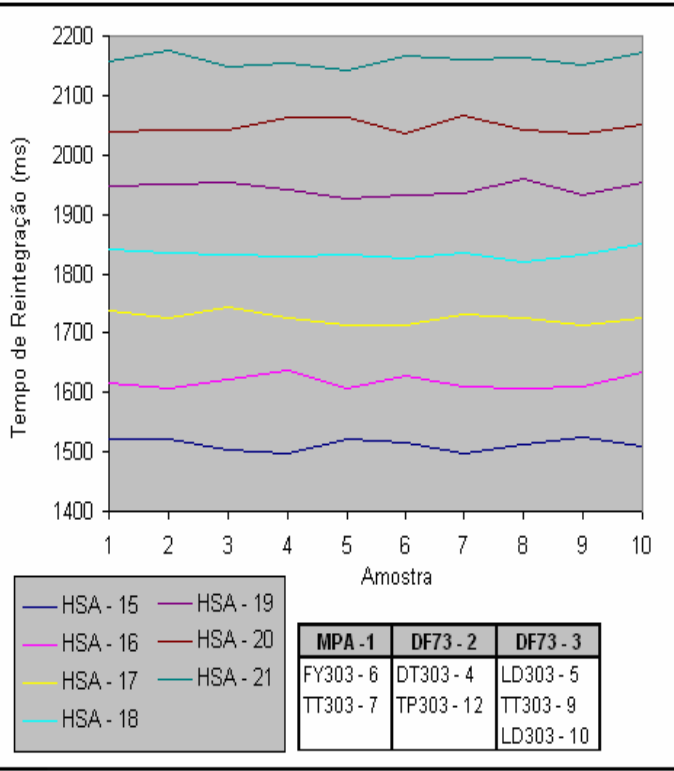

Figura 104 - Configuração D2M2D3 
- Configuração D3M2 - D3M2D3

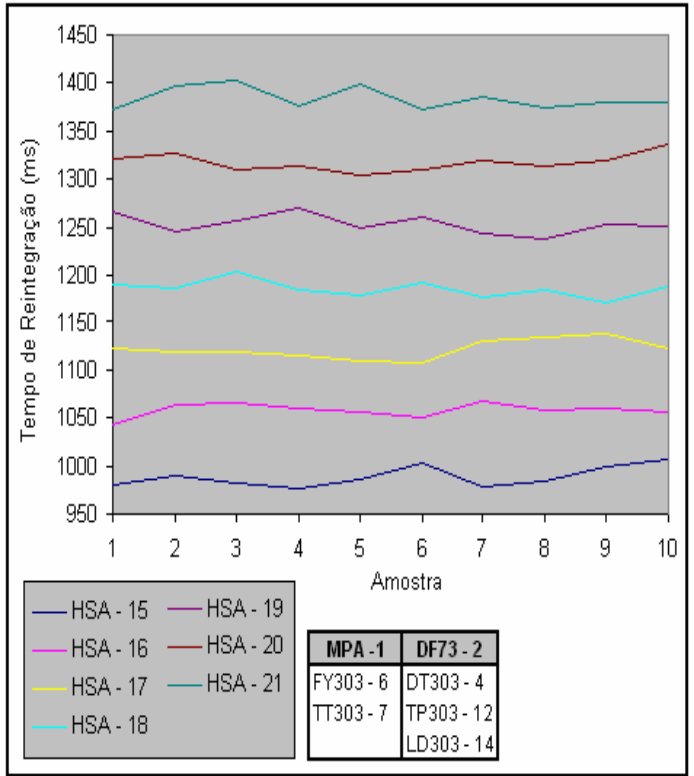

Figura 105 - Configuração D3M2

- Configuração D4M2 - D4M2D3

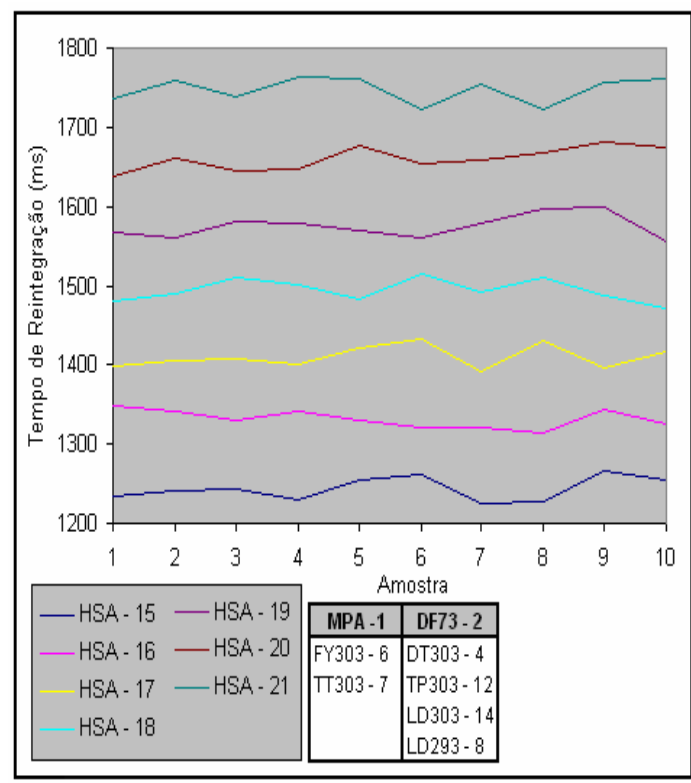

Figura 107 - Configuração D4M2

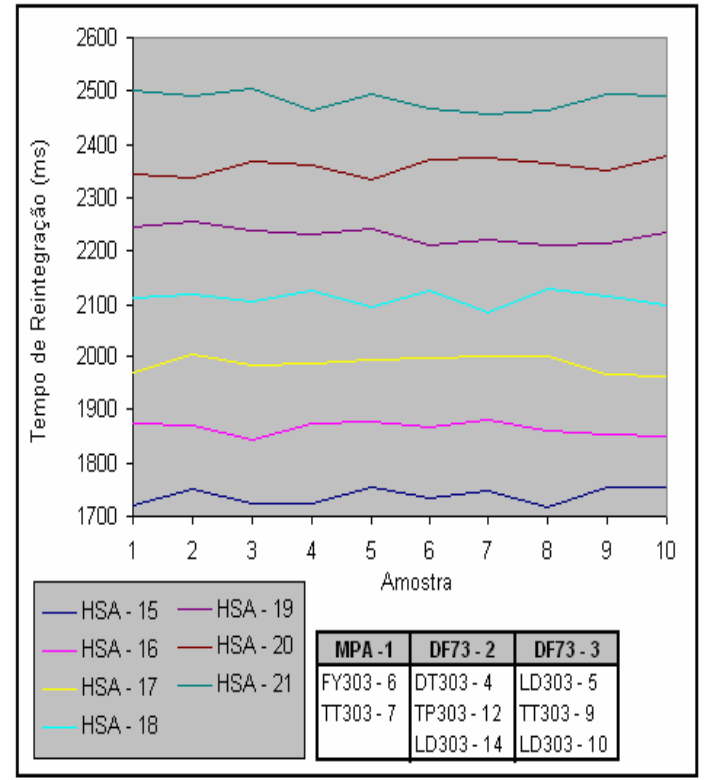

Figura 106 - Configuração D3M2D3

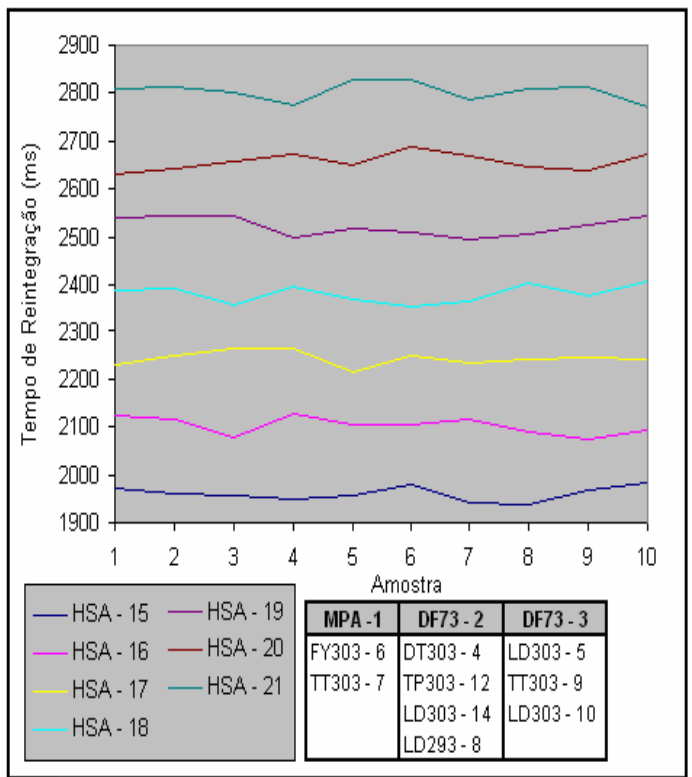

Figura 108 - Configuração D4M2D3 
- Configuração D5M2 - D5M2D3

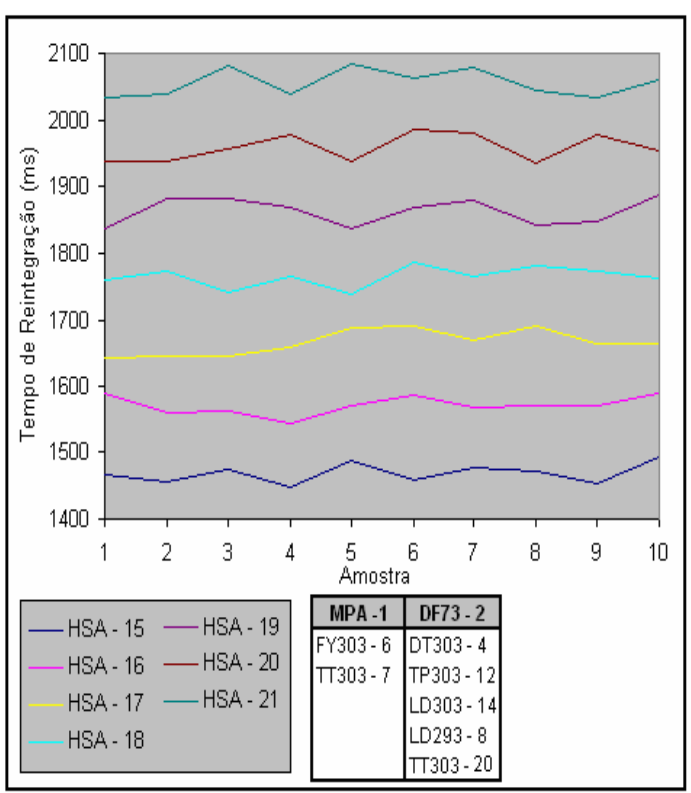

Figura 109 - Configuração D5M2

- Configuração D6M2 - D6M2D3

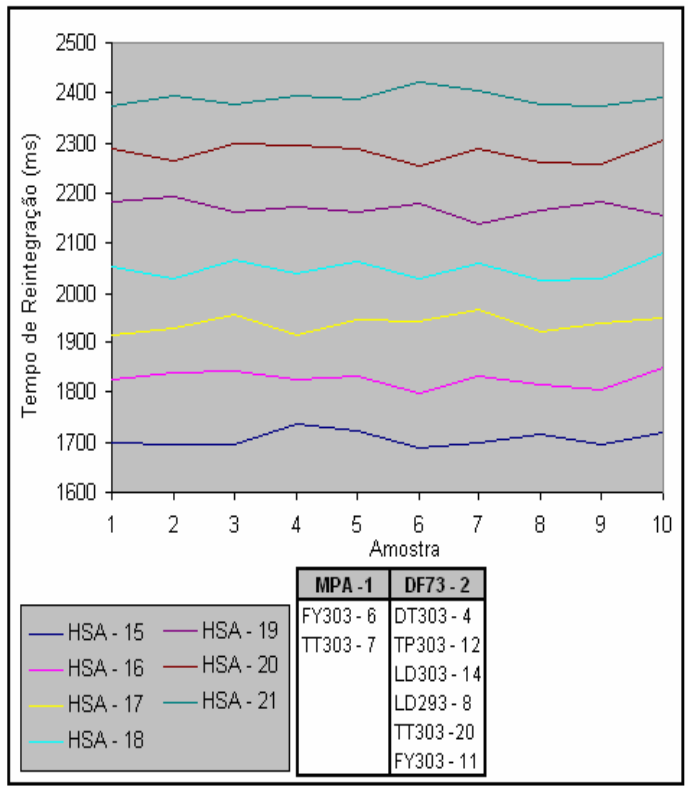

Figura 111 - Configuração D6M2D3

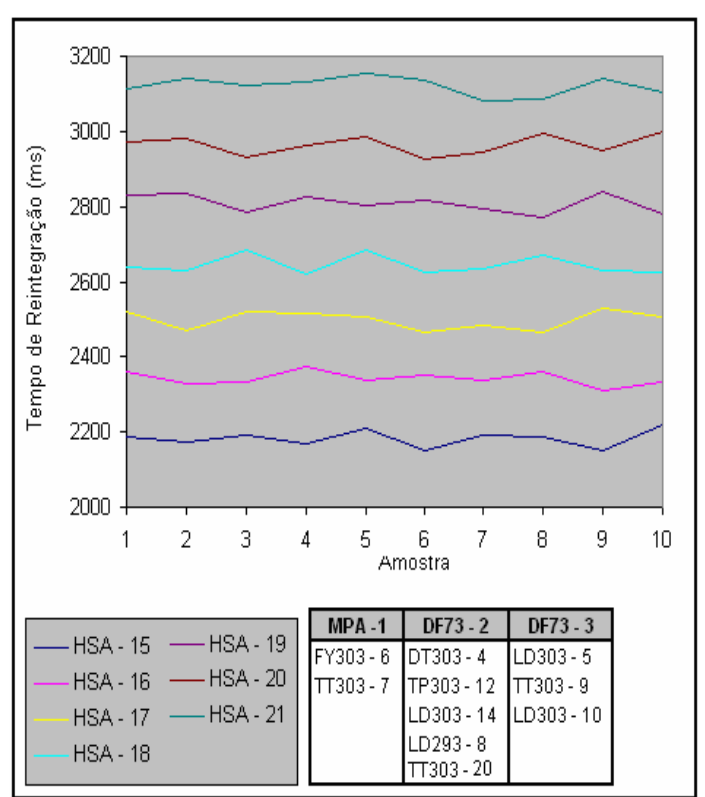

Figura 110 - Configuração D5M2D3

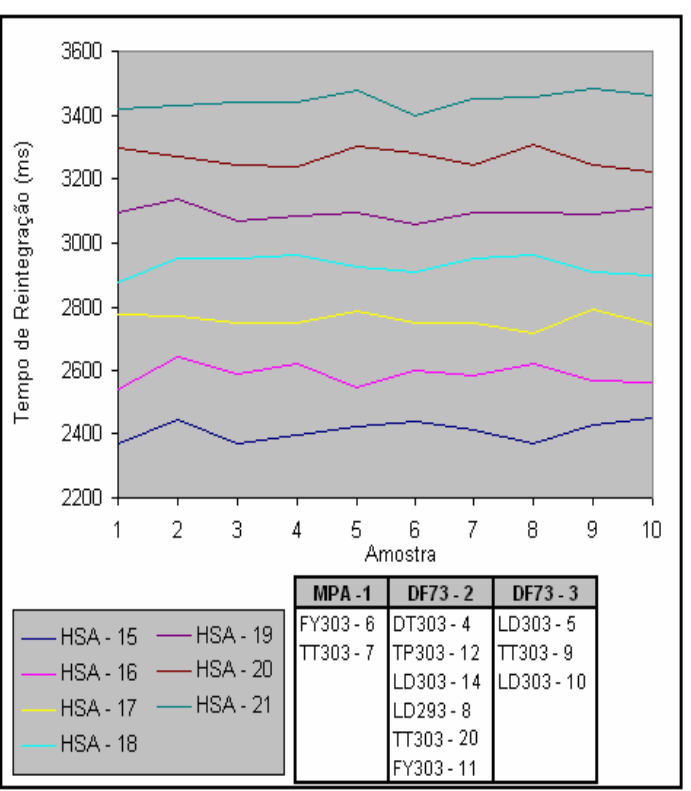

Figura 112 - Configuração D6M2D3 
As tabelas 4 e 5 e a figura 113 mostram a média dos valores apresentados nos gráficos acima.

Tabela 4 - Média do tempo de reintegração do MPA com dois mestres na rede

\begin{tabular}{cccccccc}
\hline MESTRE & HSA (15) & HSA (16) & HSA (17) & HSA (18) & HSA (19) & HSA (20) & HSA (21) \\
\hline D1M2 & 525 & 560 & 595 & 631 & 666 & 701 & 736 \\
D2M2 & 765 & 818 & 868 & 917 & 969 & 1019 & 1071 \\
D3M2 & 989 & 1058 & 1121 & 1186 & 1253 & 1318 & 1384 \\
D4M2 & 1244 & 1331 & 1409 & 1495 & 1576 & 1661 & 1748 \\
D5M2 & 1468 & 1570 & 1665 & 1765 & 1864 & 1958 & 2055 \\
D6M2 & 1707 & 1825 & 1936 & 2048 & 2169 & 2280 & 2390 \\
\hline Ciclos Token & 15 & 16 & 17 & 18 & 19 & 20 & 21 \\
\hline
\end{tabular}

Tabela 5 - Média do tempo de reintegração do MPA com três mestres na rede

\begin{tabular}{lccccccc}
\hline MESTRE & HSA (15) & HSA (16) & HSA (17) & HSA (18) & HSA (19) & HSA (20) & HSA (21) \\
\hline D1M2D3 & 1291 & 1376 & 1469 & 1564 & 1658 & 1746 & 1838 \\
D2M2D3 & 1512 & 1617 & 1725 & 1834 & 1944 & 2049 & 2160 \\
D3M2D3 & 1738 & 1865 & 1985 & 2111 & 2231 & 2359 & 2483 \\
D4M2D3 & 1961 & 2102 & 2243 & 2381 & 2522 & 2657 & 2803 \\
D5M2D3 & 2183 & 2341 & 2499 & 2647 & 2810 & 2965 & 3121 \\
D6M2D3 & 2410 & 2585 & 2755 & 2931 & 3093 & 3267 & 3446 \\
\hline Ciclos Token & 14 & 15 & 16 & 17 & 18 & 19 & 20 \\
\hline
\end{tabular}
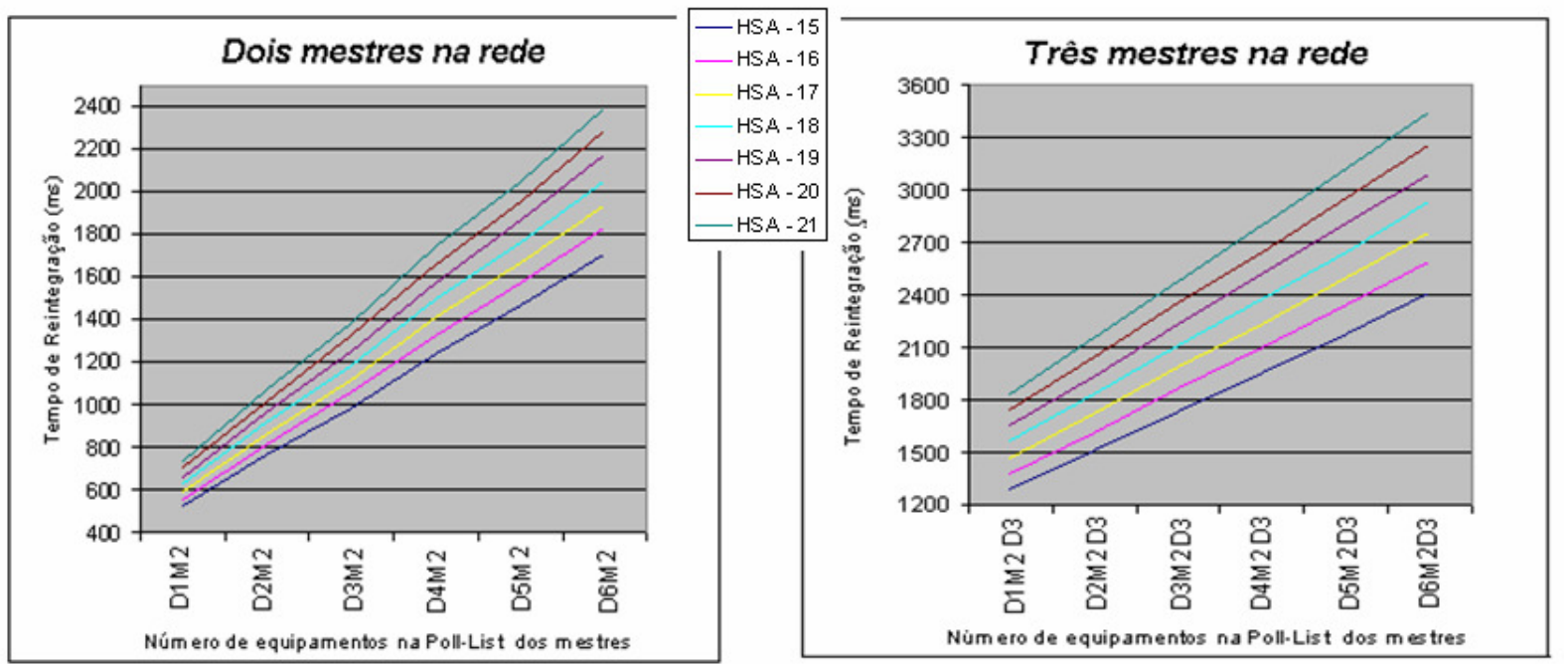

Figura 113 - Gráficos da Média do tempo reintegração do MPA

Os seguintes fatores podem ser destacados nos resultados apresentados neste experimento: 
- O número de ciclos do token necessário para reintegração do MPA no anel lógico é proporcional ao valor do parâmetro HSA do DF73 antecessor do MPA. Por exemplo, de acordo com a tabela 5 , caso o HSA seja 15, o número de ciclos do token será 14 , caso incremente o parâmetro HSA para 18, o número de ciclos do token aumentará proporcionalmente para 17.

Isto ocorre porque, o HSA representa o maior endereço da GAPL do DF73, sendo assim, caso aumente o HSA estará também aumentando a quantidade de endereços na GAPL do DF73.

- Adição de mensagem na Poll-List do DF73 aumenta o tempo de reintegração do MPA no anel lógico em: Tempo de transmissão e recepção da resposta da nova mensagem $\mathbf{X}$ número de ciclo do token necessário para a reintegração do MPA no anel lógico.

- O número de mensagens da Poll-List do MPA não interfere no tempo de reintegração.

Isto ocorre porque, durante a reintegração o MPA é considerado estação inativa.

- A adição de dispositivo mestre aumenta o tempo de reintegração do MPA no anel lógico em: Tempo de transmissão e recepção da resposta de todas as mensagens da Poll-List do novo dispositivo mestre + Tempo de transmissão da mensagem de token $\mathbf{X}$ número de ciclo do token necessário para a reintegração do MPA no anel lógico.

A partir da análise realizada neste experimento, propõe-se uma expressão matemática que represente o tempo de Reintegração da estação-mestre após perda da mensagem de token, representado pelo parâmetro TRT. 


$$
T R T=T P \_R+T T \_R+T P \_S t a t u s \_R+T M \_R
$$

Onde TP_R é o tempo necessário para que o(s) mestre(s) ativo do anel lógico transmita $(m)$ e receba $(m)$ a resposta de todas as mensagens referentes a Poll-List. TT_R é o tempo necessário para transferir o token entre o(s) mestre(s) ativo do anel lógico. TP_Status_R é o tempo necessário para que o(s) mestre(s) ativo transmita(m) e receba(m) a resposta da mensagem de Pedido de Status (RFS). TM_R é o tempo necessário para que $\mathrm{o}(\mathrm{s})$ mestre(s) ativo transmita(m) a mensagem de Multicast.

No cálculo de cada parâmetro da expressão TRT, é considerado apenas o(s) mestre(s) que permanece $(\mathrm{m})$ ativo no anel lógico após perda do token, pois a estaçãomestre que deixou de responder a mensagem de token é excluída do anel lógico e durante o cálculo do parâmetro TRT é considerada inativa.

O parâmetro TP_R pode ser expresso como:

$$
T P_{-} R=(\operatorname{ngap}+1) *\left(\sum_{i=1}^{m} \underset{j=1 .}{\left.\sum_{j} T M C(i, j)\right)}\right.
$$

Onde ngap é o número de endereços contidos na GAPL do mestre antecessor ao mestre que foi excluído do anel lógico (O número de endereços na GAPL indica o número de ciclos do token necessários para a reintegração). m é o número de mestres ativo no anel lógico. $\mathrm{p}$ é o número de mensagens na Poll-List do ith mestre. TMC ( $\mathrm{i}, \mathrm{j}, \mathrm{k}$ ) é o tempo necessário para transmitir e receber a resposta da jth mensagem da Poll-List do ith mestre.

O parâmetro TT_R pode ser expresso como:

$$
T T \_R=((\text { ngap * NM_R })+1){ }^{*} T T M \_R
$$


Onde ngap é o número de endereços contidos na GAPL do mestre antecessor ao mestre que foi excluído do anel lógico. NM_R é o número de mestres ativo no anel lógico. TTM_R é o tempo necessário para transmitir a mensagem de token.

O parâmetro TP_Status_R pode ser expresso como:

$$
\text { TP_Status_R }=\sum_{i=1}^{\text {ngap+1 }} \sum_{j=1}^{n} \operatorname{TMC}(i, j)
$$

Onde ngap é o número de endereços contidos na GAPL do mestre antecessor ao mestre que foi excluído do anel lógico. n é o numero de estações-mestres ativa no anel lógico. TMC (i,j) é o tempo necessário para transmitir e receber a resposta da mensagem de Pedido de Status (RFS) do jth mestre no ith ciclo do token.

O parâmetro TM_R pode ser expresso como:

$$
\text { TM_R }=\sum_{i=1}^{\text {ngap+1 }} \sum_{j=1}^{n} \text { TM_MR }(i, j)
$$

Onde ngap é o número de endereços contidos na GAPL do mestre antecessor ao mestre que foi excluído do anel lógico n é o número de estações-mestres ativa no anel lógico. TM_MR (i,j) é o tempo necessário para transmitir a mensagem de Multicast do jth mestre no ith ciclo do token.

O parâmetro ngap referenciado nas expressões acima é referente a GAPL antes da perda de token.

Para validar as expressões acima, o tempo de transmissão das mensagens referente ao conjunto de amostras do gráfico da Figura104 (D2M2D3), onde o parâmetro HSA foi configurado em 17 foram substituídos na expressão TRT, como mostra a tabela 6 . A Figura 
114 compara os valores das amostras do gráfico da Figura 104 (D2M2D3) com os valores obtidos pela expressão TRT.

Tabela 6 - Representação dos valores utilizados na expressão TRT

\begin{tabular}{|c|c|c|c|c|c|}
\hline Amostra & $\begin{array}{c}\text { TP_R (ngap }=15 ; \\
m=2 ; p(1)=2 ; \\
p(2)=3)\end{array}$ & $\begin{array}{c}\text { T_R (ngap = 15; } \\
\text { NM_R }=2 ; \\
\text { TM_R }=9 \mathrm{~ms} \text { ) }\end{array}$ & TP_STATUS_R (ngap $=15 ; n=2)$ & TM_R ( ngap $=15 ; n=2)$ & Total \\
\hline 1738 & $15,14,16,17,16$ & 279 & $\begin{array}{r}0,11,0,12,0,12,0,12,0,12,0,13,0,12,0 \\
12,0,11,0,8,0,12,0,9,0,8,0,8,0,9,0,12\end{array}$ & $\begin{array}{l}0,0,17,0,0,0,0,0,0,0,0,0,0,0,0,0, \\
0,0,0,0,0,0,0,18,0,0,0,0,0,0,0,0\end{array}$ & 1735 \\
\hline 1724 & $15,14,16,16,16$ & 279 & $\begin{array}{r}0,12,0,12,0,12,0,12,0,12,0,12,0,12,0 \\
12,0,12,0,9,0,12,0,8,0,8,0,8,0,8,0,12\end{array}$ & $\begin{array}{l}0,0,0,0,16,0,0,0,0,0,0,0,0,0,0,0, \\
0,0,0,0,0,0,0,0,0,17,0,0,0,0,0,0\end{array}$ & 1717 \\
\hline 1744 & $15,15,16,17,15$ & 279 & $\begin{array}{r}0,12,0,11,0,12,0,11,0,12,0,12,0,12,0 \\
11,0,12,0,8,0,12,0,9,0,8,0,8,0,8,0,11\end{array}$ & $\begin{array}{l}0,0,0,0,0,0,0,0,0,0,16,0,0,0,0,0 \\
0,0,0,0,0,0,0,0,0,0,0,0,0,0,0,16\end{array}$ & 1728 \\
\hline 1724 & $15,14,16,17,16$ & 279 & $\begin{array}{l}0,12,0,12,0,12,0,12,0,12,0,12,0,12,0 \\
12,0,13,0,8,0,13,0,10,0,8,0,8,0,8,0,12\end{array}$ & $\begin{array}{l}0,0,0,0,17,0,0,0,0,0,0,0,0,0,0,0, \\
0,0,0,0,0,0,0,0,0,16,0,0,0,0,0,0\end{array}$ & 1736 \\
\hline 1713 & $16,14,15,17,15$ & 279 & $\begin{array}{r}0,12,0,12,0,12,0,12,0,13,0,12,0,12,0 \\
12,0,12,0,8,0,12,0,8,0,8,0,9,0,8,0,12\end{array}$ & $\begin{array}{l}17,0,0,0,0,0,0,0,0,0,0,0,0,0,0,0, \\
0,0,0,0,17,0,0,0,0,0,0,0,0,0,0,0\end{array}$ & 1719 \\
\hline 1713 & $15,14,16,17,16$ & 279 & $\begin{array}{c}0,13,0,12,0,12,0,12,0,12,0,13,0,12,0 \\
12,0,12,0,8,0,12,0,8,0,8,0,8,0,8,0,12\end{array}$ & $\begin{array}{l}0,0,0,0,17,0,0,0,0,0,0,0,0,0,0,0, \\
0,0,0,0,0,0,0,0,0,17,0,0,0,0,0,0\end{array}$ & 1735 \\
\hline 1729 & $15,15,16,17,15$ & 279 & $\begin{array}{r}0,12,0,12,0,12,0,12,0,12,0,12,0,12,0 \\
11,0,12,0,8,0,12,0,8,0,8,0,8,0,8,0,12 \\
\end{array}$ & $\begin{array}{l}0,16,0,0,0,0,0,0,0,0,0,0,0,0,0,0, \\
0,0,0,0,0,0,17,0,0,0,0,0,0,0,0,0\end{array}$ & 1731 \\
\hline 1725 & $15,14,17,17,16$ & 279 & $\begin{array}{r}0,12,0,12,0,13,0,12,0,12,0,11,0,12,0 \\
12,0,12,0,8,0,12,0,8,0,8,0,8,0,8,0,11\end{array}$ & $\begin{array}{l}0,0,0,17,0,0,0,0,0,0,0,0,0,0,0,0, \\
0,0,0,0,0,0,0,17,0,0,0,0,0,0,0,0\end{array}$ & 1748 \\
\hline 1713 & $16,14,16,16,16$ & 279 & $\begin{array}{l}0,11,0,12,0,12,0,12,0,12,0,12,0,12,0 \\
12,0,12,0,9,0,12,0,8,0,8,0,8,0,10,0,12\end{array}$ & $\begin{array}{l}0,0,0,0,0,0,0,16,0,0,0,0,0,0,0,0, \\
0,0,0,0,0,0,0,0,0,0,0,0,0,0,18,0\end{array}$ & 1735 \\
\hline 1725 & $15,14,16,17,16$ & 279 & $\begin{array}{r}0,12,0,12,0,12,0,11,0,12,0,12,0,12,0 \\
12,0,12,0,8,0,12,0,8,0,8,0,8,0,9,0,12\end{array}$ & $\begin{array}{l}0,0,0,0,0,17,0,0,0,0,0,0,0,0,0,0, \\
0,0,0,0,0,0,0,0,0,0,16,0,0,0,0,0\end{array}$ & 1732 \\
\hline
\end{tabular}

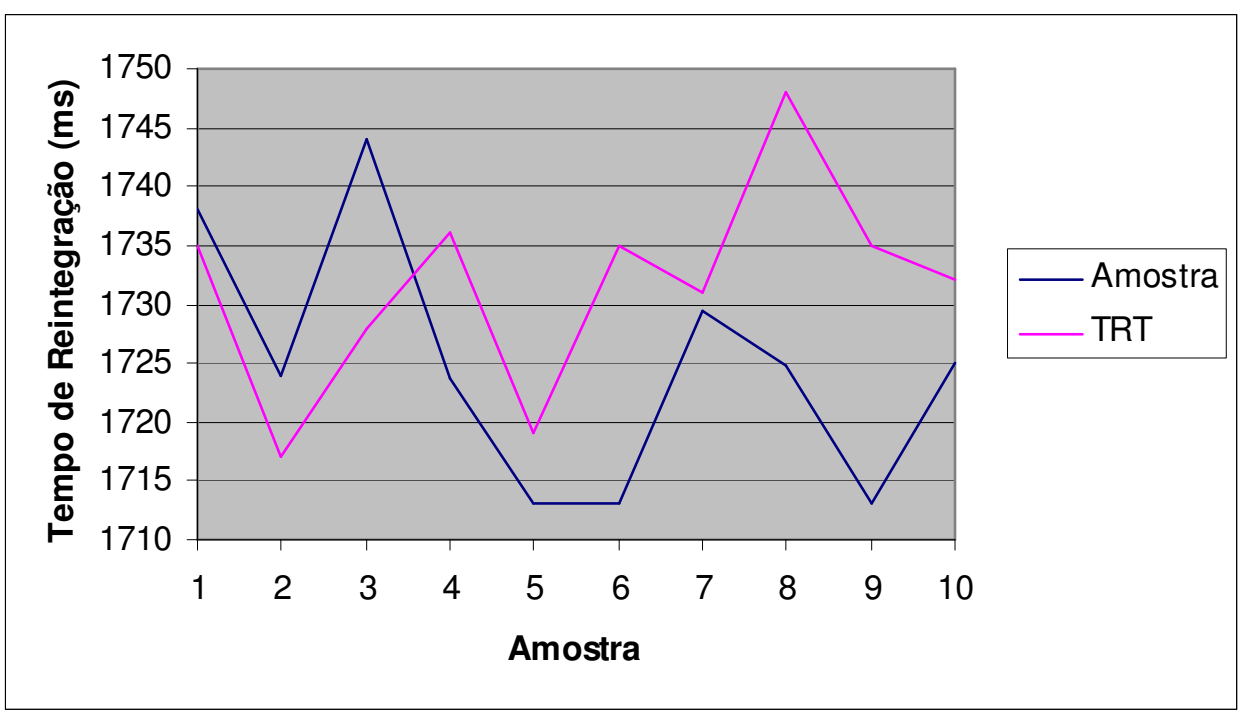

Figura 114- Gráfico de comparação entre amostra e TR 



\section{CONCLUSÃo}

Neste trabalho foi apresentado á ferramenta computacional MPA (Mestre PROFIBUS Analisador). Uma das tarefas desta ferramenta é atuar como mestre em redes PROFIBUS. No entanto, para que possa exercer esse tipo de função, o MPA cumpre um conjunto de requisitos temporais e operacionais descritos na norma PROFIBUS.

Além da função de mestre, o MPA disponibiliza um conjunto de serviços que normalmente são oferecidos por ferramentas comerciais utilizadas durante a configuração e operação de redes PROFIBUS. Dentre os serviços podem-se citar: Elaboração da Poll-List, Live-List, Diagnóstico, monitoração das variáveis de processo e Leitura acíclica de parâmetros de blocos funcionais de equipamentos de campo. Diante das funcionalidades apresentadas pelo MPA, observa-se que o protocolo PROFIBUS é suficientemente aberto para o desenvolvimento de novas ferramentas que possam interagir em tempo real com os diferentes equipamentos que compõem uma rede PROFIBUS.

O MPA oferece também um ambiente propicio para realização de análise de desempenho de redes PROFIBUS, onde apresenta em tempo-real através de uma lista, todas as mensagens transmitidas no barramento. Tal ambiente foi utilizado durante a análise de dois experimentos realizados neste trabalho. No primeiro experimento foi analisada a influência do parâmetro TTR no tempo de Polling das mensagens listadas na Poll-List e no segundo experimento foi analisado o tempo de reintegração da estaçãomestre no anel lógico após perda de mensagem de token.

De modo geral, os resultados obtidos nos experimentos mostraram claramente a necessidade de se configurar adequadamente os parâmetros do sistema, pois o protocolo PROFIBUS mostrou ser determinístico somente quando o sistema está devidamente 
configurado. Observou-se também que o aumento de equipamentos mestre e/ou escravo no barramento, aumenta proporcionalmente o tempo de atraso na atualização das variáveis de Processo. Sendo assim, constata-se que em sistemas PROFIBUS, onde os requisitos temporais são críticos, a configuração inadequada pode afetar a segurança na produção e principalmente a qualidade do produto final.

Contudo, conclui-se que, embora a ferramenta MPA seja executada em computadores pessoais (PC), com sistema operacional Windows não determinístico, a ferramenta apresentou um bom desempenho para as redes PROFIBUS ensaiadas e, com isso, evidencia-se que ferramenta computacionais podem ser plenamente utilizadas durante a fase de configuração de redes PROFIBUS permitindo a análise e a melhoria da configuração da comunicação deste tipo de rede ainda na fase de instalação e de configuração do sistema.

\subsection{TRABALHOS FUTUROS}

Algumas sugestões de trabalhos futuros nesta linha de pesquisa:

- Analisar a influência da comunicação acíclica no tempo de Polling das mensagens listadas na Poll-List.

- Aperfeiçoar a ferramenta MPA para que possa interpretar o arquivo GSD, possibilitando assim troca de dados cíclicos com equipamentos de qualquer fabricante.

- Aperfeiçoar a ferramenta MPA para que possa calcular automaticamente os parâmetros TRT e TPM com informações extraídas da rede.

- Desenvolver uma interface de comunicação que interligue a ferramenta MPA ao barramento PROFIBUS DP, onde a velocidade é mais alta que o barramento PROFIBUS PA utilizado neste trabalho. 


\section{LITERATURA REFERENCIADA}

ABB (2006). Inovação marca ampliação da fábrica da Klabin. Revista Controle \& Instrumentação. Edição 120 - $2006 . \quad$ Disponível em: < http://www.controleinstrumentacao.com.br/arquivo/ed_120/cv1.html>. Acesso em: 20 Nov. 2006.

ALBUQUERQUE (2005). Rede Ethernet avança para o chão-de-fábrica. Controle \& Instrumentação. Junho/2005.

ALTUS (2006). Protocolos de Comunicação. Disponível em: < http://www.altus.com.br/produtos_ponto.asp >. Acesso em: 15 Nov. 2006.

BELLO, L.L.; MIRABELLA, O. (2001) A Multi-Ring Scheduling Strategy for Profibus Networks. In: The $27^{\text {th }}$ Annual Conference of the IEEE Industrial Eletronics Society.

BRANDÃO, D. (2000). Bloco Funcional para controle Fieldbus por variáveis de estado. São Carlos. 117p. Dissertação (Mestrado) - Escola de Engenharia de São Carlos, Universidade de São Paulo, São Carlos, 2000.

BRANDÃO, D. (2005). Ferramenta de simulação para projeto, avaliação e ensino de redes fieldbus. São Carlos. 151p. Tese (doutorado) - Escola de Engenharia de São Carlos, Universidade de São Paulo, São carlos, 2005.

CARVALHO, J.A. et al. (2005). Experimental Analysis of Outage Times for PROFIBUS Networks

CASSIOLATO, C. (2005) Profibus: por dentro dos Identifier Formats. PROFINEWS BRASIL . Edição № 08 .- Junho/Julho - 2005.

(2005a). PROFIBUS PA e a convivência com equipamentos convencionais 4-20 mA e pneumáticos 3-15 psi. PROFINEWS BRASIL. Edição № 07 Abril/Maio (2005). 
CAVALIERI, S. et al. (2002) Evaluating Worst Case Response Time in Mono and MultiMaster Profibus DP. In: $4^{\text {th }}$ IEEE INTERNACIONAL WORKSHOP ON FACTORY COMMUNICATION SYSTEMS, SWEDEN, AUGUST 2002.

DOMINGUES, E.T. (2003) Uma estratégia em redes fieldbus usando controle adaptativo por modelo de referência aplicada a sistemas complexos. São Carlos. 172p. Tese (Doutorado) Escola de Engenharia de São Carlos. Universidade de São Paulo, São Carlos, 2003

FELSER, M.; SAUTER,T. (2002). The fieldbus war: history or short break between battles? In: IEEE INTRENATIONAL WORKSHOP ON FACTORY COMMUNICATION SYSTEMS,2002, Vasteras. Proccedings... New York: IEEE.p.73-80.

FESTO (2006). The Profibus module PS1 CP62. Disponível em: < http://www.festodidactic.com/ov3/media/customers/1100/00596431001075223829.pdf >. Acesso em: 20 Out. 2006.

FERREIRA, L.; TOVAR, E. (2004) Timing Analysis of a Multiple Logical Ring Wired/Wireless PROFIBUS Network In: IEEE

FERTRON (2006). Catálogo Família de CLP's Citrino Disponível em: < http://www.fertron.com.br/siteFertron/home/produto.php?id_cat=20\&id_subcat=306>. Acesso em: 20 Out. 2006.

HONG, S.H.; KIM, K.A. (1997) Implementation and performance evaluation of Profibus in the automation systems. In: IEEE

HONG, S.H.; KIM, Y.C. (2000) Implementation of Bandwidth Allocation Scheme in the Cyclic-Service Fieldbus Networks. In: IEEE

HONG, S.H.; KIM, Y.C. (2002) Implementation of a Bandwidth Allocation Scheme in a Token-Passing Fieldbus Network In: IEEE TRANSACTIONS ON INSTRUMENTATION AND MEASUREMENT, VOL., 51, NO.2, APRIL,2002

INTERNATIONAL ELECTROTECHNICAL COMISSION (2000). IEC 61158:

Digital data communications for measurement and control - fieldbus for use in industrial control systems. Suíça. CD-ROM 
LEE, K.C et al. (2000) On-Line Fuzzy Performance Management of Profibus Network. In: IEEE (2000)

LEE, S. et al. (2003) Development of Performance Model for Profibus Token Passing Protocol. In: IEEE

(2003a) Communication delay properties in performance model of Profibus Token Passing Protocol. In: $7^{\text {th }}$ KOREA-RUSSIA INTERNATIONAL SYMPOSIUM, KORUS 2003 . (2003b) Development of performance model for calculation of communication delay in Profibus token passing protocol

(2003c) Remote Control for guaranteeing QoC of Networked Control System via Profibus Token Passing Protocol. In: IEEE . . (2003d) Timer Selection Algorithm for Real-time Requirements of Ptofibus Protocol using GA. In: IEEE/ASME INTERNACIONAL CONFERENCE ON ADVANCED INTELLIGENT MECHATRONICS,2003

LEE, K.C. et al. (2004) Timer Selection for Satisfying the Maximum Allowable Delay Using Performance Model of Profibus Token Passing Protocol. In: IEEE TRANSACTIONS ELETRONICS, VOL. 51, NO.3, JUNE 2004

LEE, K.C. et al. (2005). QOS - Based Remote Control of Networked Control Systems Via Profibus Token Passing Protocol. In: IEEE TRANSACTIONS ON INDUSTRIAL ELETRONICS, VOL. 1, NO.3, AUGUST 2005

LI, M.; STOECKLI, L. (1996) The Time Characteristics of Cyclic Service in Profibus. In: IEEE PROCEEDINGS OF THE 4TH

LI, M. (1996) The Cyclic Services In Na Industrial Networks. In: IEEE 1996

MARCOS, M.M. et al. (2000) On the Analysis and Simulation of Temporal Behaviour of Real Time Distributed Systems Using PROFIBUS In: IEEE 
MARQUES, B. F. (2004) O Protocolo PROFIBUS. Sebenta de Redes Locais para aplicações industriais. Escola Superior de Tecnologia de Viseu. Departamento de Engenharia Eletrotécnica.

MONFORTE et al. (2000) Designing Real-Time Systems based on Mono-Master PROFIBUS-DP Networks

MONFORTE et al. (2002) Supporting Real-Time Factory Communication in Multi Master Profibus DP Networks. In: IEEE INTERNATIONAL SYMPOSIUM ON INTELLIGENT CONTROL VANCOUVER, CANADA, OCTOBER 2002

MORO, M. P. (2002) Análise e Estimativa de Desempenho de Redes Profibus. Porto Alegre. 99p. Dissertação (Mestrado) - Universidade federal do Rio grande do sul. Instituto de Informática. Programa de Pós-Graduação em computação. Porto Alegre (2002)

PINELLI, R. (2006) Curso de Integradores. Rev. 0. Associação PROFIBUS. Brasil.

POPP, M. (2003) The New Rapid Way to PROFIBUS DP (from DP-V0 to DP-V2). Livro. p. 262

POPP, M.; WEBER, K. (2004) The Rapid Way to PROFINET. Livro. p. 244

PROFIBUS - Descrição Técnica (2000). Associação PROFIBUS Brasil Out 2000.

PROFIBUS CENTER NETHERLANDS (2006). PROFIBUS Analyzer on USB. Disponível em:< http://www.procentec.com/profitrace/> Acesso em: 25 Outubro 2006

PROFIBUS Specification (1998). part 4 . Normative Parts of PROFIBUS FMS, DP, PA according to the European Standard EN 50170 Volume 2. Edition 1.0 March 1998

SANTOS, M. M. D. et al. (2003) Avaliação das propriedades temporais de duas redes de controle: CAN e PROFIBUS.

SIEMENS (2006). Controlador Lógico Programável SIMATIC S7-300. Disponível em:< http://www.siemens.com.br/templates/produto.aspx?channel=250\&produto=6851> Acesso em: 13 Outubro 2006. 
http://www.sea.siemens.com/automat/product/net/pfb/diag/auamprolyzer.html> Acesso em: 23 Outubro 2006.

SIEMENS (2007). Field Automation with PROFIBUS and SIMATIC PCS 7. Disponível em:< http://pcs.khe.siemens.com/efiles/pcs7/pdf/76/prdbrief/kb profibuspcs7.pdf> Acesso em: 16 Janeiro 2007.

SMAR EQUIPAMENTOS INDUSTRIAIS (2006) Tecnologia PROFIBUS em plantas eficientes. PROFINEWS Edição 13 - Julho/Agosto 2006. Disponível em:< http://www.profibus.org.br/news/abril2006/news.php?dentro=case.php. $>$ Acesso em: 11 Outubro 2006

SMAR EQUIPAMENTOS INDUSTRIAIS (2007). Disponível em:< http://www.smar.com.br.> Acesso em: 16 Janeiro 2007.

SIMATIC MANAGER

(2007).

Disponível

em:<

http://www.automation.siemens.com/simatic/regelsysteme/html 76/produkte/produkte.htm> Acesso em: 13 Mar 2007.

SOFTING (2006). Protocol analyzer Profibus. Disponível em:< http://www.directindustry.com/prod/softing/protocol-analyzer-11592-109253.html.> Acesso em: 13 Nov. 2006

STUDIO302 (2007). Manual do usuário System302 Studio. Disponível em:< http://graco.unb.br/alvares/smar backup 2006 instalacao/treinamento PDIII/Treina-PD3UNB/palestras/STUDIOMP.pdf> Acesso 7 Mar 2007.

TMG (2006). PROFIBUS Analyser FNL-PA. Disponível em:< http://www.tmgkarlsruhe.de/profibus_analyser_fnl-pa.html.> Acesso em: 29 Outubro 2006

TORRES, L.H.B.(2005) Profibus-PA - Especificações para o modelo de blocos. Controle e Instrumentação. Junho 2005

TOVAR, E.; VASQUES, F. (1998) - Guaranteeing Real-Time Message Deadlines in PROFIBUS Networks. In: Proc. 10 ${ }^{\text {th }}$ Euromicro Workshop Real-Time System, Berlin, Germany, June 1998. 
(1998a) Setting target rotation time in PROFIBUS based real-time distributed applications.

TOVAR, E.; VASQUES, F.; (1999) Cycle Time Properties of the PROFIBUS Timed Token Protocol. In: IEEE (1999a) Real-Time Fieldbus Communications Using Profibus Networks. In: IEEE TRANSACTIONS ON INDUSTRIAL ELECTRONICS, VOL. 46, NO.6, DECEMBER 1999

TOVAR, E; VASQUES, F (2000). Analysis of the Worst-Case Real Token Rotation Time in PROFIBUS Networks.

TOVAR, E. et al. (2002). Real-Time Communications over Hybrid Wired/Wireless PROFIBUS-based Networks. In: IEEE Proceedings of the 14th Euromicro Conference on Real-Time Systems

TRISTÃO, I. M. (2004) Implementação do protocolo PROFIBUS para aplicações industriais baseadas em microcontroladores. Gravataí. 71p. Dissertação (Conclusão do curso de Ciência de Computação) - Universidade Luterana do Brasil

VITTURI, S. (2003) On the effects of the acyclic traffic on Profibus DP networks. In: Computer Science

VITTURI, S (2004) Stochastic model of the Profibus DP cycle time. In: IEEE (2004)

YOKOGAWA (2006). The IT Machine Controller. Disponível em:< https://www.yokogawa.com/itc/pdf/itc-bl34m6a08-01e.pdf.> Acesso em: 15 Outubro 2006

WILLIG, Andreas (1999) Analysis of the PROFIBUS Token Passing Protocol over Error Prone Links. In: IEEE

WILLIG, A.; WOLISY, A. (2001) Ring Stability of the PROFIBUS Token-Passing Protocol Over Error-Prone Links. In: IEEE TRANSACTIONS ON INDUSTRIAL ELETRONICS, VOL. 48, NO.5, OCTOBER 2001

WILLIG, A. (2003) An Architecture for Wireless Extension of PROFIBUS. In: IEEE 


\section{LITERATURA CONSULTADA}

PROFIBUS PA. PROFIBUS for Process Automation. Disponível em:<http://www.profibus.com. $>$ Acesso em: 11 Maio 2006

PROFIBUS Tecnology and Application. October 2002. Disponível em:<http://www.profibus.com. $>$ Acesso em: 11 Maio 2006

THOMESSE, Jean P. (2005) Fieldbus Technology in Industrial Automation In: Proceedings of the IEEE, VOL. 93. NO. 6, JUNE 2005 